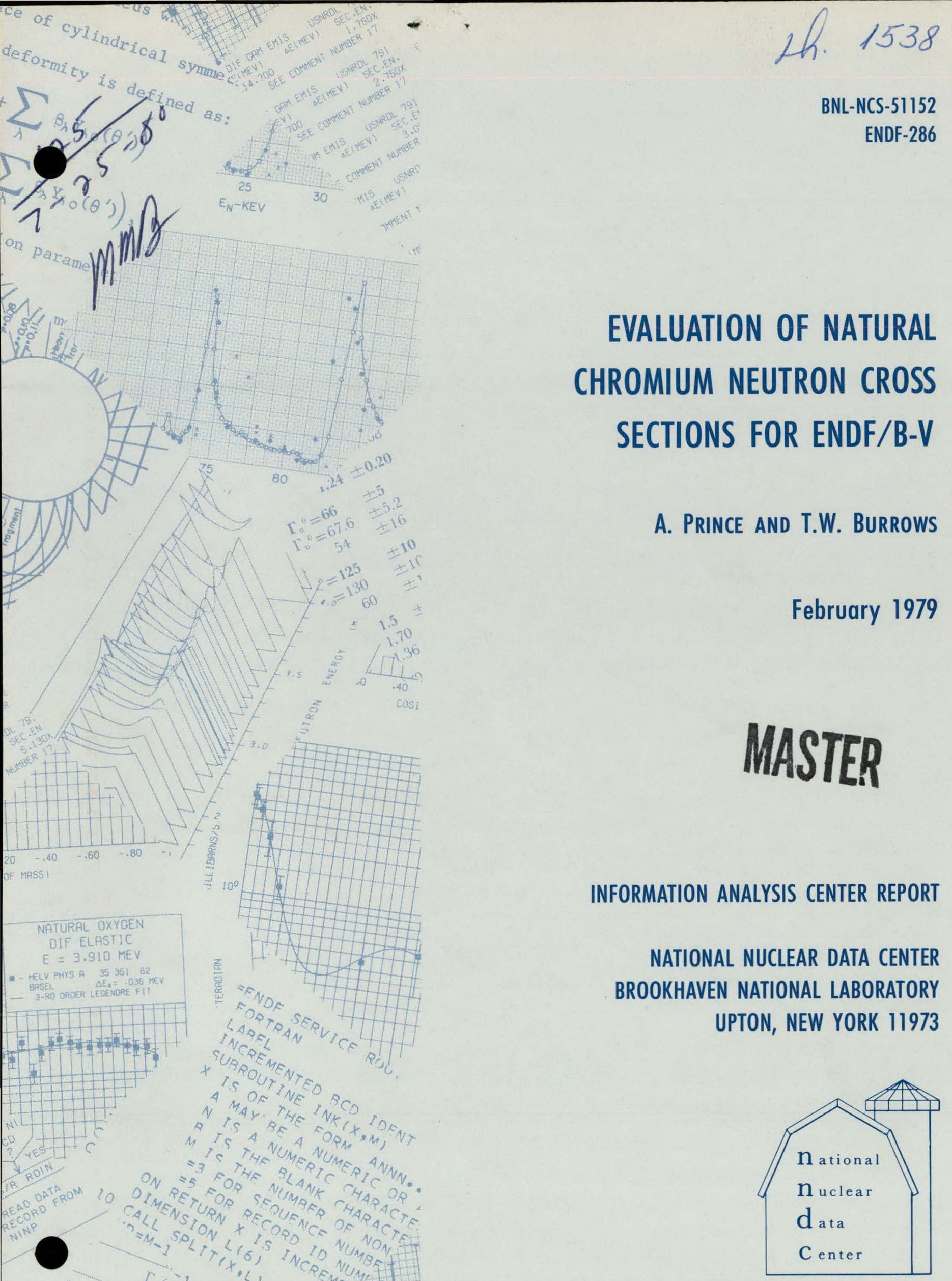

INFORMATION ANALYSIS CENTER REPORT

NATIONAL NUCLEAR DATA CENTER UPTON, NEW YORK 11973 


\section{DISCLAIMER}

This report was prepared as an account of work sponsored by an agency of the United States Government. Neither the United States Government nor any agency Thereof, nor any of their employees, makes any warranty, express or implied, or assumes any legal liability or responsibility for the accuracy, completeness, or usefulness of any information, apparatus, product, or process disclosed, or represents that its use would not infringe privately owned rights. Reference herein to any specific commercial product, process, or service by trade name, trademark, manufacturer, or otherwise does not necessarily constitute or imply its endorsement, recommendation, or favoring by the United States Government or any agency thereof. The views and opinions of authors expressed herein do not necessarily state or reflect those of the United States Government or any agency thereof. 


\section{DISCLAIMER}

Portions of this document may be illegible in electronic image products. Images are produced from the best available original document. 
BNL-NCS-51152

(ENDF-286)

UC-34c

(Physics-Nuclear - TID-4500)

\title{
EVALUATION OF NATURAL CHROMIUM NEUTRON CROSS SECTIONS FOR ENDF/B-V
}

\author{
A. Prince and T.W. Burrows
}

February 1979

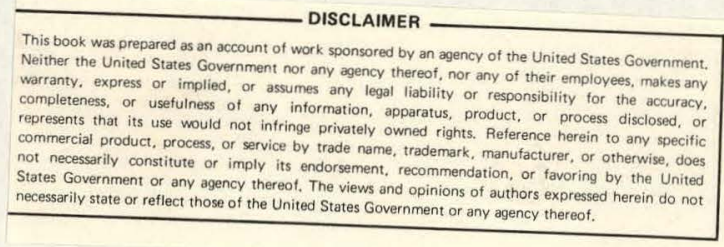

INFORMATION ANALYSIS CENTER REPORT

NATIONAL NUCLEAR DATA CENTER BROOKHAVEN NATIONAL LABORATORY

ASSOCIATED UNIVERSITIES, INC.

UNDER CONTRACT NO. DE-ACO2-76CH00016 WITH THE UNITED STATES DEPARTMENT OF ENERGY 


\section{DISCLAIMER}

This book was prepared as an account of work sponsored by an agency of the United States Government. Neither the United States Government nor any agency thereof, nor any of their employees, makes any warranty, express or implied, or assumes any legal liability or responsibility for the accuracy, completeness, or usefulness of any information, apparatus, product, or process disclosed, or represents that its use would not infringe privately owned rights. Reference herein to any specific commercial product, process, or service by trade name, trademark, manufacturer, or otherwise, does not necessarily constitute or imply its endorsement, recommendation, or favoring by the United States Government or any agency thereof. The views and opinions of authors expressed herein do not necessarily state or reflect those of the United States Government or any agency thereof.

Printed in the United States of America

$$
\text { Available from }
$$

National Technical Information Service

U.S. Department of Commerce

5285 Port Royal Road

Springfield, VA 22161

Price: Printed Copy $\$ 6.00$; Microfiche $\$ 3.00$ 


\section{ABSTRACT}

This report describes the evaluation of natural chromium for ENDF/B-V. Neutron cross sections and photon production are presented for the energy range $10^{-5} \mathrm{eV}$ to $20 \mathrm{MeV}$.

An extreme effort was made to incorporate all available new experimental data since the previous ENDF/B-IV evaluation. Particular consideration was also given to consistency between model calculation and experimental data and are described in detail.

Covariance files are given and are based on model code uncertainties along with empirical data. 
THIS PAGE

\section{WAS INTENTIONALLY LEFT BLANK}


II. Calculations and Comparison with Experiment

A. Resonance Region

B. Continuum Region

1. Total Cross Section

2. Non-Elastic Cross Section

3. Elastic Cross Section

4. Radiative Capture Cross Section

5. Inelastic Scattering Cross Section

a. Comparison of Calculations with Experimental Data . 6

b. Differential Inelastic Scattering

6. Neutron Emission And n-Particle Cross Sections 10

a. Comparison of Calculations with Experimental Data 13

i. $\mathrm{n}, 2 \mathrm{n}$ Cross Section 13

ii. n,p Cross Section . . 13

iii. $n,{ }^{4}$ He Cross Section $\quad 14$

iv. Other n-Particle Reactions . . . . 14

7. Miscellaneous Data 20

a. Angular Distributions

b. Secondary Energy Distributions 20

c. Photon Production. Data 20

C. Covariance Files 21

1. Resonance Parameters $(\mathrm{MF}=32)$. . 21

2. Cross Sections $(M F=33) \quad$.. 21

a. Total, Elastic, Non-Elastic, and Capture (MT=1, 2, 3 and 102) 21

b. Total Inelastic (MT=4) 21

c. $(n, 2 n)$ Cross Section $(M T=16) \quad 21$

d. $(n, 3 n),(n, n \alpha),(n, d),(n, t)$ Cross Sections $(M T=17,22,104.21$ and 105)

e. $(n, \alpha)$ Cross Section (MT=28) 21

f. Discrete Inelastic Cross Sections (MT=51=90) . 21

g. Continuum Inelastic (MT=91) ; $\quad 21$

h. $(n, p)$ Cross Section $(M T=103) \quad 22$

i. $(n, \alpha)$ Cross Section (MT=107) 22

j. Gas Production Cross Sections (MT=203-207) 22

\section{LIST OF TABLES}

\section{TITLE}

1. Energy Level Schemes Used for Hauser-Feshbach

Inelastic Scattering Calculations _. 6

2. Natural Abundance and Mass of Chromium Isótopes 8

3. $Q$ values for Possible Neutron-Induced Reactions in $\mathrm{Cr}$. for $\mathrm{E}_{\mathrm{n}} \leqslant 20 \mathrm{MeV} 9$

4. Selected ${ }^{50} \mathrm{Cr}$ Cross Sections. 
5. Selected ${ }^{52}$ Cross Sections

6. Comparison of $14 \mathrm{MeV}{ }^{52} \mathrm{Cr}(\mathrm{n}, \mathrm{p})$ Cross Sections 10

7. Selected ${ }^{53} \mathrm{Cr}$ Cross Sections $r$

8. Selected ${ }^{54} \mathrm{Cr}$ Cross Sections 18

9. Comparison of Calculated Fission Spectrum Average 19

10. Estimated Uncertainties in the Evaluated Cross Sections for Natura1 Chromium

\section{LIST OF FIGURES}

1. Natural Chromium Total Cross Sections (0.0001 to $0.1 \mathrm{MeV}) \quad 33$

2. Natural Chromium Total Cross Section ( 0.1 to $0.65 \mathrm{MeV}) \quad 34$

3. Natural Chromium Total Cross Section ( 0.65 to $0.7 \mathrm{MeV}$ ) 35

4. Natural Chromium Total Cross Section ( 0.70 to $0.9 \mathrm{MeV}) \quad 35$

5. Natural Chromium Total Cross Section ( 0.90 to $1.2 \mathrm{MeV}) \quad 36$

6. Natural Chromium Total Cross Section ( 1.20 to $1.5 \mathrm{MeV}) \quad 36$

7. Natural Chromium Total Cross Section ( 1.50 to $2.0 \mathrm{MeV}) \quad 37$

8. Natural Chromium TQtal Cross Section (2.0 to $2.5 \mathrm{MeV}$ ) 37

9. Natural Chromium Total Cross Section (2.5 to $3.0 \mathrm{MeV}) \quad 38$

10. Natural Chromium Total Cross Section ( 3.0 to $5.0 \mathrm{MeV}$ ) 38

11. Natural Chromium Total Cross Section ( 5.0 to $10.0 \mathrm{MeV}) \quad 39$

12. Natural Chromium Total Cross Section (10.0 to $20.0 \mathrm{MeV})$. 39

13. Chromium Non-elastic Cross Section (0 to $20.0 \mathrm{MeV}$ ) 40

14. Chromium Elastic Cross Section ( 0.65 to $0.7 \mathrm{MeV}$ ) 41

15. Chromium Elastic Cross Section (0.7 to $0.9 \mathrm{MeV}) \quad 41$

16. Chromium Elastic Cross Section ( 0.9 to $1.2 \mathrm{MeV}) \quad 42$

17. Chromium Elastic Cross Section (1.2 to $1.5 \mathrm{MeV}) \quad 42$

18. Chromium Elastic Cross Section (1.5 to $2.0 \mathrm{MeV}$ ) 43

19. Chromium Elastic Cross Section (2.0 to $2.5 \mathrm{MeV}) \quad 43$

20. Chromium Elastic Cross Section (2.5 to $3.0 \mathrm{MeV}$ ) . 44

21. Chromium Elastic Cross Section (3.0 to $5.0 \mathrm{MeV}) \quad 44$

22. Chromium Elastic Cross Section ( 5.0 to $10.0 \mathrm{MeV}) \quad 45$

23. Chromium Elastic Cross Section (10.0 to 20.0 MeV) 45

24. Chromium Differential Elastic Scattering Cross Section (E $4.0 \mathrm{MeV}$ ) 46

25. Chromium Differential. Elastic Scattering Cross Section (E = 4.56 MeV) 46

26. Chromium Differential Elastic. Scattering Cross Section ( $=6.09 \mathrm{MeV}) \quad 47$

27. ${ }^{52} \mathrm{Cr}$ Differential Elastic Scattering Cross Section $(E=6.44 \mathrm{MeV}) . \quad 47$

28. Cr (Natura1) Differential Elastic Scattering Cross Section $(E=7.05 \mathrm{MeV}) .48$

29. ${ }^{52} \mathrm{Cr}$ Differential Elastic Scattering Cross Section $(\mathrm{E}=7.54 \mathrm{MeV})$. 48

30. Cr (Natural) Differential Elastic Scattering Cross Section $(E=8.05 \mathrm{MeV}) .49$

31. ${ }^{52} \mathrm{Cr}$ Differential Elastic Scattering Cross Section $(\mathrm{E}=8.56 \mathrm{MeV})$. 49

32. Cr (Natural) Differential Elastic Scattering Cross Section ( $E=14.0$ MeV). 50

33. Chromium Radiative Capture Cross Section (1.0 to $20.0 \mathrm{MeV}$ ) 51

34. Cr (Natura1) Inelastic Cross Section (0.564 MeV Leve1- ${ }^{53} \mathrm{Cr}$ )

35. Cr (Natural) Inelastic Cross Section $\left(0.783 \mathrm{MeV}\right.$ Leve1- ${ }^{50} \mathrm{Cr}$ ) 53

36. Cr (Natural) Inelastic Cross Section $\left(0.8348 \mathrm{MeV}\right.$ Leve1- $\left.{ }^{54} \mathrm{Cr}\right) \quad 54$

37. Cr (Natura1). Inelastic Cross Section (1.006 MeV Leve1- ${ }^{53} \mathrm{Cr}$ ) 55

38. Cr (Natural) Inelastic Cross Section (1.287 MeV Leve1- ${ }^{53} \mathrm{Cr}$ ) 56

39. Cr (Natural) Inelastic Cross Section (1.434 MeV Level - ${ }^{52} \mathrm{Cr}$ ) 57 


\section{LIST OF FIGURES (cont'd)}

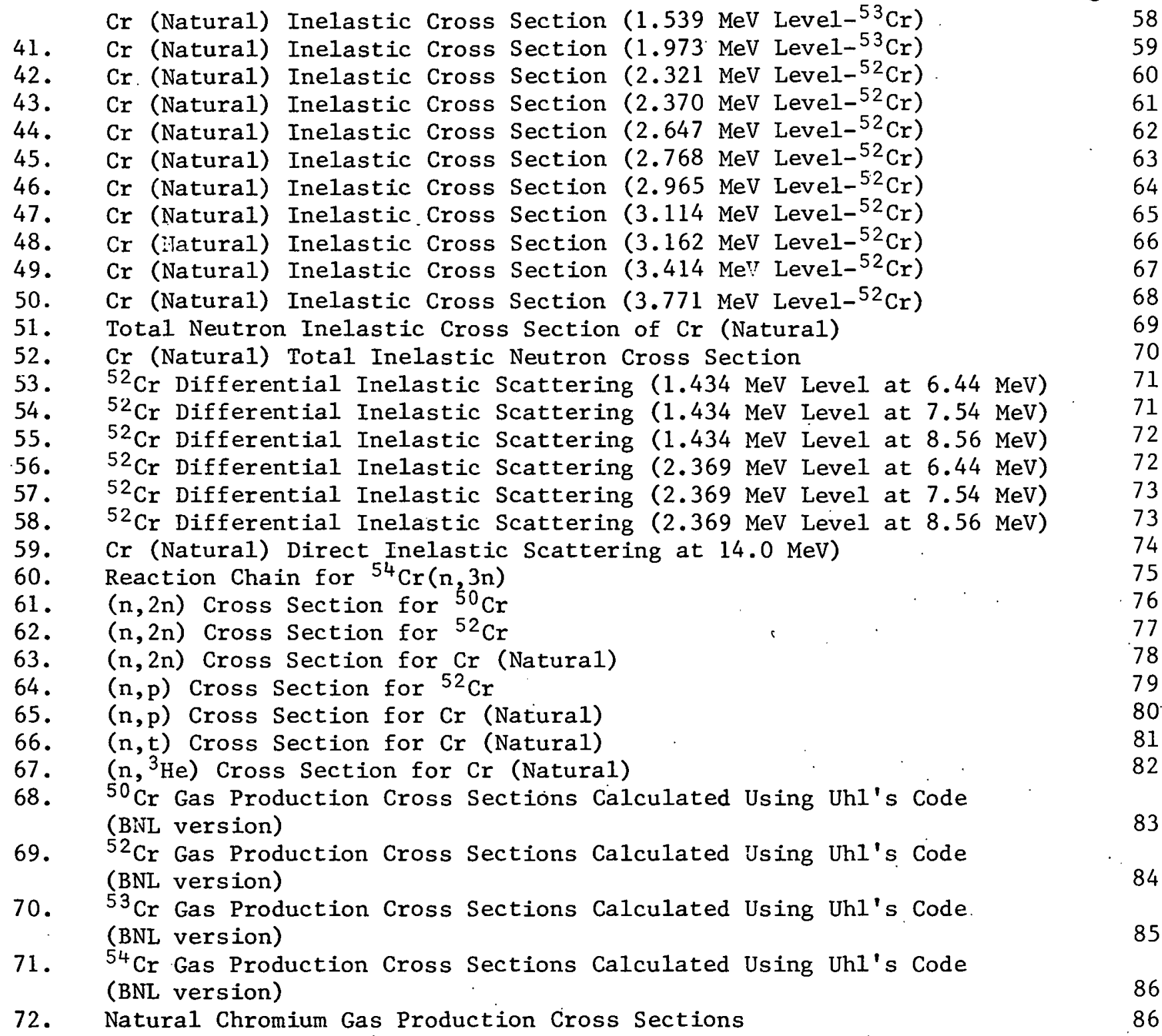




\section{INTRODUCTION}

This report describes a re-evaluation of $\mathrm{Cr}$ (Nat) for ENDF/B-V and supersedes the ENDF/B-IV, MAT=1191, evaluation by A. Prince (ENDF-246 (1976).1 Neutron cross section and photon production data are given between $10^{-5} \mathrm{eV}$ and $20 \mathrm{MeV}$. The cross sections included are total, elastic, non-elastic, inelastic capture, $(n, p),(n, d),(n, t),\left(n,{ }^{3} H e\right),(n, \alpha),(n, 2 n),(n, 3 n),(n, n \alpha)$, $(n, n p)$, and gas production. The photon data include multiplicities and transition probabilities, photon production cross sections, and secondary energy spectra.

The major differences in this re-evaluation are the inelastic excitations, the n-particle cross sections, and the photon production cross sections, which are based on new experimental data. The analysis of these data required a higher level of sophistication in the model code treatment and the results are reported herein.

\section{CALCULATIONS AND COMPARISON WITH EXPERIMENT}

\section{A. Resonance Region}

The resonance parameters and background used in determining the total, elastic, and capture cross sections up to $642.85 \mathrm{keV}$ are the same as ENDF/B-IV. ${ }^{1}$ The $0.0253 \mathrm{eV}$ values are $\sigma_{\text {tot }}=7.446 \mathrm{~b}, \sigma_{\text {elas }}=4.342 \mathrm{~b}, \sigma_{\text {ny }}=3.104 \mathrm{~b}$, and the capture resonance integral at a $0.5 \mathrm{eV}$ cutoff is $1.652 \mathrm{~b}$.

Figures 1 and 2 show the total cross section for natural chromium from $10^{-4} \mathrm{eV}$ to $650 \mathrm{keV}$.

B. Continuum Region

1. Total Cross Section. The amount of experimental data on the total cross section at energies above the resonance region is voluminous; however no significantly new experiments have been reported since the ENDF/B-IV ${ }^{1}$ evaluation. Thus, the data of Perey et al. ${ }^{2}$ (as in ENDF/B-IV) were spline fitted in this region which exhibit rapid fluctuations $(E<5.0 \mathrm{MeV})$. Beyond this region up to $20.0 \mathrm{MeV}$, optical model calculations were used. Figures 3 to 12 show the fits and calculations compared to the experimental data.

The potential used in the optical model calculations had the conventional form given below. The method used in determining the numerical values of the parameters used in the potential has been given in ref. 3 .

$$
\begin{aligned}
& V(r)=-V_{R} f\left(R_{R} a_{R} r\right)-i W_{v} f\left(R_{I} a_{I} r\right)+i 4 a_{I} W_{S} f^{\prime}\left(R_{I} a_{I} r\right) \\
& +V_{\text {so }}\left(\frac{\hbar}{m_{\pi} c}\right)^{2} \frac{1}{r} f^{\prime}\left(R_{\text {so }} a_{\text {so }} r\right) \bar{\sigma} \cdot \bar{l} .
\end{aligned}
$$

where

$$
f\left(R_{I} a_{I} r\right)=\left[1+\exp \frac{r-R_{I}}{a_{I}}\right]^{-1} \text {, }
$$


and:

$$
\begin{aligned}
& \mathrm{V}_{\mathrm{R}}=\text { depth of the real potential, } \\
& \mathrm{W}=\text { depth of the imaginary potential ( } \mathrm{v}=\mathrm{vol}, \mathrm{s}=\text { surf), } \\
& \mathrm{V}_{\mathrm{so}}=\text { depth of the spin-orbit potential, } \\
& \mathrm{R}_{\mathrm{R}}=\text { radius of the real nuclear potential } \\
& \mathrm{R}_{\mathrm{I}}=\text { radius of the imaginary nuclear potential, } \\
& \mathrm{a}_{\mathrm{R}}=\text { diffuseness paramenter of the real potential, } \\
& \mathrm{a}_{I}=\text { diffuseness parameter of the imaginary potential, } \\
& \mathrm{a}_{\mathrm{So}}=\text { diffuseness parameter of the spin-orbit potential, } \\
& \mathrm{m}_{\pi}=\text { pion mass, } \\
& \sigma=\text { Pauli's spin operator, and } \\
& 1=\text { orbital angular momentum operator. }
\end{aligned}
$$

In order to obtain the contribution of the direct inelastic scattering component (see Section 5), a vibrational model undergoing dynamic deformations about a spherical shape was assumed. Thus, the radius in Eq. (1) was expressed as:

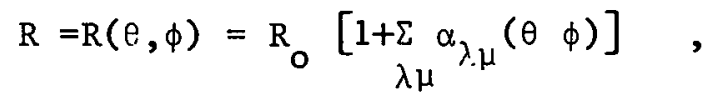

where

$\alpha_{\lambda \mu}$ may be described in terms of the deformation parameter $\beta$.

The optical model paraneters derived for the chromium isotopes are given bèlow (all $\mathrm{E}$ in $\mathrm{MeV}$ and in the laboratory system).

$$
\begin{aligned}
& \frac{{ }^{52} \mathrm{Cr}}{\mathrm{V}_{R}}=(50.9617-0.574 \mathrm{E}) \mathrm{MeV} \\
& \mathrm{W}_{\mathrm{S}}=\left(6.18+0.4195 \mathrm{E}+0.0089 \mathrm{E}^{2}\right) \mathrm{MeV} \\
& \mathrm{W}_{\mathrm{V}}=(0.0) \mathrm{MeV} \\
& \mathrm{V}_{\mathrm{so}}=(7.35) \mathrm{MeV} \\
& { }_{R}=(1.2647-0.00527 \mathrm{E}) \mathrm{fm} \\
& { }_{S}=(1.3202-0.00527 \mathrm{E}) \mathrm{fm} \\
& r_{s o}=r_{R} \\
& a_{R}=(0.7692-0.00528 \mathrm{E}) \mathrm{fm} \\
& a_{s}=(0.4638-0.00318 \mathrm{E}) \mathrm{fm} \\
& a_{S O}=a_{r}
\end{aligned}
$$




$$
\begin{aligned}
& { }^{50} \mathrm{Cr} \\
& \mathrm{V}_{\mathrm{R}}=(51.6137-0.584 \mathrm{E}) \mathrm{MeV} \\
& W_{s}=\left(6.2984+0.4192+0.0086 E^{2}\right) \mathrm{MeV} \\
& \mathrm{W}_{\mathrm{V}}=(0.0) \cdot \mathrm{MeV} \\
& \mathrm{V}_{\text {so }}=(7.6) \mathrm{MeV} \\
& r_{\mathrm{R}}=(1.2584-0.0037 \mathrm{E}) \mathrm{fm} \\
& r_{S}=(1.3142-0.0037 \mathrm{E}) \mathrm{fm} \\
& r_{\text {so }}=r_{R} \\
& a_{R}=(0.7640-0.005 \mathrm{E}) \mathrm{fm} \\
& a_{\text {so }}=a_{R} \\
& { }^{54} \mathrm{Cr} \\
& \mathrm{V}_{\mathrm{R}}=(48.8352-0.544 \mathrm{E}) \mathrm{MeV} \\
& \mathrm{W}_{\mathrm{S}}=\left(5.871+0.4217 \mathrm{E}+0.0099 \mathrm{E}^{2}\right) \mathrm{MeV} \\
& \mathrm{W}_{\mathrm{V}}=(0.0) \mathrm{MeV} \\
& \mathrm{V}_{\text {so }}=(6.89) \mathrm{MeV} \\
& r_{R}=(1.2658-0.0039 \mathrm{E}) \mathrm{fm} \\
& r_{s}=(1.3210-0039 \mathrm{E}) \mathrm{fm} \\
& \mathrm{r}_{\text {So }}=\mathrm{r}_{\mathrm{R}} \\
& a_{R}=(0.7756-0.00564 \mathrm{E}) \mathrm{fm} \\
& a_{s}=(0.466-0.0034 \mathrm{E}) \mathrm{fm} \\
& a_{\text {SO }}=a_{R} \\
& \underline{53 \mathrm{Cr}} \\
& V_{R}=(47.3319-0.516 \mathrm{E}) \mathrm{MeV} \\
& W_{S}=\left(5.716+0.4294 E+0.0114 E^{2}\right) \mathrm{MeV} \\
& \mathrm{W}_{\mathrm{V}}=(0.0) \mathrm{MeV} \\
& \mathrm{V}_{\text {So }}=(6.75) \mathrm{MeV} \\
& r_{R}=(1.2628-0.0039 \mathrm{E}) \mathrm{fm} \\
& r_{s}=(1.3182-0.0039 \mathrm{E}) \mathrm{fm} \\
& r_{\text {so }}=r_{R}
\end{aligned}
$$




$$
\begin{aligned}
& { }^{53} \mathrm{Cr} \text { (cont) } \\
& a_{R}=(0.7729-0.0058 \mathrm{E}) \mathrm{fm} \\
& a_{s}=(0.4649-0.0035 \mathrm{E}) \mathrm{fm} \\
& a_{\text {so }}=a_{R}
\end{aligned}
$$

While the optical model calculations were carried out over the entire energy range, only the calculated total cross sections for $E>5.0 \mathrm{MeV}$ were used. These cross sections are shown in Figs. 11 and 12. Höwever, all of the calculated angular distributions were used for generating the Legendre coefficients for File 4. Likewise, the transmission coefficients calculated from these potentials were also used to describe the inelastic and n-particle cross sections (see the following Sections).

2. Non-Elastic Cross Section. The non-elastic cross section, up to about $5.0 \mathrm{MeV}$, is due primarily to $\sigma_{\mathrm{nn}}$, and $\sigma_{\mathrm{n} \gamma}$.

Slightly above this energy, the $n, p$ and $n, \alpha$ contributions become significant. At still higher energies, the $n, 2 n$ and other reactions must be considered.

Direct measurements of $\sigma_{\text {non }}$ are practically non-existent. There is a rather old set of experimental data by Taylor et al., ${ }^{4}$ who carried out spherical shell transmission measurements in the energy range of 3.5 to $14.1 \mathrm{MeV}$. There is one other experimental measurement at $E=2.5 \mathrm{MeV}\left(\sigma_{\text {non }}=1.4 \pm 0.3 \mathrm{~b}\right)$. reported by Strizhak. ${ }^{5}$

Up to $\mathrm{E}=4.0 \mathrm{MeV}$, the non-elastic cross section was determined from the experimental data on $\sigma_{\mathrm{nn}}$, and $\sigma_{\mathrm{n} \gamma}$, with $\sigma_{\mathrm{non}}=\sigma_{\mathrm{n} \gamma}$ for $\mathrm{E}<650 \mathrm{keV}$. In evaluating $\sigma_{\text {non }}$ for the higher energies, a combination of the experimental direct measurements of Taylor et $a 1.4$ and the $\sigma_{\text {tot }}$ and $\sigma_{\text {el }}$ measurements of Kinney and Perey ${ }^{6}$ were used in conjunction with the optical model calculations.

A comparison of the evaluated, experimental, and model calculations are shown in Fig. 13. In this figure $\sigma_{\text {non }}$ is $3.8 \mathrm{mb}$ at $650 \mathrm{keV}$, a value too small to be seen on a linear-linear plot. non

3. Elastic Cross Section. For energies between the resonance region and $1.5 \mathrm{MeV}$. The ANL groups ${ }^{7-9}$ have produced quite a bit of angular data. At higher energies, the data are rather sparse with the major portion coming from Refs. 10 to 12. Thus, as in ENDF/B-IV, the additional angular distributions necessary to fill the gaps were described by optical model calculations.

In the highly-structured region, the total elastic cross section was determined by subtracting the non-elastic from the total cross section. For energies $\mathrm{E}>5.0 \mathrm{MeV}$, a combination of model calculations and experimental data on the non-elastic were used.

The comparisons between the evaluated elastic cross section and the experimental angle-integrated data are shown in Figs. 14 to 23 .

In Figs. 24 to 32 , the optical model calculations of the differential scattering are compared to some experimental results. These calculations were used to generate the Legendre coefficients in File 4. 
4. Radiative Capture Cross Section. Above the resolved energy region $(E>0.7 \mathrm{MeV})$, the capture cross sections were determined from calculations sing COMNUC ${ }^{13}$ for the compound nucleus capture, taking into account $\sigma_{\text {nn' }}$ ' competition, and FISPRO ${ }^{14}$ for the direct and collective capture. At energies E>10 MeV, the capture cross section resulting from compound nuclear processes was negligible and the calculated direct and collective results were normalize to th $14 \mathrm{MeV}$ experimental point of Cvelbar et al. 15

This direct and collective calculation resulted in a slight peaking of the cross section at $\mathrm{E}_{\mathrm{n}}=17 \mathrm{MeV}$, as seen in $\mathrm{Fig}$. 33. A similar peak, at about the same energy, was reported by Nishimura et al., 16 however, their results are high by about a factor of two. This could be due to the fact that they did not normalize to the $14 \mathrm{MeV}$ data point Cvelbar. 15

5. Inelastic Scattering Cross Sections. As mentioned earlier, one of the major changes in the ENDF/B-V Cr evaluation occurs in the inelastic cross section. These modifications results from primarily two sources, namely, recent measurements and new level structure data.

In ENDF/B-IV, the evaluation was primarily based on the data of Van Patter et al., 17 who analyzed differential gamma-ray spectra from the ( $n, n^{\prime} \gamma$ ) reaction and converted the data to inelastic scattering cross sections. Other experimental data were also used.18-22 These experiments produced neutron inelastic scattering data for some individual levels of chromium for neutron incident energies, $E_{n}<4.0 \mathrm{MeV}$. Kinney and Perey ${ }^{6}$ made measurements for natural $\mathrm{Cr}$ between $4^{\mathrm{n}} .07$ and $8.56 \mathrm{MeV}$ and ${ }^{52} \mathrm{Cr}$ for energies between 6.44 and 8.56 MeV. These latter experimental data were very significant in determining not only the level excitations for the low-lying levels in ${ }^{52} \mathrm{Cr}$ and $\mathrm{Cr}$ (Nat) at the higher energies, but also in establishing the importance of the direct inelastic contributions.

However, the more recent experimental data of the Lowell group, 23,24 with improved measurement techniques, showed that more low energy $(E<4 \mathrm{MeV})$ level excitation cross sections could be resolved. The ENDF/B-IV evaluation, based on the previous measurements were only in fair agreement with the Lowe11 results, differing as much as $30 \%$ in some cases.

The Lowel1 group measured absolute 125 degree differential gamma-ray production cross sections for neutron scattering in natural chromium, for neutrons in the 0.84 to $3.97 \mathrm{MeV}$ region. From these measurements, they inferred neutron inelastic scattering cross sections for several individual states in $505253{ }^{54} \mathrm{Cr}$. It was observed that the excitation fuhctions displayed considerable structure and provided a possible explanation for the rather large inconsistencies that appear among the previous measurements.

These fluctuations had also been observed by the measurements at Karlsruhe 25 and by Tessler and Glickstein ${ }^{26}$ and are believed to be the reason for the high discrepancy existing between the various experimental data.

The ENDF/B-IV Cr evaluation relied on the data of Refs. 17 to 22, where, according to the Lowell group, the energy increments for excitation functions were much broader than the structure expected from the neutron energy spread. Therefore, all the level excitations in the $\mathrm{Cr}$ isotopes were re-evaluated in terms of the Lowell results. The energy levels associated with the chromium isotopes are given in Table 1. 
Table 1

Energy Level Schemes Used for H-F Inelastic Scattering Calculations

\begin{tabular}{|c|c|c|c|c|c|c|c|}
\hline \multicolumn{2}{|c|}{$\mathrm{Cr}-50$} & \multicolumn{2}{|c|}{$\mathrm{Cr}-52$} & \multicolumn{2}{|c|}{$\mathrm{Cr}-53$} & \multicolumn{2}{|c|}{$\mathrm{Cr}-54$} \\
\hline $\mathrm{E}(\mathrm{MeV})$ & $\mathrm{J}^{\pi}$ & $\mathrm{E}(\mathrm{MeV})$ & $\mathrm{J}^{\pi}$ & $\mathrm{E}(\mathrm{MeV})$ & $\mathrm{J}^{\pi}$ & $\mathrm{E}(\mathrm{meV})$ & $\mathrm{J}^{\pi}$ \\
\hline $\begin{array}{l}0.000 \\
0.783 \\
1.879 \\
2.922 \\
3.160 \\
3.320 \\
3.593 \\
3.787 \\
3.895 \\
4.524 \\
4.653\end{array}$ & $\begin{array}{l}0^{+} \\
2^{+} \\
4^{+} \\
2^{+} \\
2^{+} \\
4^{+} \\
2^{+} \\
5^{+} \\
0^{+} \\
3^{-} \\
2^{+}\end{array}$ & $\begin{array}{l}0.000 \\
1.434 \\
2.370 \\
2.647 \\
2.768 \\
2.965 \\
3.114 \\
3.162 \\
3.414 \\
3.471 \\
3.617 \\
3.771 \\
3.947 \\
4.015 \\
4.039 \\
4.563 \\
4.630 \\
4.837 \\
5.097 \\
5.292 \\
5.585 \\
5.737 \\
6.070 \\
6.154 \\
6.490 \\
6.820 \\
7.070 \\
7.900\end{array}$ & $\begin{array}{l}0^{+} \\
2^{+} \\
4^{+} \\
0^{+} \\
4^{+} \\
2_{+}^{+} \\
6^{+} \\
2^{+} \\
4^{+} \\
3^{+} \\
5^{+} \\
2^{+} \\
1^{+} \\
5^{+} \\
4^{+} \\
3^{+} \\
4^{+} \\
4^{+} \\
4^{+} \\
2^{+} \\
0_{+}^{+} \\
0^{+} \\
2_{+}^{+} \\
2^{+} \\
3_{+}^{+} \\
2^{+} \\
3^{-} \\
3^{-}\end{array}$ & $\begin{array}{l}0.000 \\
0.564 \\
1.006 \\
1.287 \\
1.539 \\
1.973 \\
2.171 \\
2.233 \\
2.321 \\
2.455 \\
2.661 \\
2.670 \\
2.711 \\
2.775 \\
2.995 \\
3.132 \\
3.153 \\
3.186 \\
3.268 \\
3.352\end{array}$ & $\begin{array}{l}3 / 2^{-} \\
1 / 2^{-} \\
5 / 2^{-} \\
7 / 2^{-} \\
7 / 2^{-} \\
9 / 2^{-} \\
1 / 2^{-} \\
7 / 2^{-} \\
3 / 2^{-} \\
1 / 2^{-} \\
5 / 2^{-} \\
1 / 2^{-} \\
1 / 2^{-} \\
5 / 2^{-} \\
5 / 2^{-} \\
9 / 2^{-} \\
3 / 2^{+} \\
3 / 2^{-} \\
3 / 2^{+} \\
7 / 2^{-}\end{array}$ & $\begin{array}{l}0.000 \\
0.835 \\
1.827 \\
2.619 \\
2.829 \\
3.074 \\
3.437 \\
3.487 \\
3.800 \\
4.015 \\
4.129 \\
4.573\end{array}$ & $\begin{array}{l}0^{+} \\
2^{+} \\
4^{+} \\
2^{+} \\
0^{+} \\
2^{+} \\
2^{+} \\
4^{+} \\
4^{+} \\
0^{+} \\
3^{-} \\
0^{+}\end{array}$ \\
\hline
\end{tabular}

As with the previous evaluation, it was necessary to carry out HauserFeshbach calculations for the discrete and continuum inelastic cross sections to fill the gaps and also compare with the experimental data. The latter analysis provided a reasonable substantiation of the various model parameters used in the calculations.

The anisotropy observed in the differential inelastic scattering data of the ORNL group dictated that a coupled-channel analysis also be carried out for the low-lying collective levels. It was assumed that the higher states are weakly coupled to the ground state so their contributions to the direct inelastic excitation were taken to be negligible.

a. Comparison of Calculations with Experimental Data. Model calculations, based on the Hauser-Feshbach formalism modified to account for width fluctuations, provided data for both the discrete and continuum inelastic cross sections for the $\mathrm{Cr}$ isotopes. The analysis was carried out using a 
combination of the statistical model codes COMNUC 13 and the early version of Uhl's $\operatorname{code}^{27}(\mathrm{a})$ (now called $\operatorname{STAPRE}^{27}(\mathrm{~b})$ ).

In order to obtain meaningful comparisons of the theoretical calculations with experiment, certain corrections had to be considered. First the calculations for the inelastic cross sections for the individual isotopes, when weighted by their respective abundances, had to be renormalized so as to be in agreement with the total inelastic cross section of natural $\mathrm{Cr}$, which, in turn, had to made consistent with the predictions in the non-elastic, i.e.,

where:

$$
\sigma_{n n^{\prime}}(\text { tot })=\sigma_{n o n}-\left(\sigma_{n, \gamma}+\sigma_{n, 3 n}+\sum \sigma_{n x}+\sum \sigma_{n \times n^{\prime}}+\sum \sigma_{n n^{\prime} x}\right)
$$

$$
x=p, d, t,{ }^{3} \mathrm{He},{ }^{4} \mathrm{He} \text {. }
$$

Also, the inconsistency between the Hauser-Feshbach calculations of the inelastic scattering and the coupled-channel calculations was removed by introducing a reduction factor $\mathrm{R}$ given by:

$$
\mathrm{R}=\frac{\sigma_{\text {expt'1 }}-\sigma_{\text {direct inelastic }}}{\sigma_{\text {expt' } 1}}
$$

where it has been assumed that the difference between the experimental inelastic cross section and the direct inelastic cross section is the true compound inelastic cross section.

While all the levels shown in Table 1 were used in calculating the excitation functions for the various isotopes, only the first low-lying levels of ${ }^{50} \mathrm{Cr}(0.7831 \mathrm{MeV})$ and ${ }^{54}(0.8348 \mathrm{MeV})$ were put into ENDF/V as discrete. The rest of the level excitations for these two isotopes were put into the continuum. This was necessary since the present ENDF format allows for only 40 discrete levels.

On the other hand, all the levels for ${ }^{52} \mathrm{Cr}$ up to and including the one at $5.097 \mathrm{MeV}$, and all those for ${ }^{53} \mathrm{Cr}$ were taken into consideration, giving a total of 38 excitations in the discrete region for ${ }^{52} \mathrm{Cr}$ and ${ }^{53} \mathrm{Cr}$.

The various calculations were run with pre-equilibrium fractions using the Uhl code. More will be said about this later in the discussion of the n-particle cross sections.

In the case of inelastic scattering at low energies, i.e., below the continuum threshold $(E<1.86 \mathrm{MeV})$, the Uhl code greatly underestimated the compound-elastic contribution. The failure of the early version $27(a)$ of the code to take width fluctuations into account and the coarse grid of the generated internal table of transmission coefficients caused this underestimation. However, after adjustment of the compound elastic from the CoMNuC results, the agreement with experimental data was greatly improved.

The foregoing analysis of the isotopic $\mathrm{Cr}$ inelastic cross sections was abundance weighted (see Table 2) to provide the inelastic contributions for natural $\mathrm{Cr}$. These results are presented in Figs. 34 to 50, where the comparisons with the Lowell data are shown. It should be noted that the structure in the evaluated data (e.g.; Figs. 34-36, 38, 40) arises not so much from the calculations but shape-fitting and renormalization to the experimental results. 
Table 2

Natural Abundance and Mass of $\mathrm{Cr}$ Isotopes

\begin{tabular}{cccc}
\hline Isotopes & \% Abundance & Mass (amu) & $\mathrm{S}_{\mathrm{n}}(\mathrm{MeV})^{\mathrm{a}}$ \\
\hline 50 & 4.35 & 49.946049 & 9.262 \\
52 & 83.79 & 51.940510 & 7.940 \\
53 & 9.50 & 52.940651 & 9.720 \\
54 & 2.36 & 53.938881 & 6.246 \\
\hline
\end{tabular}

$a_{S_{n}}=$ Binding energy of last neutron in compound nucleus.

The most important level due to its large contribution, is the $1.434 \mathrm{MeV}$ level of ${ }^{52} \mathrm{Cr}$. The amount of experimental data for this level provided adequate confirmation for both its magnitude and shape (see Fig. 39).

The total inelastic scattering for natural chromium is shown in Fig. 51 from threshold to $4.0 \mathrm{MeV}$ and Fig. 52 to $20.0 \mathrm{MeV}$. This evaluated curve includes the abundance weighted discrete and continuum contributions of all four isotopes.

The wide gap in the experimental data for $E_{n}>3.5 \mathrm{MeV}$ required a careful consideration of the competing processes $(n, 2 n),(n, 3 n)$, (n-particle) so that an adequate interpretation of the total inelastic cross section would result in the high energy region. The various experimental results around 14.0 MeV were of particular importance in satisfying these criteria.

A good agreement having been established between the optical model calculations and the experimental results of Taylor el al. ${ }^{3}$ for the nonelastic cross sections, the contributions for all competing processes were subtracted such that $\mathrm{Eq}$. (3) was satisfied for all significant reactions below $20.0 \mathrm{MeV}$. Table 3 shows all these reactions which includes those used in the evaluated file.

A few details of the various experimental points at $14 \mathrm{MeV}$ are worth mentioning since their interpretation played a very important role in fixing the value of the cross section at this energy.

Salnikov and Lovchikova ${ }^{28}$ analyzed the energy spectra of the inelastically-scattered neutrons at various angles, and thus, obtained the differential inelastic cross section. They reported a value of $\sigma_{\mathrm{nn}}=880 \pm 40 \mathrm{mb}$. Fujita el al. ${ }^{29}$ also measured the continuous spectra of inelasticallyscattered neutrons using a time-of-flight method. They made their measurement a.t only one angle $\left(\theta=110^{\circ}\right)$ and assumed isotropic scattering. Their value of $\sigma_{\mathrm{nn}}=1.27 \pm 0.13 \mathrm{~b}$ was not used in the evaluation since it is at great variance with other measurements at this energy. The probable reason for this value is due to the fact that they assumed isotropic scattering and ignored certain $\mathrm{n}$, particle reactions which emitted neutrons.

Tagesen and Hille, 30 along with Breunlich and Stengel, 31 detected the gamma-rays resulting from the de-excitation of the excited states similar to the method of Van Patter et a1.17 Tagesen and Hille ${ }^{30}$ established an upper bound of $\sigma_{\mathrm{nn}}{ }^{\prime}=870 \pm 80 \mathrm{mb}$, based on certain observations of the $\mathrm{n}, 2 \mathrm{n}$ reaction. They also carried out an absolute determination of the inelastic cross section achieving a value in agreement with $\sigma_{\mathrm{nn}^{\prime}}=740 \mathrm{mb} \pm 20 \%$ reported by Morgan et al. 32 
Table 3

$Q$ Values for Possible Neutron-Induced Reactions in $\mathrm{Cr}$ for $\mathrm{E}_{\mathrm{n}} \cong 20.0 \mathrm{MeV}$

\begin{tabular}{|c|c|c|c|c|c|}
\hline & $\mathrm{Cr}-50$ & $\mathrm{Cr}-52$ & $\mathrm{Cr}-53$ & $\mathrm{Cr}-54$ & \\
\hline Reaction & $-Q(\mathrm{MeV})$ & $-Q(\mathrm{MeV})$ & $-Q(\mathrm{MeV})$ & $-(\mathrm{MeV})$ & $\begin{array}{c}\text { ENDF } \\
\text { MT }\end{array}$ \\
\hline $\begin{array}{l}(n, p) \\
\left(n,{ }^{3} \mathrm{He}\right) \\
\left(n, n^{\prime} d\right) \\
\left(n, n^{\prime}{ }^{4} \mathrm{He}\right) \\
\left(n,{ }^{4} \mathrm{He}, n^{\prime}\right) \\
\left(n, p,{ }^{4} \mathrm{He}\right) \\
(n, 2 n) \\
(n, d) \\
\left(n,{ }^{4} \mathrm{He}\right) \\
\left(n, n^{\prime} t\right) \\
\left(n, n^{\prime}\right) \\
\left.\left(n,{ }^{4}{ }^{\prime}\right), p\right) \\
(n, 3 n) \\
(n, t) \\
\left(n, n^{\prime} p\right) \\
\left(n, n^{3} \mathrm{He}\right) \\
(n, 2 p) \\
(n, d, n)\end{array}$ & $\begin{array}{r}0.257 \\
8.628 \\
18.920 \\
8.555 \\
8.555 \\
10.139 \\
12.939 \\
7.364 \\
-0.322 \\
23.200 \\
9.588 \\
10.140 \\
23.581 \\
12.662 \\
9.590 \\
20.255 \\
8.204 \\
18.919\end{array}$ & $\begin{array}{r}3.196 \\
10.844 \\
19.335 \\
9.353 \\
9.353 \\
12.562 \\
12.041 \\
8.282 \\
1.211 \\
22.409 \\
10.507 \\
12.562 \\
21.302 \\
13.077 \\
10.507 \\
21.788 \\
12.190 \\
19.335\end{array}$ & $\begin{array}{r}2.640 \\
12.412 \\
16.222 \\
9.150 \\
9.151 \\
10.374 \\
7.940 \\
8.911 \\
-1.794 \\
21.017 \\
11.136 \\
10.374 \\
19.981 \\
9.965 \\
11.136 \\
18.784 \\
12.323 \\
16.222\end{array}$ & $\begin{array}{r}6.220 \\
14.325 \\
18.631 \\
7.927 \\
7.927 \\
14.031 \\
9.720 \\
10.135 \\
1.554 \\
19.685 \\
12.360 \\
14.031 \\
17.660 \\
12.374 \\
12.360 \\
22.132 \\
16.863 \\
18.631\end{array}$ & $\begin{array}{l}16 \\
104 \\
107\end{array}$ \\
\hline
\end{tabular}

Breunlich and Stengel ${ }^{31}$ quoted a value of $\sigma_{n n}{ }^{\prime}=790 \pm 112 \mathrm{mb}$ of which, based on an assumption by Uh1, $33100 \mathrm{mb}$ is due to the direct inelastic scattering process. Colli and Marcazzan ${ }^{34}$ have also reported that at $14 \mathrm{MeV}$ precompound emission might account for as much as $30 \%$ of the inelastic cross section.

The combined results of the $(n, 2 n)$ and ( $n$,particle) cross sections were determined to be about $0.58 \mathrm{~b}$ at $14.0 \mathrm{MeV}$ (see section 6). From a value of $\sigma_{\text {non }}=1.31 \mathrm{~b}$, the total inelastic scattering cross sections turned out to be $0.73 \mathrm{~b}$ which is in excellent agreement with the aforementioned experimental results. This agreement at $14.0 \mathrm{MeV}$ provides a rather high level of confidence for the total inelastic scattering in the higher energy.region.

b. Differential Inelastic Scattering. As mentioned earlier since the ORNL data on the inelastic angular distributions showed some anisotropy, it seemed advisable to carry out coupled-channel calculations. These calculations were carried out using a modified version of JUPITOR. 35

Figures 53 to 58 show the comparison between the compound differential inelastic and the direct differential inelastic (coupled-channel calculations) of the $1.434-\mathrm{MeV}(2+)$ and $2.369-\mathrm{MeV}(4+)$ levels in ${ }^{52} \mathrm{Cr}$. The sum of the compound and direct contribution produces the total differential inelastic cross section. The experimental data is that of Kinney and Perey. ${ }^{6}$ Note the symmetry about $90^{\circ}$ in the compound inelastic process (Hauser-Feshbach 
calculations) as compared to the high forward peaking in the direct process. This forward peaking accounts for some asymmetry about $90^{\circ}$ in the calculations as to be expected; however, the Kinney and Perey ${ }^{6}$ data do not show this since their measurements ranged only from 35.7 to 135.4 degrees.

The measurements at $14.0 \mathrm{MeV}, 36$ shown in Fig. 59, definitely shows the high degree of anisotropy in the differential inelastic which is assumed to be due primarily to the direct excitation of these levels. The coupledchannel calculations, while producing a satisfactory shape, slightly underestimated the magnitude of the cross section by about $20 \%$. However, it should be mentioned that this experimental data of stelson et al. ${ }^{36}$ are for natural Cr which means that the data for the $1.434-\mathrm{MeV}$ level possibly contain a contribution from the $1.287-\mathrm{MeV}$ level in ${ }^{53} \mathrm{Cr}$. The solid curves in $\mathrm{Fig}$. 59 have been normalized to the experimental data at $60^{\circ}$. These calculated inelastic angular distributions have been incorporated into File 4 in the form of Legendre coefficients.

6. Neutron Emission and n-Particle Cross Section. The relative sparsity of experimental data on the various reactions, such as the $(n, 2 n)$, $(n, 3 n),(n, p),(n, \alpha)$, etc., made this evaluation highly dependent on model calculations. As noted in the previous section, the statistical model code of Uh1 27 (a) played a vital role in calculating these reaction cross sections. For those reactions which could not be handled by the code, namely $(n, t)$ and $\left(n,{ }^{3} \mathrm{He}\right)$, the evaporation code THRESH ${ }^{37}$ was used.

Calculations were carried out for all energetically possible reactions (see Table 3) on the four stable isotopes of chromium. As an example of the various reaction channels considered in the Uhl code calculations, a schematic of the reaction ${ }^{54} \mathrm{Cr}(n, 3 n)$ is given in Fig. 60 . The squares in relief show the various compound nuclei considered at each step of the calculation. Other residual nuclei for which data must be provided are also indicated.

The transmission coefficients employed as input to the Uh1 code were generated by the code ABACUS-2.38 The neutron optical model parameters necessary for the various residual nuclei were generated by the method mentioned ear1ier. ${ }^{3}$

The optical model parameters necessary for proton, neutron, and $\alpha$-particle emission are given below.

Proton Parameters: F.D. Becchetti and G.W. Greenlees, Phys. Rev. 182,1190 (1969).

$$
\begin{aligned}
V_{R} & =54.0-0.32 \mathrm{E}+0.4 \mathrm{z} / \mathrm{A}^{1 / 3}+24.0(\mathrm{~N}-\mathrm{Z}) / \mathrm{A} \\
\mathrm{r}_{\mathrm{R}} & =1.17 \mathrm{fm} \\
{ }^{a_{R}} & =0.75 \mathrm{fm} \\
\mathrm{W}_{\mathrm{V}} & =0.22 \mathrm{E}-2.7 \text { or zero, whichever is greater } \\
\mathrm{W}_{\mathrm{SF}} & =11.8-0.25 \mathrm{E}+12.0(\mathrm{~N}-\mathrm{Z}) / \mathrm{A} \text { or zero, whichever is greater } \\
\mathrm{r}_{I} & =1.32 \mathrm{fm} \\
\mathrm{a}_{I} & =0.51+0.7(\mathrm{n}-\mathrm{Z}) / \mathrm{A} \mathrm{fm} \\
\mathrm{V}_{\text {So }} & =6.2
\end{aligned}
$$


$r_{\text {so }}=1.01 \mathrm{fm}$
$a_{\text {so }}=1.01 \mathrm{fm}$

Where $\mathrm{E}$ is the incident laboratory energy, (in $\mathrm{MeV}$ ).

Deuteron Parameters: F. Hinterberger, Nuc1. Phys. Al11, 265 (1968).

$\mathrm{V}=100+2.5 \mathrm{Z} / \mathrm{A}^{1 / 3}-0.5 \mathrm{E}$

$r_{\mathrm{v}}=1.05 \mathrm{fm}$

$a_{v}=\left(0.71+0.04 \mathrm{~A}^{1 / 3}\right) \mathrm{fm}$

$\mathrm{W}=\left(5.0+2.0 \mathrm{~A}^{1 / 3}\right) \mathrm{MeV}$

$\mathrm{r}_{\mathrm{W}}=1.28 \mathrm{fm}$

$a_{W}=0.71+0.02 \mathrm{~A}^{1 / 3}$

$\mathrm{V}_{\text {so }}=6.0 \mathrm{MeV}$

$r_{c}=1.3 \mathrm{fm}$

$r_{\text {so }}=r_{v}$

$a_{\text {so }}=a_{\mathrm{v}}$

Where $\mathrm{E}$ is the incident laboratory energy, (in $\mathrm{MeV}$ ).

Alpha Parameters: R. Bock, Nuc1. Phys. $\underline{\text { A92 }} 539$ (1967).

$\mathrm{V}_{\mathrm{R}}=183.7 \mathrm{MeV}$

$\mathrm{r}_{\mathrm{R}}=1.4 \mathrm{fm}$

$a_{R}=0.564 \mathrm{fm}$

$\mathrm{W}_{\text {vol }}=26.6 \mathrm{MeV}$

$r_{w}=r_{R}$

$a_{\dot{w}}=a_{R}$

$r_{c}=1.3 \mathrm{fm}$

It should be noted that as a preliminary step to substantiate these global

optical-model parameters, a comparison of the experimental angular distribution and polarization data to the calculations was performed. Where specific experimental data on chromium did not exist, the comparison was made with experimental data in the region around chromium.

Also incorporated in the statistical model calculations were a "best-set" of level-density parameters, based on the work of Dilg et al., 39 which reproduced the available experimental data (see Tables 4 to 8 ).

A summary of the level-density parameters, based on the back-shifted Fermi gas model, 39 are presented below.

Level-Density Parameters:

$\sigma_{\text {rigid }} \approx 0.0150 \mathrm{~A}^{5 / 3} \mathrm{t} \quad(\mathrm{t}=$ thermodynamic temperature $)$

$a t^{2}-t=U-\Delta \quad$ (Effective excitation energy) 
Average Parameters for $40<\mathrm{A}<63$.

$$
\begin{aligned}
& \sigma=\sigma_{\text {rigid }} \\
& r_{0}=1.25 \mathrm{fm} \\
& \mathrm{a}\left(\mathrm{MeV}^{-1}\right)=2.40+0.067 \mathrm{~A} \\
& \Delta(\mathrm{MeV})=130 \mathrm{~A}^{-1}+\mathrm{P} \\
& 2 \delta \mathrm{A}^{-1 / 2} \\
& \mathrm{P}=\quad \delta \mathrm{A}^{-1 / 2} \\
& \mu \mathrm{A}^{-1} \\
& \text { doubly even } \\
& \text { odd mass } \\
& \text { doubly odd } \\
& \delta=12.8 \mathrm{MeV} \\
& \mu=29.4 \mathrm{MeV}
\end{aligned}
$$

In the attempt to fit the experimental data in a constant manner, the adjustment of 'a'was constrained to $+12 \%$ of the above value and of $\Delta$ to $\pm 1.0 \mathrm{MeV}$. These constraints were made on the basis of Dilg's quoted mear. deviations of $6 \%$ and $0.5 \mathrm{MeV}$, respectively. The authors attempted to fit the available experimental data on reactions for all four isotopes simultaneously.

Discrete level information along with spins, parities were obtained from Refs. 40 and 41. The nuclear reaction Q-values (Table 3) were taken from Ref. 42 .

All calculations were run with assumed pre-equilibrium fractions of $0 \%, 20 \%$, and $40 \%$. After comparison with the experimental cross sections, arbitrary fractions of $0 \%$ for incident energies below $12 \mathrm{MeV}$ and $20 \%$ above (up to $20.0 \mathrm{MeV}$ ) were chosen.

Prior to a specific comparison of the calculations with experimental data, it is useful to discuss the problems associated with the version of Uhl's code 27 (a) employed and the problems encountered in attempting to reconcile the various data available for the most abundant isotope ${ }^{52} \mathrm{Cr}$.

As mentioned above, the lack of width fluctuations and the coarse grid of the generated internal table of transmission coefficients in the version of Uhl's code used caused problems in the case of inelastic scattering below $\mathrm{E}=1.86 \mathrm{MeV}$. This coarse grid also caused problems in almost all the calculations near the reaction threshold. Also, as with most statistical model codes, Uhl's code cannot account for such phenomenon as the Giant Resonance. In ${ }^{52} \mathrm{Cr}$, this may be important since the Giant Resonance would be expected at $\mathrm{E}_{\mathrm{n}} \approx 8 \mathrm{MeV}$, where the ${ }^{52} \mathrm{Cr}(\mathrm{n}, \mathrm{p})$ cross section is rapidly rising. However, no data existed in this region which could have given us an estimate of the Giant Resonance effect, if any.

For ${ }^{52} \mathrm{Cr}$, experimental data exist for the $(n, 2 n),(n, p)$ and $(n, \alpha)$ reactions for $E_{n}>14 \mathrm{MeV}$. Detailed comparisons will be made between the calculations and each set of reaction data below. At this point, an intercomparison of the available data (see Tables 5 and 6 and Figs. 62, 64, 69) will be made and a discussion of the problems associated with fitting these data, presented. While the calculations reproduce the total inelastic and the $(n, p)$ cross sections fairly well, they overpredict the $(n, 2 n)$ and $(n, \alpha)$ cross sections. An attempt to fit the $(n, 2 n)$ and $(n, \alpha)$ data resulted in over prediction of the $(n, p)$ and total inelastic. If the experimental data for the 
$(n, p),(n, 2 n),(n, \alpha)$, and total inelastic were appropriately summed, it will be found that the total nonelastic cross section thus calculated is substantially less than the measured value (see Fig. 13). This would indicate that one or more of the data sets are in error. Since the $(n, 2 n)$ and $(n, \alpha)$ data in this region were each based on one measurement, Ref. 46 and Ref. 66, respectively, the evaluators placed less weight on these data.

\section{a. Comparison of Calculations with Experimental Data}

i. $n, 2 n$ Cross Sections. As pointed out at the Lowell Conference 43 and Ref. 1 at the time of the ENDF/B-IV evaluation, no data existed for the $n, 2 n$ reaction in natural chromium, thus the results were highly dependent on model code interpretation. The calculations were carried out for each of the four isotopes and combined with the experimental data of Refs. 44 to 51 .

Figure 61 comparies the results for ${ }^{50} \mathrm{Cr}(n, 2 n)$. As can be seen the agreement with experimental data is rather poor. However, it should be noted that the Bormann data at the higher energies does not portray the shape one would expect for this threshold reaction. It has been pointed out that many experimenters using neutron generators quote a neutron energy which is 200 to $300 \mathrm{keV}$ higher than the actual energy. If this is the case here, then such a shift would slightly improve the fit.

Similarly in Fig. 62, the comparison for ${ }^{52} \mathrm{Cr}(n, 2 n)$, while fitting the data very well for $E<16 \mathrm{MeV}$, shows a deviation beyond this energy. A possible cause for the variance could be the contamination of the neutron spectra above $17 \mathrm{MeV}$ by neutrons from the $D(d, n)$ reaction due to buildup of deuterium on the source target.

Unfortunately, the Bormann data 46 is the only experiment in this range for the ${ }^{50} \mathrm{Cr}$ and ${ }^{52} \mathrm{Cr}$ isotopes, which eliminates any possible comparison with others.

Despite this lack of agreement between the calculations and data for the aforementioned isotopes, the results of the model calculations on ${ }^{53} \mathrm{Cr}$ and ${ }^{54} \mathrm{Cr}$ were combined with ${ }^{50} \mathrm{Cr}$ and $52 \mathrm{Cr}$ to yield the $\mathrm{n}, 2 \mathrm{n}$ reaction for natural $\mathrm{Cr}$. When these results were compared (see Fig. 63), with the recent data of Frehaut and Mosinski ${ }^{52}$ (which we obtained after the evaluation), the agreement was very good. In fact, except for a minor difference near threshold, the ENDF/B-IV data also is in rather goo agreement with the Frehaut data.

One cannot rule out the fact that this harmony between the calculations and experiment might well be fortuitous in that the ${ }^{53} \mathrm{Cr}$ and ${ }^{54} \mathrm{Cr}$ calculations could be causing cancellation effects (e.g., overpredicting and underpredicting), thus leading to such a concurrence.

ii. $n, p$ Cross sections. With the exception of ${ }^{52} \mathrm{Cr}$, only a very sma1l number of experiments exist for the $n, p$ reaction in the $\mathrm{Cr}$ isotopes and most of them are clustered about $14.0 \mathrm{MeV}$ point. The $(n, p)$ data are based on Refs. 51 and 53 to 64 .

Figure 64 shows the calculated values compared to the experimental data for ${ }^{52} \mathrm{Cr}(\mathrm{n}, \mathrm{p})$. Since the relatively large amount at "14 MeV" cannot be clearly seen in Fig. 64, the "14 MeV" results are summarized in Table 6 . The agreement is fair between 14 to $17 \mathrm{MeV}$; however, it is rather high in the 12 to $14 \mathrm{MeV}$ region. Changing the model paramcters to fit the $(n, p)$ data in this region would manifest itself in an increased $n, 2 n$ reaction over the entire range; and an underprediction of the $n, p$ reaction above $14 \mathrm{MeV}$. As seen in 
Figs. 61 and 62 , the $n, 2 n$ cross section is already on the high side.

A recent communication from D.L. Smith and J.W. Meadows ${ }^{65}$ indicates the possibility that the present evaluation may be overestimating the ${ }^{52} \operatorname{Cr}(n, p)$ cross section in the 6- to 9-MeV region. A possible explanation of this discrepancy would be the effect of the Giant Resonance. As noted above, the Uhl code does not take this effect into account and at the time of the evaluation we had no experimental data in this energy region.

Fig. 65 shows the difference between ENDF/B-IV and $-V$ for the $(n, p)$ cross section of natural $\mathrm{Cr}$. The large difference is caused by the difference in the evaluation of the ${ }^{52} \operatorname{Cr}(n, p)$. For $E N D F / B-I V$, the shape of the ${ }^{52} \operatorname{Cr}(n, p)$ was calculated using the evaporation model code THRESH and normalized to the "best value" cited by Kenna and Harrison ${ }^{44}$. As has been noted above, the present evaluation, ENDF/B-V, is heavily based on an early version of the statisical model code of $\mathrm{Uh}^{27(a)}$. While the parameters were adjusted in an attempt to fit all experimental data, the final results for the ( $n$, particle) cross sections were not renormalized. There is the possibility that the ${ }^{52} \mathrm{Cr}(n, p)$ cross section is overestimated due to the relatively heavy weight placed on the data of Kern et al.; ${ }^{4}$ however, as we noted in the introduction to this section, any reduction in the ${ }^{52} \mathrm{Cr}(\mathrm{n}, \mathrm{p})$ cross section would result in an overestimation of the total inelastic, $n, 2 n$, and $n, \alpha$ cross sections of ${ }^{52} \mathrm{Cr}$.

iii. ( $\left.n,{ }^{4} \mathrm{He}\right)$ Cross Section. Up until recently only one measurement existed for this reaction and this was for ${ }^{54} \mathrm{Cr} .66$

Dolya et al. ${ }^{67}$ at the $1973 \mathrm{Kiev}$ Conference reported on their direct measurement at $14.7 \mathrm{MeV}$ of the $(n, \alpha)$ cross section for all four chromium isotopes. These were angular distribution experiments ranging from 0 to 150 degrees, whose integrated cross sections produced the following:

$$
\begin{aligned}
& { }^{50} \mathrm{Cr}\left(\sigma_{\mathrm{na}}=121.0 \pm 8.5 \mathrm{mb}\right) \\
& { }^{52} \mathrm{Cr}\left(\sigma_{\mathrm{na}}=40.2 \pm 3.6 \mathrm{mb}\right) \\
& { }^{53} \mathrm{Cr}\left(\sigma_{\mathrm{na}}=45.1 \pm 3.7 \mathrm{mb}\right) \\
& { }^{54} \mathrm{Cr}\left(\sigma_{\mathrm{na}}=37.2 \pm 3.0 \mathrm{mb}\right)
\end{aligned}
$$

These data were used to normalize the model calculations in ENDF/B-IV. In the present evaluation, ENDF/B-V, these data were included in the data set that we attempted to fit by adjusting the model code parameters. However, since it is not clear whether these measurements are of the $n, \alpha$ cross sections or of the total $\alpha$-production cross sections, some care must be used in considering these values. In Tables 4, 5, 7, and 8 and in Figs. 68 to 72 , it is assumed that these measurements are for the total $\alpha$-production.

The resulting calculations for the $(n, \alpha)$ cross sections and ${ }^{4} \mathrm{He}$ production cross sections for each isotope were weighted by abundance and summed to provide the cross sections for natural chromium (Fig. 72).

iv. Other n-Particle Reactions. The amount of experimental data on reactions such as $(n, t),(n, d),(n, n p)$, etc. is very very meager and the evaluation is highly model dependent. However, due to the high threshold for these reactions (see Table 3), they are expected to be of the order of a few millibarns even at $20.0 \mathrm{MeV}$.

Figures 66 and 67 present the evaluated reaction cross sections for the $(n, t)$ and $\left(n,{ }^{3} \mathrm{He}\right)$ reactions which are the same as those given in ENDF/B-IV. 
Table 4

Selected ${ }^{50} \mathrm{Cr}$ Cross Sections

\begin{tabular}{|c|c|c|c|c|c|}
\hline & \multirow{2}{*}{$\mathrm{E}_{\mathrm{n}}(\mathrm{MeV})$} & \multirow{2}{*}{$\begin{array}{l}\text { Calculated } \\
\sigma(\mathrm{mb})\end{array}$} & \multicolumn{2}{|c|}{ Experimental $\sigma(\mathrm{mb})$} & \multirow[b]{2}{*}{ Ref. } \\
\hline & & & Original. & Renormalized $^{\mathrm{a}}$ & \\
\hline${ }^{50} \mathrm{Cr}(\mathrm{n}, \mathrm{p})$ & 14.0 & 351 & $277 \pm 21$ & $256+19$ & 1 \\
\hline${ }^{50} \mathrm{Cr}(\mathrm{n}, \mathrm{np})$ & 14.0 & 406 & $153+21$ & $141+19$ & 1 \\
\hline $\begin{array}{l}{ }^{50} \mathrm{Cr} \mathrm{p}- \\
\text { production }\end{array}$ & 15.0 & 811 & $830+100$ & & 3 \\
\hline $\begin{array}{l}{ }^{50} \mathrm{Cr} \mathrm{d}- \\
\text { production }\end{array}$ & 15.0 & 4.6 & $12 \pm 4$ & & 3 \\
\hline $\begin{array}{l}{ }^{50} \mathrm{Cr} \alpha- \\
\text { production }\end{array}$ & $\begin{array}{l}14.7 \\
15.0\end{array}$ & $\begin{array}{l}102 \\
105\end{array}$ & $\begin{array}{l}121 \pm 8 \\
94 \pm 15\end{array}$ & & $\begin{array}{l}2 \\
3\end{array}$ \\
\hline
\end{tabular}

$a_{\text {Renormalized to }}{ }^{54} \mathrm{Fe}(\mathrm{n}, \mathrm{p})$ cross sections from ENDF/B-IV Dosimetry File edited by B. Magurno (BNL-NCS-50466, April 1975).

1. D.L. Allan, Nucl. Phys. 24, 274 (1961).

2. G.P. Dolja, YK-11, 9 (1973).

3. S.M. Grimes, R.C. Haight, K.R. Alvar, H.H. Barschall and R.R. Borchers. Reprint UCRL-81802 (1978). To be published in Rev. C. Data received after evaluation.

\begin{tabular}{|c|c|c|c|c|}
\hline & \multirow[b]{2}{*}{$E_{n}(M e V)$} & \multicolumn{2}{|c|}{$\begin{array}{c}\text { Table } 5 \\
\text { lected }{ }^{52} \mathrm{Cr} \text { Cross Sections }\end{array}$} & \multirow[b]{2}{*}{ Ref. } \\
\hline & & $\begin{array}{l}\text { Calculated } \\
\sigma(\mathrm{mb})\end{array}$ & $\begin{array}{l}\text { Experimental } \sigma(\mathrm{mb}) \\
\text { Original Renormalized }\end{array}$ & \\
\hline $\begin{array}{l}{ }^{52} \mathrm{Cr} \\
\text { inelastic }\end{array}$ & $\begin{array}{l}14.0 \\
14.4\end{array}$ & $\begin{array}{l}805 \\
710\end{array}$ & $\begin{array}{l}740 \pm 180 \\
727 \pm 100\end{array}$ & $\begin{array}{l}1 \\
2\end{array}$ \\
\hline${ }^{52} \mathrm{Cr}(\mathrm{n}, \mathrm{p})$ & & & & \\
\hline $\begin{array}{l}{ }^{52} \mathrm{Cr} \mathrm{p}- \\
\text { production }\end{array}$ & 15.0 & 165 & $180 \pm 25$ & 4 \\
\hline${ }^{52} \mathrm{Cr} d-$ & 15.0 & 0 & $8 \pm 3$ & 4 \\
\hline $\begin{array}{l}{ }^{52} \mathrm{Cr} \alpha- \\
\text { production }\end{array}$ & $\begin{array}{l}14.7 \\
15.0\end{array}$ & $\begin{array}{l}69 \\
85\end{array}$ & $\begin{array}{l}40 \pm 4 \\
36 \pm 6\end{array}$ & $\begin{array}{l}3 \\
4\end{array}$ \\
\hline
\end{tabular}

1. S. Tagesen, Acta Phys. Austriaca 23, 31 (1966).

2. S. Breunlich and G. Stengel, Zeit. Natur. A26, 451 (1971).

3. G.P. Do1ja, YK-11, 9 (1973).

4. S.M. Grimes, R.C. Haight, K.R. Alvar, H.H. Barschall, and R.R. Borchers. Preprint UCRL-81802 (1978). To be published in Phys. Rev. C. Data received after evaluation. 


\begin{tabular}{|c|c|c|c|c|}
\hline & Com & $\begin{array}{r}\text { Table } 6 \\
\text { parison of "14-Me } \\
\text { Cross Sectic }\end{array}$ & ${ }^{52} \operatorname{Cr}(n, p)$ & \\
\hline $\operatorname{En}(\mathrm{MeV})$ & $\begin{array}{c}\text { Calculated } \\
\sigma(\mathrm{mb}) \\
\end{array}$ & $\begin{array}{c}\text { Experimenta } 1^{a} \\
\sigma(\mathrm{mb})\end{array}$ & Renormalized * & Reference \\
\hline 14.1 & 136 & $130 \pm 30^{b}$ & & 1 \\
\hline 14.1 & 136 & $67 \pm 1 u^{c}$ & & 2 \\
\hline 14.8 & 124 & $82.7 \pm 9$ & & 3 \\
\hline 14.4 & 131 & $115 \pm 25$ & & 4 \\
\hline 14.6 & 128 & $96.1 \pm 3$ & $95.2 \pm 3.0$ & 5 \\
\hline $14.7 \pm 0.3$ & 126 & $94 \pm 10$ & $105 \pm 11$ & 6 \\
\hline $14.8 \pm 0.2$ & 124 & $115 \pm 15$ & $118 \pm 15$ & 7 \\
\hline 14.01 & 137 & $133.3 \pm 15$ & & \\
\hline 14.28 & 133 & $109.3 \pm 12$ & & 8 \\
\hline 14.52 & 128 & $100 \pm 12^{d}$ & & \\
\hline 14.99 & 121 & $107 \pm 12^{e}$ & & \\
\hline 14.8 & 124 & $118 \pm 16$ & $116 \pm 16$ & 9 \\
\hline $14.8 \pm 0.1$ & 124 & $82.8 \pm 5.8$ & $86 \pm 6$ & 10 \\
\hline 14.8 & 124 & $105 \pm 10$ & $104 \pm 10$ & 11 \\
\hline 14.5 & 128 & $78 \pm 10$ & & 12 \\
\hline $14.8 \pm 0.5$ & 124 & $73 \pm 5$ & $56 \pm 4$ & 13 \\
\hline $14.7 \pm 0.3$ & 126 & $80 \pm 6$ & $76 \pm 6$ & 14 \\
\hline 14.7 & 126 & $\stackrel{82}{\text { Reduced }} \chi^{2}=26.5$ & $\begin{array}{l}78.5 \\
62.5\end{array}$ & 15 \\
\hline
\end{tabular}

${ }^{a}$ All measurements were activation measurements except as noted.

${ }^{b}$ CounterTelescope

$c_{\text {Emulsion }}$

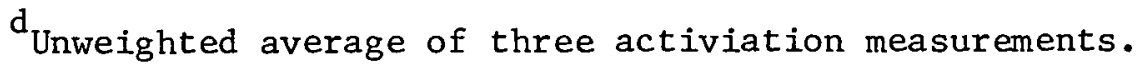

*Where author has given sufficient information on the activation standard, the data have been renormalized to standard values obtained from the ENDF/IV dosimetry file.

1. D.V. Aleksandrov, L.I. Klochkova, and B.S. Kourigin. At. Energia 39, (2), 137 (1975).

2. D.L. Allan, Nuc1. Phys. 24, 274 (1961).

3. D.M. Chittenden and D.G. Gardner. Arkansas Report (1961). 
4. I.G. Clator. Diss. Abst. 30, 2850 (1969). Priv. Comm. from T. Clator (1969).

5. J. Dressler, J. Araminowicz, and U. Garuski. INR-1464, 12 (1973).

6. P. Holmberg, R. Rieppo, J.K. Keinaenen, and M. Valkonen. J. Inorg. Nucl. Chem. 36, 715 (1974).

7. L. Husain and P.K. Kuroda. J. Inorg. Nucl. Chem. 29, 2665 (1967).

8. B.D. Kern and W.E. Ferguson. Nucl. Phys 10, 226 (1959).

9. C.S. Khurana and I.M. Govil. Nucl. Phys 69,153 (1965).

10. B. Mitra and A.M. Ghose. Nuc1. Phys $83, \overline{157}$ (1966).

11. S.K. Mukherjee, A.K. Ganguly, and N.K. Majumder. Proc. Phys. Soc. (London) 77, 508 (1961).

12. E.B. Paul and R.L. Clarke. Can. J. Phys. 31,267 (1953).

13. R. Prasad and D.C. Sarkar. Nuoud Cimento $\overline{\mathrm{A} 3}(3), 467$ (1971).

14. S.M. Qaim and N.I. Molla. Ninth Symposium on Fusion Technology (Garmish, 1976), p. 589.

15. J.F. S.train and W.J. Ross, ORNL-3672 (1965). 


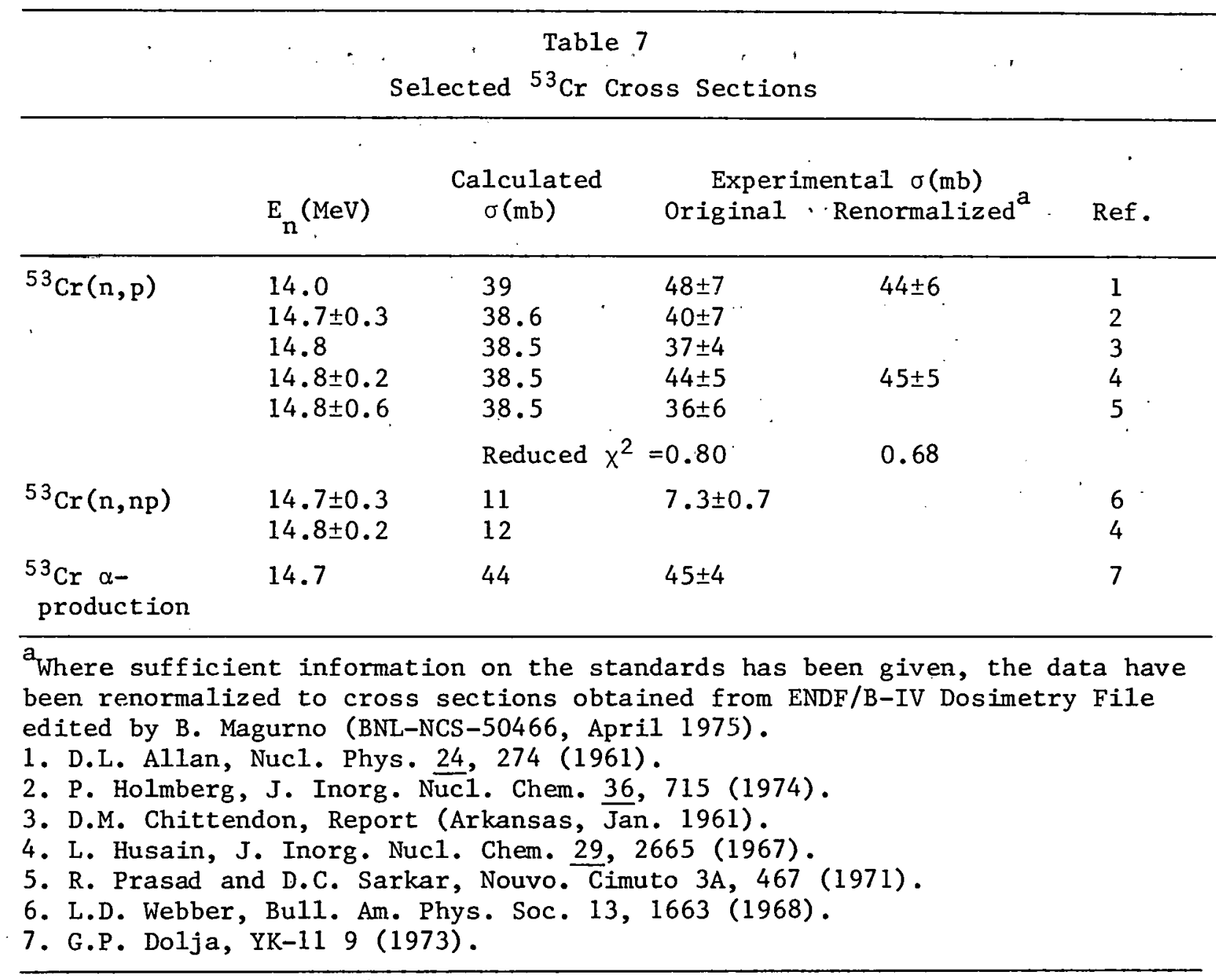

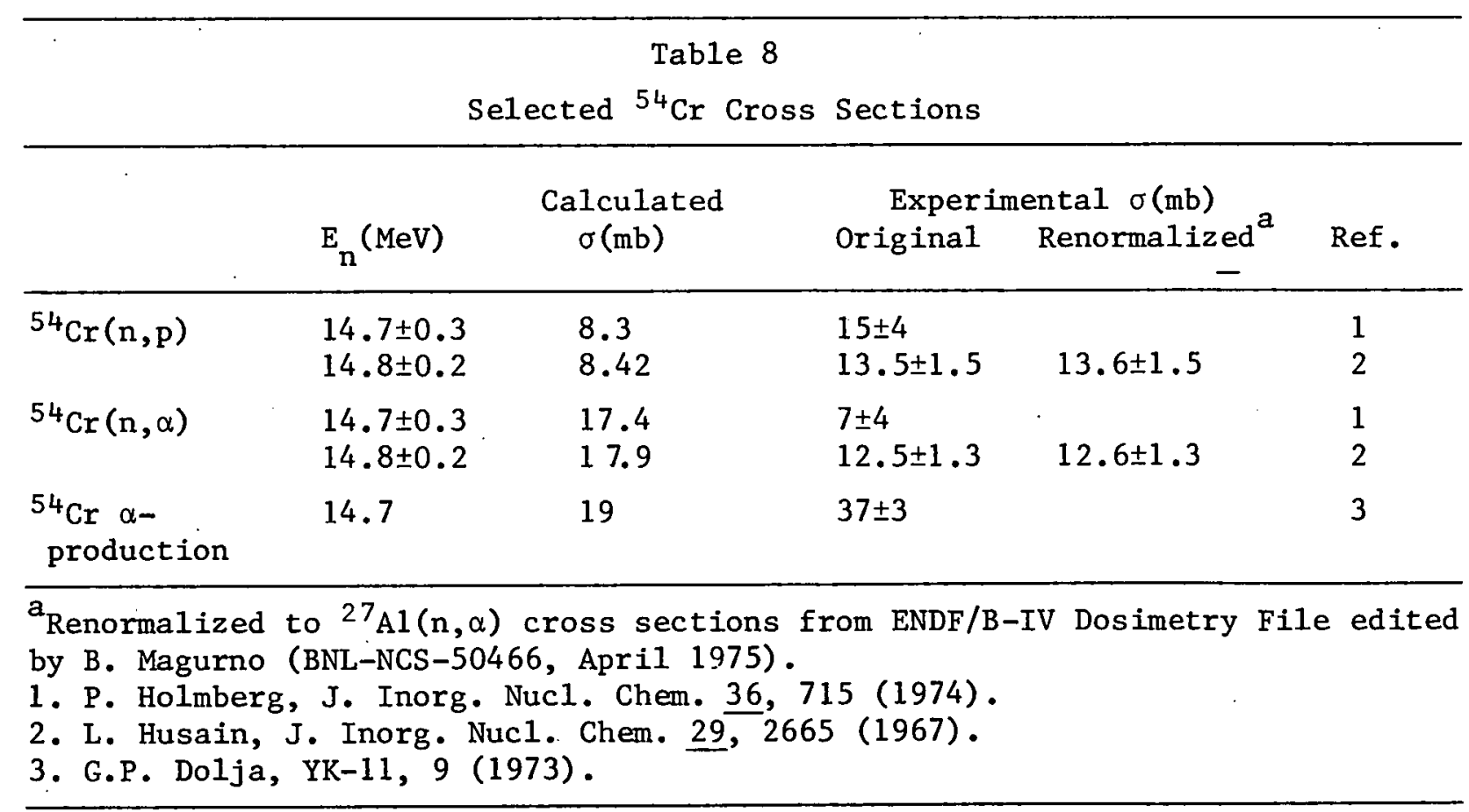


As mentioned earlier in the $\left(n, n^{\prime} \alpha\right)$ and $\left(n, \alpha n^{\prime}\right)$ reactions are probability hidden in the $(n, \alpha)$ data of Dolya.67

Figures 68 through 71 show the hydrogen, deuterium and helium gas production for the four stable isotopes of chromium and elemental chromium. Also shown in these figures are the available experimental data. Figure 72 also compares gas production cross sections derived from ENDF/B-IV to present calculations. The present data are marked in File 3 at $M T=203$ to 207 .

Although there are few fission spectrum average data available, a comparison of the present work and the available experimental data related to gas production in the $\mathrm{Cr}$ isotopes was made. The results are shown in Table 9. The three spectral distributions were obtained from Ref. 68.

Table 9

Comparison of Calculated Fission Spectrum Average Cross Sections to Experimental Values*

\begin{tabular}{clllcc}
\hline \multicolumn{1}{c}{ Type } & Watt & $\begin{array}{c}\text { Calculated } \\
\text { Maxwe11 }\end{array}$ & Cranberg & Experimental & Ref. \\
\hline a-prod. $\operatorname{Cr}(\mathrm{Nat})$ & 0.17 & 0.18 & 0.16 & 0.14 & 1 \\
& & & & $0.19^{\mathrm{a}}$ & 2 \\
${ }^{52} \operatorname{Cr}(\mathrm{n}, \mathrm{p}){ }^{\mathrm{b}, \mathrm{c}}$ & 1.69 & 1.69 & 1.57 & $1.31 \pm 0.05$ & 4 \\
${ }^{53} \operatorname{Cr}(\mathrm{n}, \mathrm{p})^{c}$ & 0.41 & 0.40 & 0.38 & $0.44 \pm 0.030$ & 4 \\
${ }^{54} \operatorname{Cr}(\mathrm{n}, \mathrm{p})^{c}$ & $6.0 \times 10^{-3}$ & $6.0 \times 10^{-3}$ & $5.2 \times 10^{-3}$ & $(5.8 \pm 1.0) \times 10^{-3}$ & 4 \\
\hline
\end{tabular}

*

These data were not used to renormalize the differential calculations in File 3 .

${ }^{a}$ Mean value of results obtained by using ${ }^{58} \mathrm{Ni}(\mathrm{n}, \mathrm{p}),{ }^{46} \mathrm{Ti}(\mathrm{n}, \mathrm{p})$, and ${ }^{63} \mathrm{Cu}(\mathrm{n}, \alpha)$ as monitors.

${ }^{b}$ Rau used activation techniques to measure ${ }^{52} \operatorname{Cr}(n, p)$. For a target he employed natural $\mathrm{Cr}_{2} \mathrm{O}_{3}$. Therefore, he has really observed ${ }^{52} \operatorname{Cr}(n, p)+{ }^{53} \operatorname{Cr}(n, n p)$ $+{ }^{53} \mathrm{Cr}(\mathrm{n}, \mathrm{pn})+{ }^{53} \mathrm{Cr}(\mathrm{n}, \mathrm{d})$. The calculated values have been corrected for the ${ }^{5} \mathrm{Cr}$ reactions. Also, it appears that he did not correct for the natural abundance of ${ }^{52} \mathrm{Cr}$, therefore this correction has been applied.

$c_{\text {Rau used the }}{ }^{58} \mathrm{Ni}(\mathrm{n}, \mathrm{p})$, reaction as a standard citing a vajue of $95 \mathrm{mb} .5$ Three recent evaluations give values of $101.5 \mathrm{mb}, 6104 \mathrm{mb}, 7$ and $113+3 \mathrm{mb}^{8}$ for the ${ }^{58} \mathrm{Ni}(\mathrm{n}, \mathrm{p})$ fission spectrum average cross section. We have corrected Rau's results using the evaluation of Fabry. 8

1. E.P. Lippencott, W.N. McElrow, and H. Farrar IV, 4th Conf. Nuclear Cross Sections and Technology, Washington, D.C., 3-7 March 1975, P. 375.

2. J. Weitmann, N. Davenhog, and S. Farvolden, ANS 13, 558 (1970).

3. N.J. Freeman, J.F. Barry, and N.L. Campbe11, JNE 23, 713 (1969).

4. C. Rau, Nuk $\underline{9}, 228$ (1967).

5. F. Hertlein, Ann. Physik 7, 308 (1961).

6. B.A. Magurno (editor), BNL-NCS-50446, 285 (1975).

7. M. Divadeenam, Private Communication, February 23, 1979.

8. A. Fabry, BLG-465 (1972). 


\section{Miscellaneous Data}

a. Angular Distributions. The angular distributions of secondary neutrons were derived as follows. The elastic distribution is the same as ENDF/B-IV. The angular distributions for $(n, 2 n),(n, 3 n),(n, n \alpha),(n, n p)$ and continuum inelastic ( $M T=16,17,22$, and 91) were assumed to be isotropic. The discrete inelastic angular distributions (MT $=51$ to 90) are the results of compound-nucleus Hauser-Feshbach calculations and direct reaction calculations combined to describe angular distributions and of available experimental data.

b. Secondary Energy Distribution. The secondary energy distributions for $(n, 2 n),(n, 3 n),\left(n, n^{\prime} \alpha\right)$ and $\left(n, n^{\prime} p\right)(M T=16,1722$, and 28) are presented as nuclear temperature histograms based on the Gilbert-Cameron formalism. 69 Since the threshold for the $(n, 3 n)$ reaction is so high, it was necessary to arbitrarily renormalize the temperatures to conserve energy. The continuum inelastic secondary energy distributions are presented as histograms based on the experimental data of Salnikov et a1.28

c. Photon Production Data. In the evaluation of the photon production data, the procedures for the different energy regions ( $E_{\mathfrak{n}} \leq t$ thermal; $\mathrm{E}_{\mathrm{n}}=$ thermal-200 keV, 200-600 keV, $600 \mathrm{keV}-1 \mathrm{MeV}$, and $\mathrm{E}_{\mathrm{n}} \geq 1 \mathrm{MeV}$ ) were different. This approach was necessary since the types of data available for these energy regions differed as did the complexity of the data in File 3. Care was taken to ensure no sharp discontinuities in the total photon production cross section; however, there are probably slight discontinuities in the photon spectra between energy regions caused by the assumptions made.

Three sets of data70-72 were combined in a consistent manner to obtain the thermal capture- $\gamma$ spectrum ( $M F=15$, $M T=102$ ) with the final total multiplicity adjusted to conserve energy. The capture- $\gamma$ spectrum at $10^{-5} \mathrm{eV}$ was assumed to be the same at thermal and the total multiplicity adjusted to conserve energy.

Between thermal and $200 \mathrm{keV}$, the spectrum-average capture- $\gamma$ data of Allen et al. 73 were employed with the assumption that the distribution did not vary with neutron energy and the final total multiplicity adjusted to conserve energy.

In the 200 to $600-\mathrm{keV}$ range the data of Morgan and Newman ${ }^{74}$ were assumed to be pure capture. These data were integrated over the photon-energy range and the capture cross section from this evaluation was used to calculate the total multiplicity. The resulting multiplicities and photo-energy spectra were entered in $\mathrm{MF}=12, \mathrm{MT}=15, \mathrm{MT}=102$.

In the $600-\mathrm{keV}$ to $1-\mathrm{MeV}$ region, the data of Morgan and Newman ${ }^{74} \mathrm{did}$ not have detail corresponding to the capture cross section. It was necessary, therefore, to convert their photon production cross sections to capture- $\gamma$ multiplicitities. Since inelastic processes begin to enter in this region, the data had to be adjusted for the inelastic contribution prior to conversion to capture- $\gamma$ multiplicities. The discrete photon production $(M F=12, M t=4)$ was obtained from the total inelastic and inelastic scattering from the firstexcited states of $50,53,54 \mathrm{Cr}(\mathrm{MF}=3, \mathrm{MT}=4,51,52,53)$. These discrete data were subtracted from the $E_{n}=600$ to $1000 \mathrm{keV}$ photon distributions of Morgan and Newman in an energy-conserving manner. The resulted spectra were assumed to result from capture and the total multiplicities adjusted to conserve energy. Above $1 \mathrm{MeV}$, the photon production cross sections ( $M F=13, M T=3$ ) and energy distributions $(M F=15, M T=3)$ were obtained from the data of 
Morgan and Newman. 74

Electron production was assumed to be negligible. The photon proluction angular distributions were assumed to be isotropic.

C. Covariance Files

1. Resonance Parameters ( $M F=32)$. Since the resonance parameters and background used in determining the total, elastic, and capture cross sections up to $642.85 \mathrm{keV}$ are the same as ENDF/B-IV and no uncertainties were assigned, 1 there is no covariance file for the resonance parameters.

2. Cross Sections (MF $=33)$. Since there were, in general, many channels open and the statistical model code of $\mathrm{Uhl}^{27}$ (a) does not give the covariance between channels, no attempt was made to estimate the off-diagonal covariance between competing reactions.

The evaluation of chromium was independent of other ENDF/B-V evaluations. Therefore, there are no covariance matrices relating this material to other ENDF materials.

Model code uncertainties were estimated by varying the input parameters. The estimated uncertainties are summerized in the Appendix.

\section{a. Total, Elastic, Non-elastic, and Capture (MT $=1,2,3,102)$.}

These sections being unchanged from ENDF/V-IV, the uncertainties were taken from Table 12 of Reference 1 . In the resonance region, the total cross section was derived as the sum of the elastic and capture cross sections and the nonelastic was assumed to be equal to the capture. Above the resonance region, the elastic cross section was obtained by subtracting the nonelastic from the total.

b. Total Inelastic $(M T=4)$. The total inelastic cross section was completely derived. Between threshold and $3.97 \mathrm{MeV}$, the total inelastic cross section was derived from the sum of the first 31 discrete levels. Above $3.97 \mathrm{MeV}$, the total inelastic was assumed to be the difference between the nonelastic and the sum of the reaction channels.

c. $(n, 2 n)$ Cross Section $(M T=16)$. Below $15 \mathrm{MeV}$, the covariance are based on estimates in the model code uncertainty. Above $15 \mathrm{MeV}$, the covariances were derived by comparing the calculations and experimental data, both for the natural and for the individual isotopes.

$$
\text { d. }(n, 3 n),(n, n \alpha),(n, d),(n, t) \text { Cross Sections }(M T=17,22,104,105)
$$

Since there were no experimental data for these reactions, the covariance matrices are based on the estimates of the model uncertainty.

e. $(n, \alpha)$ Cross Section $(M T=28)$. Between 13.5 and $15.0 \mathrm{MeV}$, the covariance matrix represents a comparison between calculations and experiment. The remainder of the matrix represents the uncertainty in the model calculations.

f. Discrete Inelastic Cross Sections (MT $=51-90)$. The covariance matrices represent a comparison between calculations and available experimental data. Where no experimental data were available, the representation is a estimate of the model code uncertainties:

g. Continuum Inelastic (MT =91). Although the continuum was derived from the difference between the total and discrete inelastic, we have elected to represent the matrix an "evaluated." We chose this representation because 
the correlations between the discrete inelastic cross sections have not been included. Without these correlations the continuum inelastic matrix would be distorted if represented as "derived."

h. $(n, p)$ Cross Section (MT = 103). The covariance between 12 and $17 \mathrm{MeV}$ results from a comparison of calculations and experiment. The remainder is a representation of the model uncertainties.

i. $(\mathrm{n}, \alpha)$ Cross Section (MT =107). The 14 - to $15-\mathrm{MeV}$ region represents a comparison between experiment and calculation; the remainder, model uncertainties.

j. Gas Production Cross Sections (MT $=203-207)$. Covariance matrices have not been included for gas production. The gas production cross sections were derived from the appropriate ( $n$,particle) cross sections (MT = 103-107) except near $20 \mathrm{MeV}$ where there was a small contribution from more esoteric reactions. The following relationships hold for the gas production uncertainties.

$$
\begin{aligned}
& (\Delta \sigma)^{2} \text { Hydrogen }=(\Delta \sigma)^{2} n, n p+(\Delta \sigma)^{2} n, p \\
& \text { production } \\
& \Delta \sigma_{\text {Deuteron }} \\
& \text { production }=\Delta \sigma_{\mathrm{n}, \mathrm{d}} \\
& \Delta \sigma_{\text {Tritium }} \\
& \text { production } \quad=\Delta \sigma_{\mathrm{n}, \mathrm{t}} \\
& (\Delta \sigma)^{2} \text { Helium }=(\Delta \sigma)^{2} n, n \alpha+(\Delta \sigma)^{2} n, \alpha \\
& \text { production }
\end{aligned}
$$

\section{REFERENCES}

1. A. Prince, BNL-NCS-50593 (ENDF-246) (1976).

2. F.G. Perey \& W.E. Kinney (Priv. Comm.) CSISRS (1973).

3. A. Prince, Proc. Int'1 Conf. on the Interactions of Neutrons with Nuclei, Lowell Mass., July 1976 (Vol. 1).

4. H.L. Taylor, et al., Phys. Rev. 100, 174 (1955).

5. V.I. Strizhak; JETP 4, 769 (1957) Eng. 'I'rans.

6. W.E. Kinney \& F.G. Perey, ORNL-4806 (1974).

7. A.B. Smith (unpublished) See BNL-400, 3rd Ed., 1970.

8. A.J. Elwyn, et a1., Bu11. Am. Phys. Soc. 12, 473 (1967).

9. S.A. Cox, Bull. Am. Phys. Soc. 10, 576 (1965).

10. B. Holmqvist, Ark. Fys. 38, 403 (1968).

11. B. Holmqvist \& T. Wied1ing, AE, 366 (1969).

12. B. Holmqvist \& T. Wiedling, AE 430 (1971).

13. COMNUC., C. Dunford, AI-AEC 12931 (1970).

14. TISPRO., V. Benzi, et a1., $\operatorname{CEC}(69) 24$.

15. F. Cvelbar, et a1., Nuc1. Phys. A130, 401 (1969).

16. K. Nishamura, et al., Helsinki Conf. 1970, IAEA-CN-26/28.

17. D.M. Van Patter, et a1., Phys. Rev. 128, 1246 (1962).

18. D.L. Broder, et al., Sov. J. At. En. 16, 113 (1965).

19. Yu, G. Degtyarev \& V.N. Protopopov, J. At. En. 23, 1350 (1967).

20. Yu. G. Degtyarev \& V.N. Protopopov, Bu11. Acad. Sai, USSR, Phys., Series 35 (11) 2123 (1971). 
21. A.I. Abramov, Sov. J. At. En. 12, 65 (1962).

22. N.P. Glazkov, Sov. J. At. En. $\overline{15}, 416$ (1963).

23. G.P. Couchel1, (Priv. Comm.) 1 $\overline{978}$, Lowell Tech. Mass.

24. P.T. Karatzes, et a1., NSE 67, 34 (1978).

25. F. Voss, et a1., Proc. Conf. on Nuclear Cross Sections \& Technology, NBS 425, 916 (1975).

26. G. Tessler \& S.S. Glickstein, ibid (p. 934).

27. (a) M. Uh1, Acta Phys. Austria 31, 245 (1970).

27. (b) M. Uh1 \& B. Strohmaier, $\operatorname{IRK} 76 / 01$, Inst. fur Radiumforschung and Kernphysik der Osterreichischen; Vienna, 1976.

28. D.A. Salnikov \& G.N. Lovchikova, Helsinki Conf. (1970), IAEA-CN26/79 (Also see BNL TR-545, 1970).

29. I. Fujita, et al., J. Nucl. Sci. \& Tech. 9. (5), 301, (197.2).

30. S. Tagesen \& P. Hille, Acta Phys. Austria 23, 31 (1966).

31. W. Breunlich \& G. Stengel, A. Naturforsch $\underline{26}$ A, 451 (1971).

32. I.L. Morgan, et al., TID 20658 (unpublished).

33. M. Uhl, Nuc. 1. Phys. A184, 253 (1972).

34. L.M. Colli \& G.M. Marcazzan, Riv. d. Nouvo Cim. 3 (4) 535, 1973.

35. JUPITOR I, T. Tamura, ORNL-4152 (1967).

36. P.H. Stelsen, et a1., Nucl. Phys. 68, 97 (1965).

37. THRESH, S. Pearlstein, J. Nucl. En. 27, 81 (1973).

38. ABACUS 2, E.H. Auerbach, BNL-6562 (1 $\overline{96} 2$ ) unpublished.

39. W. Dilg, et a1., Nucl. Phys. A217, 269 (1973).

40. Nuclear Level Schemes, $A=45$ through

41. Nuclear Data A3, 367 (1967).

42. Nuclear Data Tables A. Vol. $11(2,3)$ 1972), N.B. Gove \& A.W. Wapstra, Academic Press, N.Y., 1972.

43. T.W. Burrows \& A. Prince, Proc. Int'I Conf. on the Interactions of Neutrons with Nuclei, Lowe11, Mass., 1976.

44. B.T. Kenna \& P.E. Harrison, SLA-73-0637 (1973).

45. M. Bormann, et a1., Nuc1. Phys. Al15, 309 (1968).

46. M. Bormann, CSISR (unpublished) 1965 .

47. S.M. Qaim, et al., Proc. Int'l Conf. Canterbury (1971).

48. Z.T. Boedy, INDC (HUN) -10, Jan. 1973.

49. L.A. Rayburn, Phys. Rev. 122, 168 (1961).

50. G.N. Maslov, et al., Jadernye Konstanty 9 , 50 (1972).

51. P. Holmberg, et a1., J. Inorg. Nucl. Chem 36 (4) 715, 1974.

52. J. Frehaut \& G. Mosinski, 5th Int'l Symposium on the Interaction of Fast Neutrons with Nuclei, Gaussis, DDR 1975.

53. L. Husain \& P.K. Kuroda, J. Inorg. Nuc1. Chem 29, 2665 (1967).

54. B.D. Kern, et al., Nuc1. Phys. 10, 226 (1959).

55. I.G. Clator, Priv. Comm. (1969).

56. E.B. Paul and R.L. Clark, Can. J. Phys. 31, 267 (1953).

57. D.L. Allan, Nuc. 1 Phys. 24, 274 (1961).

58. B. Mitra and A.M. Ghose, Nuc1. Phys. 83,157 (1966).

59. J.K. Mukherjee, Proc. Phys. Soc. (London) 77, 508 (1961).

60. J. Dressler, et al., INR-1464, 12 (1973).

61. C.J. Khurana \& I.M. Gavil, Nucl. Phys. 69, 153 (1965).

62. D.V. Aleksandrov, et al., Sov. J. At. En. 39, 736 (1976).

63. R. Prasad \& D.C. Sarker, Nuovo, Cimento 3H, 467 (1971). 
64. W.N. Levkovskii, Sov. J. Nucl. Phys. 18 (4), 361 (1974).

65. D.L. Smith and J.W. Meadows, ANL (Friv. Comm. 1979).

66. L. Husain, J. Inorg. \& Nuc1. Chem 29, 2665 (1967).

67. G.P. Dolya, et al., Kiev. Conf. (USSR) YK-11, 9 (1973).

68. J.A. Grundl, "Fission Neutron Spectra; Macroscopic and Ingegral. Results," Neutron Standards \& Flux Normalization, edited by A.B. Smith, p. 417 (Conf.-701002, 1970).

69. A. Gilbert \& A.G.W. Cameron, Can. J. of Phys. 43, 1446 (1965).

70. D.L. Broder, et al., Sov. J. Nucl. Phys. 13, 129 (1971).

71. V.J. Orphan, et al., GA-10248 (1970).

72. D.C. Kocher, Nuc1. Data Sheets 18,463 (1976).

73. B.J. Allen, et al., AAEC/E-200 (1969).

74. G.L. Morgan \& E. Newman, ORNL-TM-5098 (1976). 
APPENDIX

Estimated Uncertainties in the Evaluated

Cross Sections for Natural Chromium

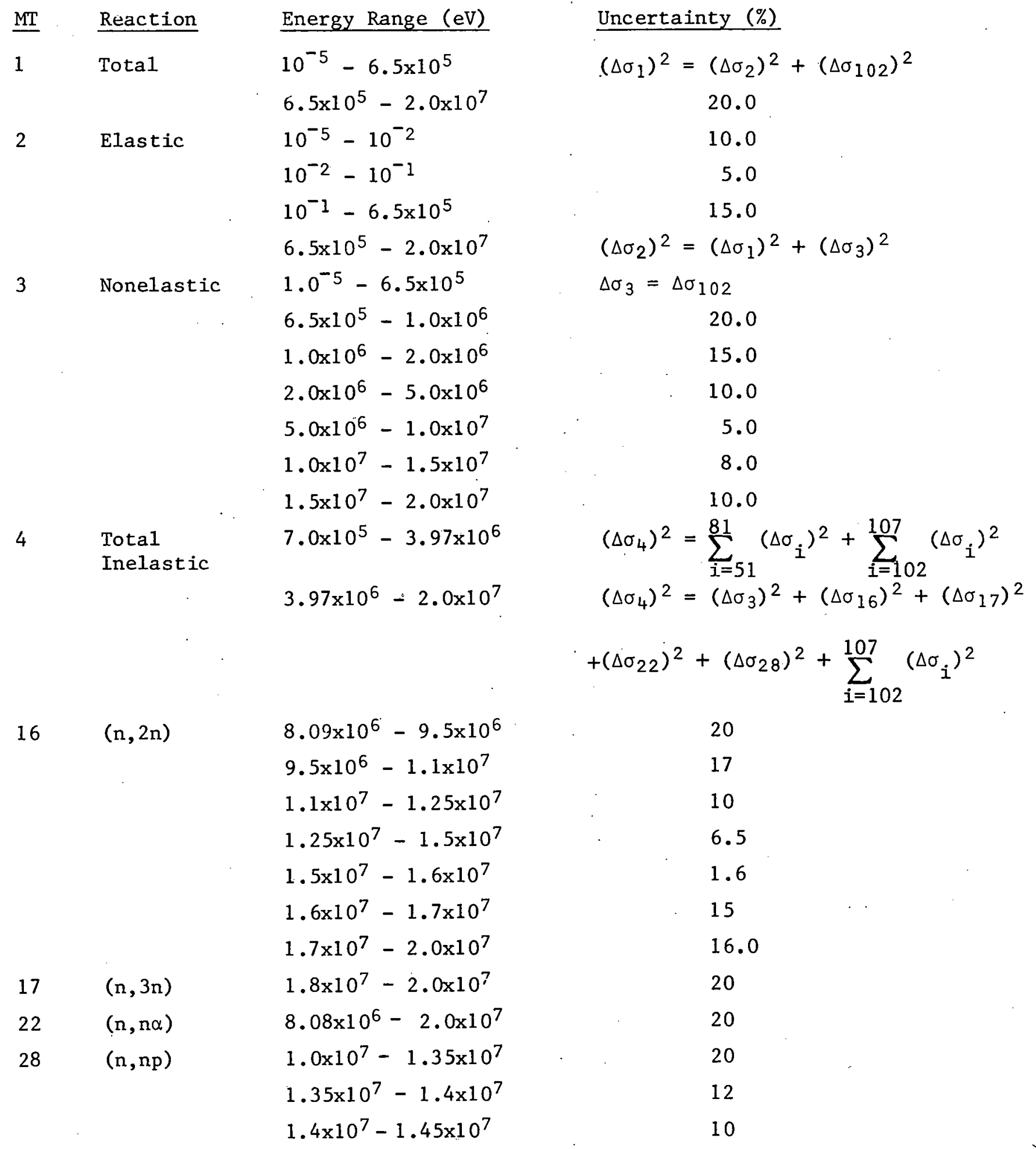


Estimated Uncertainties in the Evaluated Cross Sections for Natural Chromium (cont.)

MT Reaction

Energy Range (eV)

28

$1.45 \times 10^{7}-1.5 \times 10^{7}$

Uncertainty (\%)

$1.5 \times 10^{7}-1.8 \times 10^{7}$

9.4

$1.8 \times 10^{7}-2.0 \times 10^{7}$

12

20

Direct Inelastic

51

$5.75 \times 10^{5}-8.8 \times 10^{5} \quad 20$

$8.8 \times 10^{5}-1.13 \times 10^{6} \quad 10$

$1.13 \times 10^{6}-1.24 \times 10^{6} \quad 16$.

$1.24 \times 10^{6}-1.65 \times 10^{6} \quad 10$.

$1.65 \times 10^{6}-1.75 \times 10^{6} \quad 14$.

$1.75 \times 10^{6}-1.95 \times 10^{6} \quad 10$

$1.95 \times 10^{6}-2.16 \times 10^{6} \quad 13.0$

$2.16 \times 10^{6}-2.21 \times 10^{6} \quad 11$.

$2.21 \times 10^{6}-3.57 \times 10^{6} \quad 13$

$3.57 \times 10^{6}-3.77 \times 10^{6} \quad 14$.

$3.77 \times 10^{6}-3.87 \times 10^{6} \quad 17$.

$3.87 \times 10^{6}-3.97 \times 10^{6} \quad 21$

$3.97 \times 10^{6}-5.0 \times 10^{6} \quad 15$.

$5.0 \times 10^{6}-1.0 \times 10^{7} \quad 20$

52

$1.0 \times 10^{7}-2.0 \times 10^{7} \quad 30$

$7.98 \times 10^{5}-8.4 \times 10^{5} 20$.

$8.4 \times 10^{5}-1.24 \times 10^{6} \quad 14$.

$1.24 \times 10^{6}-1.65 \times 10^{6} \quad 9.3$

$1.65 \times 10^{6}-1.75 \times 10^{6} .13$.

$1.75 \times 10^{6}-1.85 \times 10^{6} \quad 10$.

$1.85 .10^{6}-1.95 \times 10^{6} \quad 7.1$

$1.95 \times 10^{6}-2.76 \times 10^{6} \quad 9.6$

$2.76 \times 10^{6}-2.97 \times 10^{6} \quad 12$.

$2.97 \times 10^{6}-3.02 \times 10^{6} \quad 13$.

$3.02 \times 10^{6}-3.07 \times 10^{6} \quad 16$.

$3.07 \times 10^{6}-3.17 \times 10^{6} \quad 14$.

$3.17 \times 10^{6}-3.27 \times 10^{6} \quad 19$. 
Estimated Uncertainties in the Evaluated Cross Sections for Natural Chromium (cont.)

MT. Reaction:

52

53

\section{Energy Range (eV) \\ Uncertainty (\%)}

$3.27 \times 10^{6}-1.0 \times 10^{7}$

$1.0 \times 10^{7}-2.0 \times 10^{7}$

$8.51 \times 10^{5}-1.03 \times 10^{6}$

$1.03 \times 10^{6}-1.13 \times 10^{6}$

$1.13 \times 10^{6}-1.24 \times 10^{6}$

$1.24 \times 10^{6}-1.34 \times 10^{6}$

$1.34 \times 10^{6}-1.44 \times 10^{6}$

$1.44 \times 10^{6}-1.49 \times 10^{6}$

$1.49 \times 10^{6}-1.54 \times 10^{6}$

$1.54 \times 10^{6}-1.60 \times 10^{6}$

$1.60 \times 10^{6}-1.65 \times 10^{6}$

$1.65 \times 10^{6}-1.85 \times 10^{6}$

$1.85 \times 10^{6}-2.21 \times 10^{6}$

$2.21 \times 10^{6}-2.26 \times 10^{6}$

$2.26 \times 10^{6}-2.31 \times 10^{6}$

$2.31 \times 10^{6}-2.46 \times 10^{6}$

$2.46 \times 10^{6}-2.66 \times 10^{6}$

$2.66 \times 10^{6}-2.92 \times 10^{6}$

$2.92 \times 10^{6}-2.97 \times 10^{6}$

$2.97 \times 10^{6}-3.1 .7 \times 10^{6}$

$3.17 \times 10^{6}-3.27 \times 10^{6}$

$3.27 \times 10^{6}-3.47 \times 10^{6}$

$3.47 \times 10^{6}-3.57 \times 10^{6}$

$3.57 \times 10^{6}-3.97 \times 10^{6}$

$3.97 \times 10^{6}-2.0 \times 10^{7}$

$1.02 \times 10^{6}-1.13 \times 10^{6}$

$1.13 \times 10^{6}-1.24 \times 10^{6}$

$1.24 \times 10^{6}-1.34 \times 10^{6}$

$1.44 \times 10^{6}-1.49 \times 10^{6}$

$1.49 \times 10^{6}-1.55 \times 10^{6}$

$1.55 \times 10^{6}-1.60 \times 10^{6}$
25 .

30 .

33.

14.

63

38.

14.

33.

10.

19.

14 .

19.

16.

9.7

12.

8.5

11 .

14.

20.

14.

20.

22.

29.

33.

38.

25 .

24.

15.

7.7

10.

12. 
Estimated Uncertainties in the Evaluated Cross Sections for Natural Chromium (cont.)

\begin{tabular}{|c|c|c|}
\hline Reaction & Energy Range (eV) & Uncertainty (\%) \\
\hline \multirow[t]{16}{*}{54} & $1.60 \times 10^{6}-1.65 \times 10^{6}$ & 11 . \\
\hline & $1.65 \times 10^{6}-1.75 \times 10^{6}$ & 14. \\
\hline & $1.75 \times 10^{6}-1.85 \times 10^{6}$ & 19. \\
\hline & $1.85 \times 10^{6}-2.05 \times 10^{6}$ & 12. \\
\hline & $2.05 \times 10^{6}-2.16 \times 10^{6}$ & 9.7 \\
\hline & $2.16 \times 10^{6}-3.02 \times 10^{6}$ & 13. \\
\hline & $3.02 \times 10^{6}-3.17 \times 10^{6}$ & 22 . \\
\hline & $3.17 \times 10^{6}-3.27 \times 10^{6}$ & 16. \\
\hline & $3.27 \times 10^{6}-3.37 \times 10^{6}$ & 23. \\
\hline & $3.37 \times 10^{6}-3.47 \times 10^{6}$ & 24. \\
\hline & $3.47 \times 10^{6}-3.57 \times 10^{6}$ & 27 . \\
\hline & $3.57 \times 10^{6}-3.77 \times 10^{6}$ & 19. \\
\hline & $3.77 \times 10^{6}-3.87 \times 10^{6}$ & 22 . \\
\hline & $3.87 \times 10^{6}-3.97 \times 10^{6}$ & 25 . \\
\hline & $3.97 \times 10^{6}-5.0 \times 10^{6}$ & 21 \\
\hline & $5.0 \times 10^{6}-2.0 \times 10^{7}$ & 20 . \\
\hline \multirow[t]{15}{*}{55} & $1.31 \times 10^{6}-1.44 \times 10^{6}$ & 15. \\
\hline & $1.44 \times 10^{6}-1.49 \times 10^{6}$ & 11 . \\
\hline & $1.49 \times 10^{6}-1.55 \times 10^{6}$ & 18. \\
\hline & $1.55 \times 10^{6}-1.60 \times 10^{6}$ & 12 . \\
\hline & $1.60 \times 10^{6}-1.65 \times 10^{6}$ & 18 . \\
\hline & $1.65 \times 10^{6}-1.75 \times 10^{6}$ & 30. \\
\hline & $1.75 \times 10^{6}-1.85 \times 10^{6}$ & 26 \\
\hline & $1.85 \times 10^{6}-1.95 \times 10^{6}$ & 30 \\
\hline & $1.95 \times 10^{6}-2.05 \times 10^{6}$ & 17 . \\
\hline & $2.05 \times 10^{6}-2.16 \times 10^{6}$ & 11. \\
\hline & $2.16 \times 10^{6}-2.76 \times 10^{6}$ & 12. \\
\hline & $2.26 \times 10^{6}-2.76 \times 10^{6}$ & 14. \\
\hline & $2.76 \times 10^{6}-2.97 \times 10^{6}$ & 17 . \\
\hline & $2.97 \times 10^{6}-3.17 \times 10^{6}$ & 19. \\
\hline & $3.17 \times 10^{6}-3.57 \times 10^{6}$ & 21 \\
\hline
\end{tabular}


Estimated Uncertainties in the Evaluated Cross Sections for Natural Chromium (cont.)

MT $\quad$ Reaction

55

56

57

58

\section{Energy Range (eV)}

$3.57 \times 10^{6}-5.0 \times 10^{6}$

$5.0 \times 10^{6}-1.0 \times 10^{7}$

$1.0 \times 10^{7}-2.0 \times 10^{7}$

$1.46 \times 10^{6}-1.49 \times 10^{6}$

$1.49 \times 10^{6}-1.54 \times 10^{6}$

$1.54 \times 10^{6}-1.60 \times 10^{6}$

$1.60 \times 10^{6}-1.65 \times 10^{6}$

$1.65 \times 10^{6}-1.7 .5 \times 10^{6}$

$1.75 \times 10^{6}-2.86 \times 10^{6}$

$2.86 \times 10^{6}-3.07 \times 10^{6}$

$3.07 \times 10^{6}-3.37 \times 10^{6}$

$3.37 \times 10^{6}-3.57 \times 10^{6}$

$3.57 \times 10^{6}-3.77 \times 10^{6}$

$3.77 \times 10^{6}-5.0 \times 10^{6}$

$5.0 \times 10^{6}-1.0 \times 10^{7}$

$1.0 \times 10^{7}-2.0 \times 10^{7}$

$1.57 \times 10^{6}-1.61 \times 10^{6}$

$1.61 \times 10^{6}-1.75 \times 10^{6}$

$1.75 \times 10^{6}-1.85 \times 10^{6}$

$1.85 \times 10^{6}-1.95 \times 10^{6}$

$1.95 \times 10^{6}-.2 .05 \times 10^{6}$

$2.05 \times 10^{6}-2.21 \times 10^{6}$

$2.21 \times 10^{6}-2.26 \times 10^{6}$

$2.26 \times 10^{6}-2.46 \times 10^{6}$

$2.46 \times 10^{6}-5.0 \times 10^{6}$

$5.0 \times 10^{6}-1.5 \times 10^{7}$

$1.5 \times 10^{7}-2.0 \times 10^{7}$

$2.01 \times 10^{6}-2.16 \times 10^{6}$

$2.16 \times 10^{6}-2.26 \times 10^{6}$

$2.26 \times 10^{6}-2.36 \times 10^{6}$

$2.36 \times 10^{6}-2.46 \times 10^{6}$
Uncertainty (\%)

33

10.

20.

40.

40.

15

7.1

10.

7.1

7.3

10 .

13.

14.

18.

15

20

57

50

35

29.

33.

22.

17.

11 .

14.

15.

20.

33.

20.

27.

36. 
Estimated Uncertainties in the Evaluated Cross Sections for Natural Chromium (cont.)

MT Reaction

58

59,60

61

62
Energy Range(*eV)

$$
2.46 \times 10^{6}-2.56 \times 10^{6}
$$$$
2.56 \times 10^{6}-2.76 \times 10^{6}
$$$$
2.76 \times 10^{6}-2.87 \times 10^{6}
$$$$
2.87 \times 10^{6}-2.92 \times 10^{6}
$$$$
2.92 \times 10^{6}-3.07 \times 10^{6}
$$$$
3.07 \times 10^{6}-3.17 \times 10^{6}
$$$$
3.17 \times 10^{6}-3.57 \times 10^{6}
$$$$
3.57 \times 10^{6}-3.67 \times 10^{6}
$$$$
3.67 \times 10^{6}-3.77 \times 10^{6}
$$$$
3.77 \times 10^{6}-3.87 \times 10^{6}
$$$$
3.87 \times 10^{6}-3.97 \times 10^{6}
$$$$
3.97 \times 10^{6}-5.0 \times 10^{6}
$$$$
5.0 \times 10^{6} \quad 1.5 \times 10^{7}
$$$$
1.5 \times 10^{7}-2.0 \times 10^{7}
$$$$
2.2 \times 10^{6}-1.5 \times 10^{7}
$$$$
1.5 \times 10^{7}-2.0 \times 10^{7}
$$$$
2.3 \times 10^{6}-2.76 \times 10^{6}
$$$$
2.76 \times 10^{6}-3.17 \times 10^{6}
$$$$
3.17 \times 10^{6}-3.47 \times 10^{6}
$$$$
3.47 \times 10^{6}-3.57 \times 10^{6}
$$$$
3.57 \times 10^{6}-3.67 \times 10^{6}
$$$$
3.67 \times 10^{6}-3.77 \times 10^{6}
$$$$
3.77 \times 10^{6}-3.87 \times 10^{6}
$$$$
3.87 \times 10^{6}-3.97 \times 10^{6}
$$$$
3.97 \times 10^{6}-2.0 \times 10^{7}
$$$$
2.4 \times 10^{6}-2.66 \times 10^{6}
$$$$
2.66 \times 10^{6}-2.76 \times 10^{6}
$$$$
2.76 \times 10^{6}-2.86 \times 10^{6}
$$$$
2.86 \times 10^{6}-3.02 \times 10^{6}
$$$$
3.02 \times 10^{6}-3.37 \times 10^{6}
$$

\section{Uncertainty (\%)}

57.

28.

20 .

28 .

12.

27.

36.

24.

28.

17.

20.

13.

20.

30.

20.

30 .

60 .

43.

60 .

40.

75.

67.

36.

33.

47.

20.

13.

7.4

8.3

7.5 
Estimated Uncertainties in the Evaluated Cross Sections for Natural Chromium (cont.)

$\frac{\text { MT }}{62}$

63

64

$65-67,69$

$71-74,76-81,83-90$

68

70
Energy Range (eV)

$3.37 \times 10^{6}-3.77 \times 10^{6}$

Uncertainty (\%)

$3.77 \times 10^{6}-3.87 \times 10^{6}$

8.2

$3.87 \times 10^{6}-1.0 \times 10^{7}$

$1.0 \times 10^{7}-1.5 \times 10^{7}$

$1.5 \times 10^{7}-2.0 \times 10^{7}$

$2.5 \times 10^{6}-5.0 \times 10^{6}$

$5.0 \times 10^{6}-2.0 \times 10^{7}$

$2.70 \times 10^{6}-2.97 \times 10^{6}$

$2.97 \times 10^{6}-3.17 \times 10^{6}$

$3.17 \times 10^{6}-3.57 \times 10^{6}$

$3.57 \times 10^{6}-3.67 \times 10^{6}$

$3.67 \times 10^{6}-3.87 \times 10^{6}$

$3.87 \times 10^{6}-5.0 \times 10^{6}$

$5.0 \times 10^{6}-1.5 \times 10^{7}$

$1.5 \times 10^{7}-2.0 \times 10^{7}$

$2.7 \times 10^{6}-1.25 \times 10^{7}$

$5.0 \times 10^{6}-1.25 \times 10^{7}$

$1.25 \times 10^{7}-2.0 \times 10^{7}$

$2.8 \times 10^{6}-3.02 \times 10^{6}$

$3.02 \times 10^{6}-3.17 \times 10^{6}$

$3.17 \times 10^{6}-3.27 \times 10^{6}$

$3.27 \times 10^{6}-3.37 \times 10^{6}$

$3.37 \times 10^{6}-3.47 \times 10^{6}$

$3.47 \times 10^{6}-3.77 \times 10^{6}$

$3.77 \times 10^{6}-3.87 \times 10^{6}$

$3.87 \times 10^{6}-3.97 \times 10^{6}$

$3.97 \times 10^{6}-5.0 \times 10^{6}$

$5.0 \times 10^{6}-1.5 \times 10^{7}$

$1.5 \times 10^{7}-2.0 \times 10^{7}$

$3.0 \times 10^{6}-3.08 \times 10^{6}$

$3.08 \times 10^{6}-3.17 \times 10^{6}$
7.1

20

30

50

40

23 .

8.1

13.

10.

9.4

10.

20.

30.

50.

40.

50.

25.

31 .

13.

10

8.1

9.6

21.

12.

15.

20.

30.

20.

12 .
16. 
Estimated Uncertainties in the Evaluated

Cross Sections for Natural Chromium (cont.)

MT $\quad$ Reaction

70

75

82

91

Continuum

Inelastic

102

103

$(n, p)$

$104(n, d)$

$105 \quad(n, t)$

$106 \quad\left(\mathrm{n},{ }^{3} \mathrm{He}\right)$

$107(n, \alpha)$
Energy Range (eV)

$3.17 \times 10^{6}-5.0 \times 10^{6}$

Uncertainty (\%)

$5.0 \times 10^{6}-1.0 \times 10^{7}$

7.3

$1.0 \times 10^{7}-2.0 \times 10^{7}$

15.

$3.2 \times 10^{6}-3.37 \times 10^{6}$

20.

$3.37 \times 10^{6}-3.47 \times 10^{6}$

25.

$3.47 \times 10^{6}-3.67 \times 10^{6}$

16.

$3.67 \times 10^{6}-5.0 \times 10^{6}$

10 .

$5.0 \times 10^{6}-1.5 \times 10^{7}$

$1.5 \times 10^{7}-1.8 \times 10^{7}$

$1.8 \times 10^{7}-2.0 \times 10^{7}$

$3.84 \times 10^{6}-3.87 \times 10^{6}$

$3.87 \times 10^{6}-5.0 \times 10^{6}$

$5.0 \times 10^{6}-2.0 \times 10^{7}$

$1.9 \times 10^{6}-2.0 \times 10^{7}$

$1.0 \times 10^{-5}-1.0 \times 10^{-2}$

$1.0 \times 10^{-2}-1.0 \times 10^{-1}$

$1.0 \times 10^{-1}-6.5 \times 10^{5}$

$6.5 \times 10^{5}-5.0 \times 10^{6}$

$5.0 \times 10^{6}-1.5 \times 10^{7}$

$1.5 \times 10^{7}-2.0 \times 10^{7}$

$1.8 \times 10^{6}-1.2 \times 10^{7}$

$1.2 \times 10^{7}-1.3 \times 10^{7}$

$1.3 \times 10^{7}-1.35 \times 10^{7}$

$1.35 \times 10^{7}-1.45 \times 10^{7}$

$1.45 \times 10^{7}-1.7 \times 10^{7}$

$1.70 \times 10^{7}-2.0 \times 10^{7}$

$7.51 \times 10^{6}-2.0 \times 10^{7}$

$8.80 \times 10^{6}-2.0 \times 10^{7}$

$8.80 \times 10^{6}-2.0 \times 10^{7}$

$1.0 \times 10^{6}-1.4 \times 10^{7}$

$1.40 \times 10^{7}-1.50 \times 10^{7}$

$1.50 \times 10^{7}-1.90 \times 10^{7}$

$1.90 \times 10^{7}-2.0 \times 10^{7}$
7.8

15.

20.

30 .

40.

32 .

40 .

40.

13.

9.7

13.

20.

15.

10.

20.

14.

8.6

9.6

8.9

20.

20 .

40.

40.

20.

6.8

9.8

20. 
CHROMIUM (NATURAL) TOTAL CROSS SECTION

$E_{n}=0.0001$ to $0.1 \mathrm{MeV}$

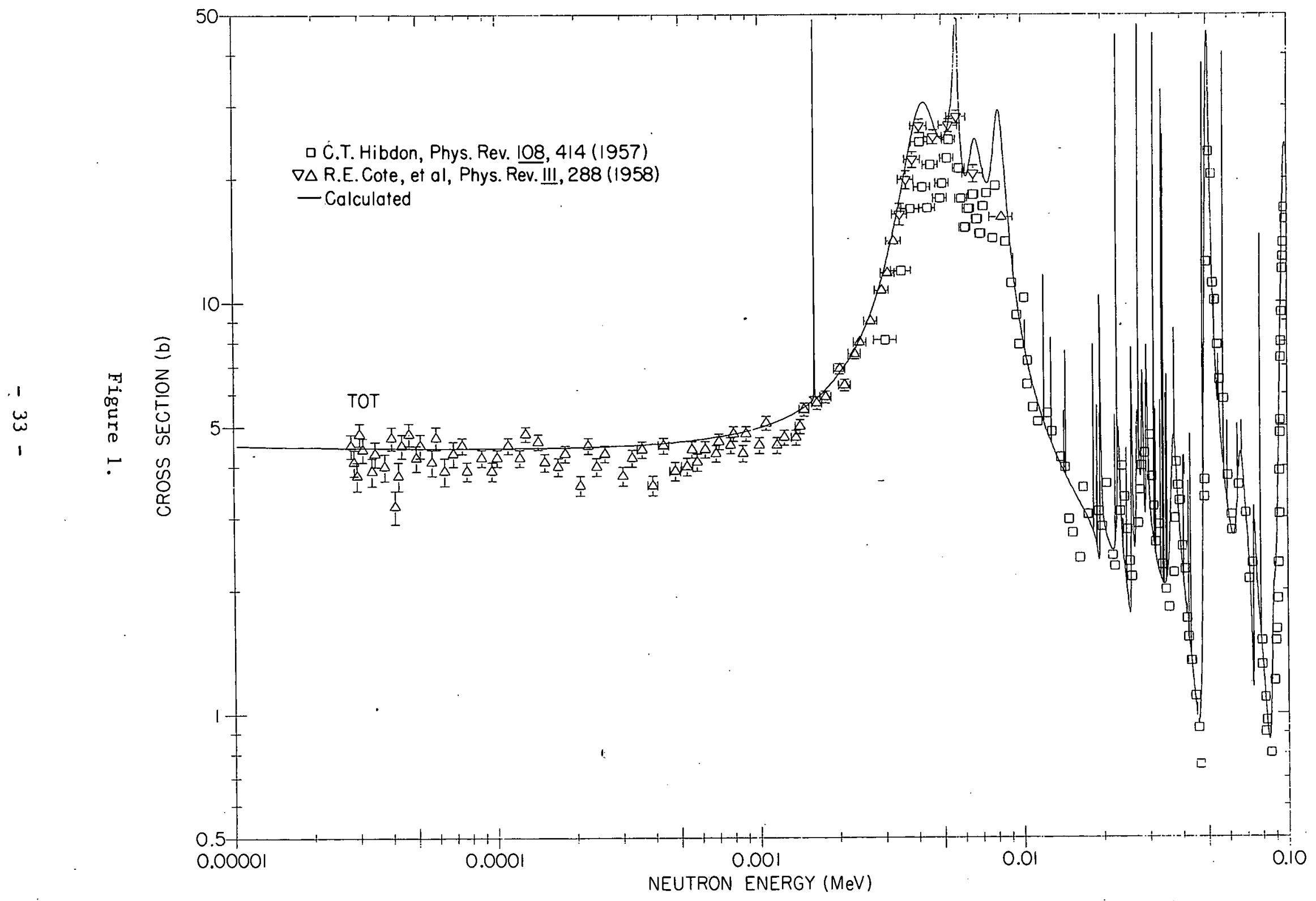


CHROMIUM (NATURAL) TOTAL CROSS SECTION

$E_{n}=0.1$ to $0.65 \mathrm{MeV}$

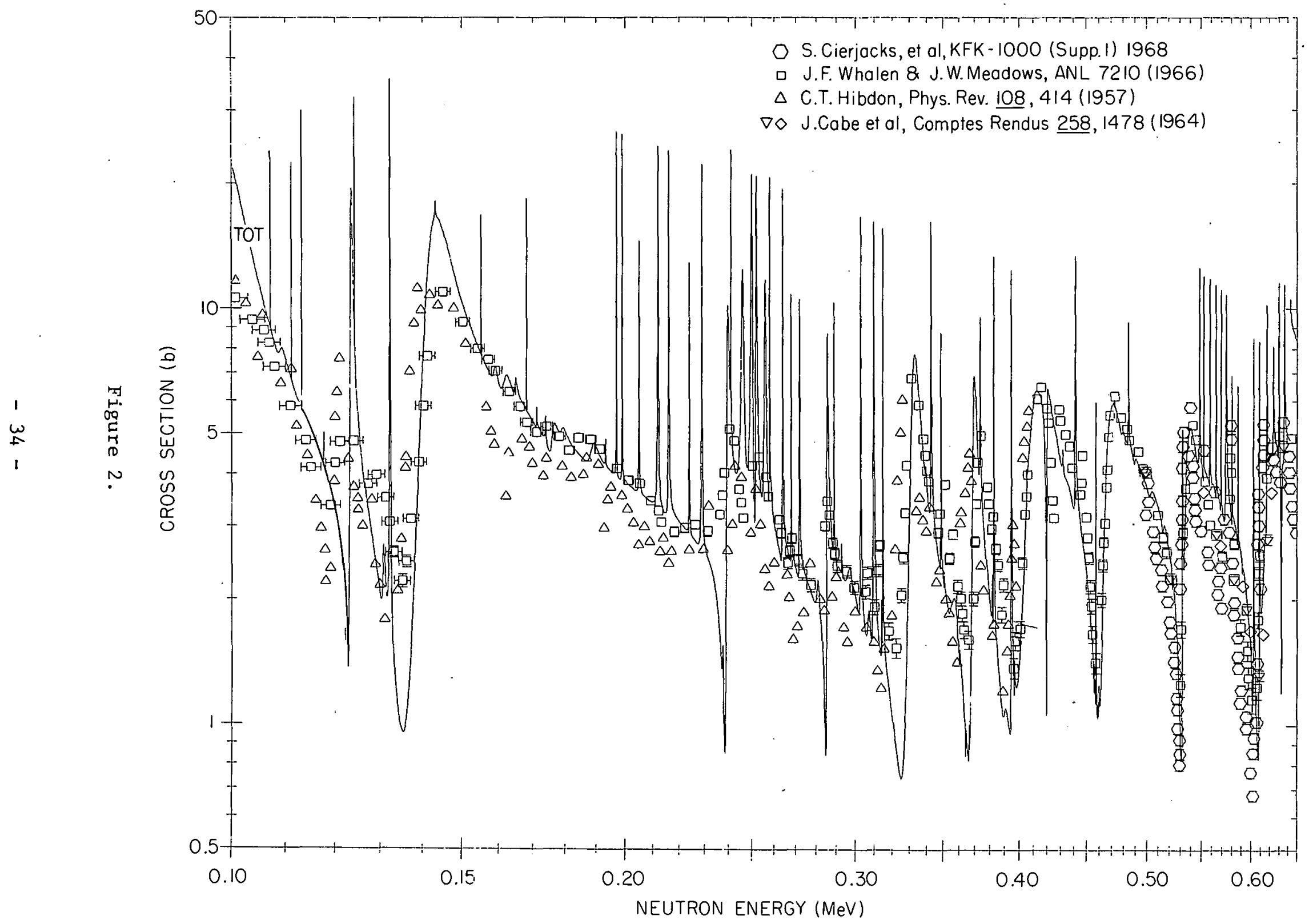


CHROMIUM

TOTAL CROSS SECTION

$\triangle$ F.G. PEREY et al-ORNL(1973)

0.65 to $0.70 \mathrm{MeV}$

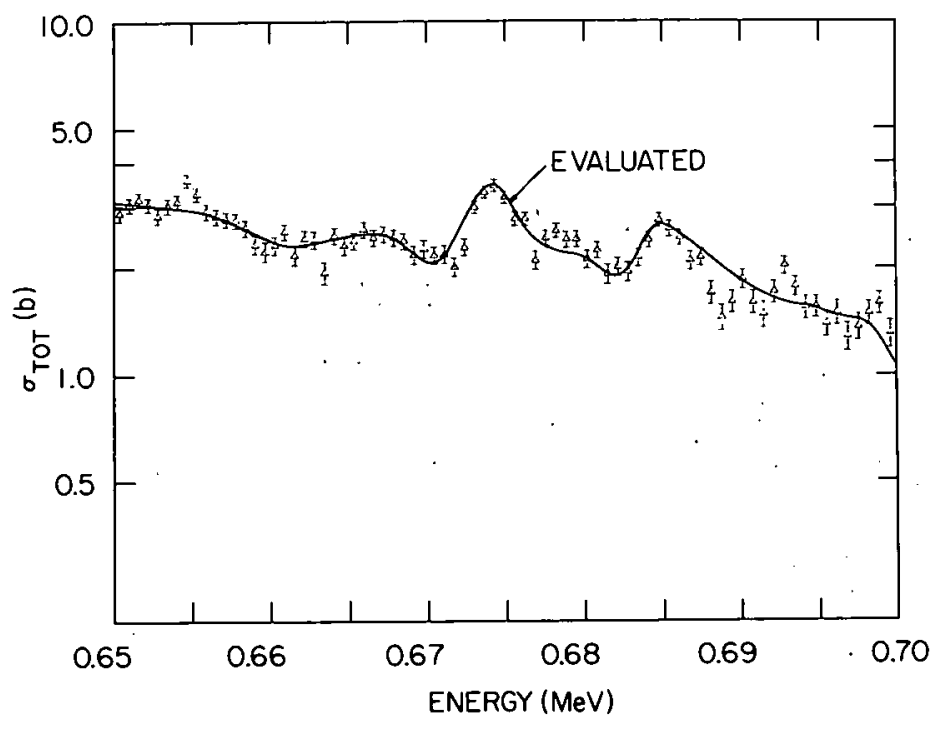

Figure 3.

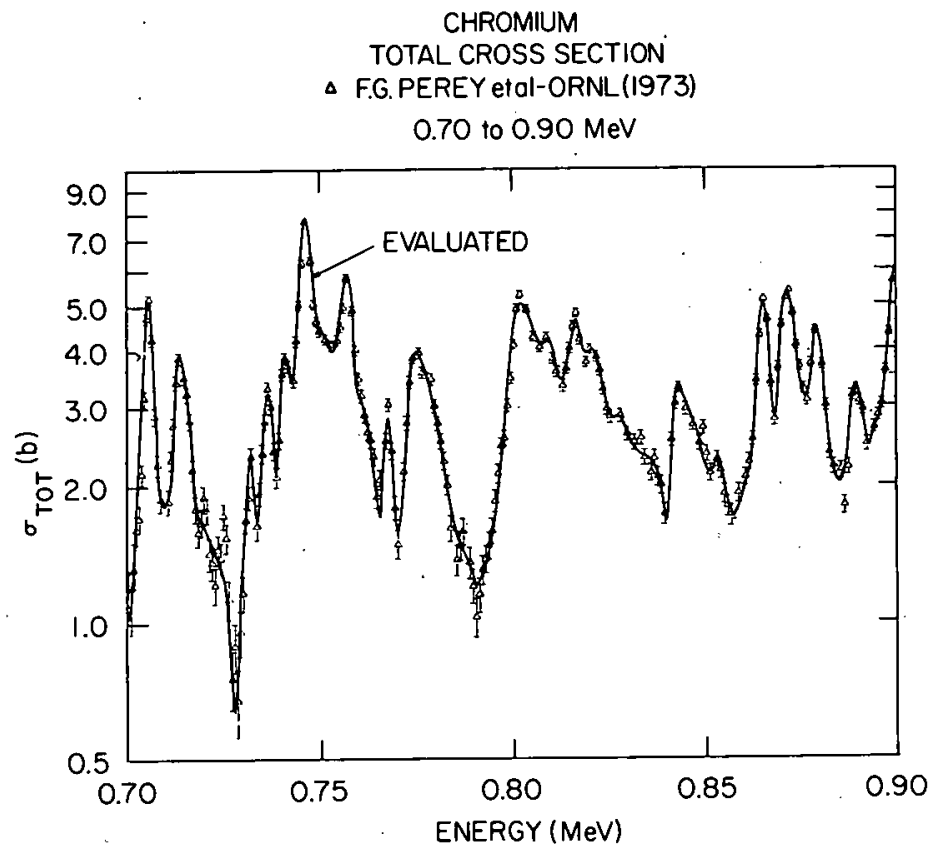

Figure 4 . 


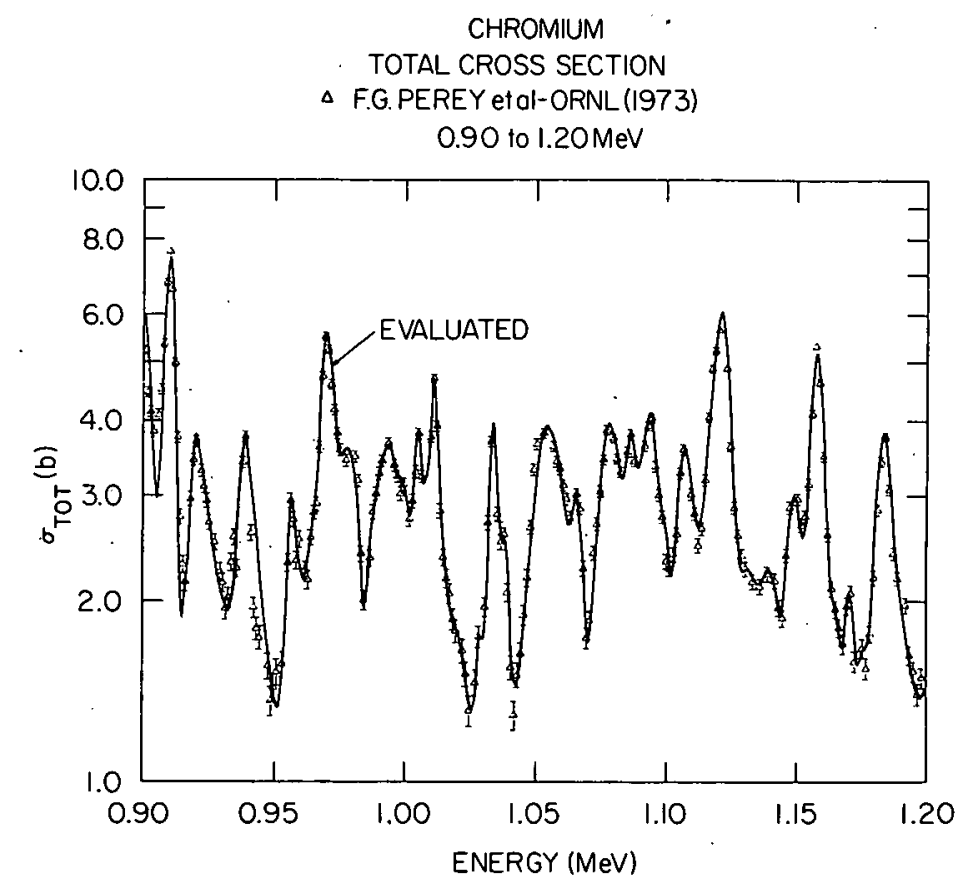

Figure 5.

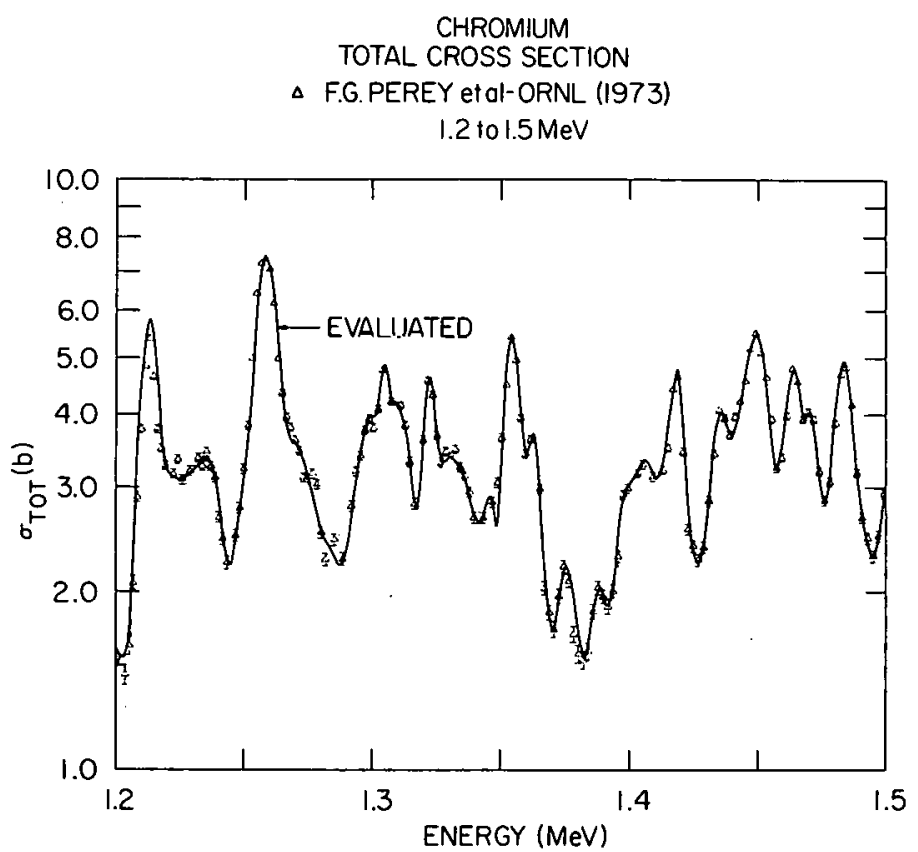

Figure 6. 


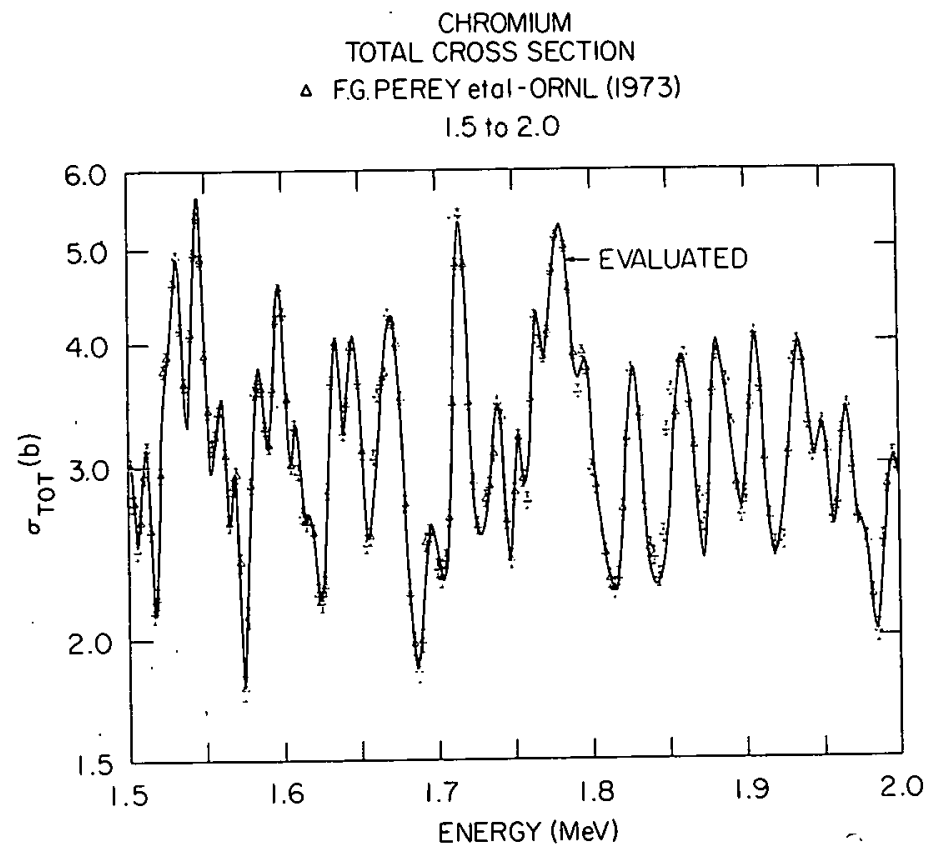

Figure 7.

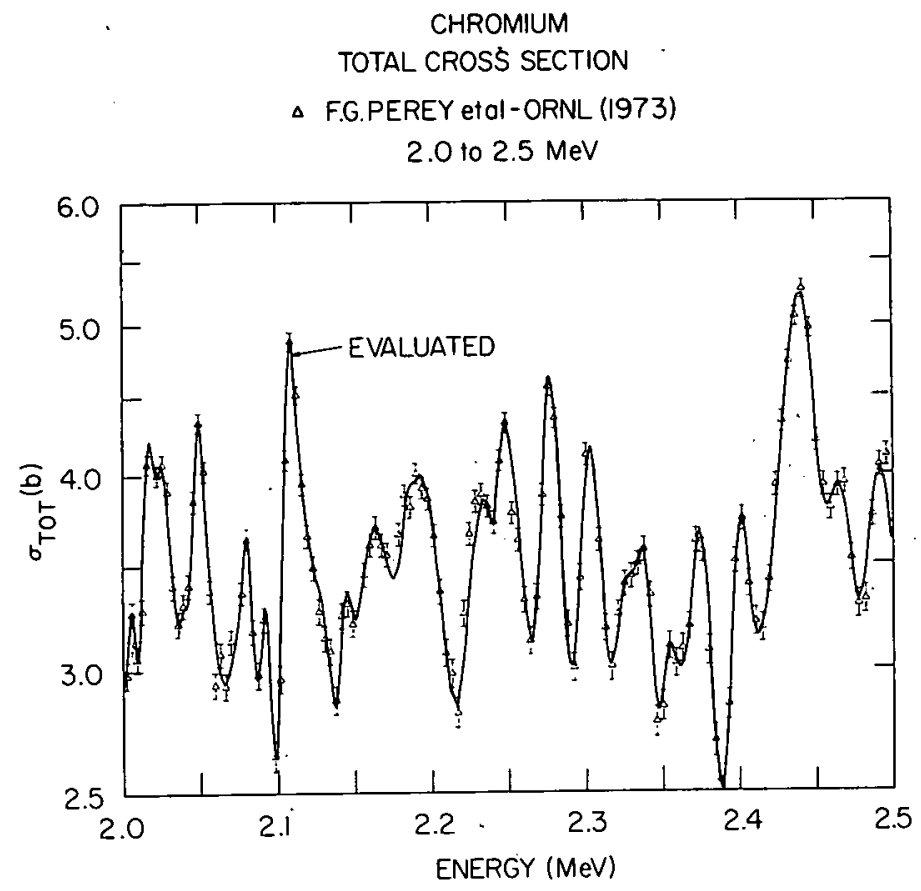

Figure 8. 


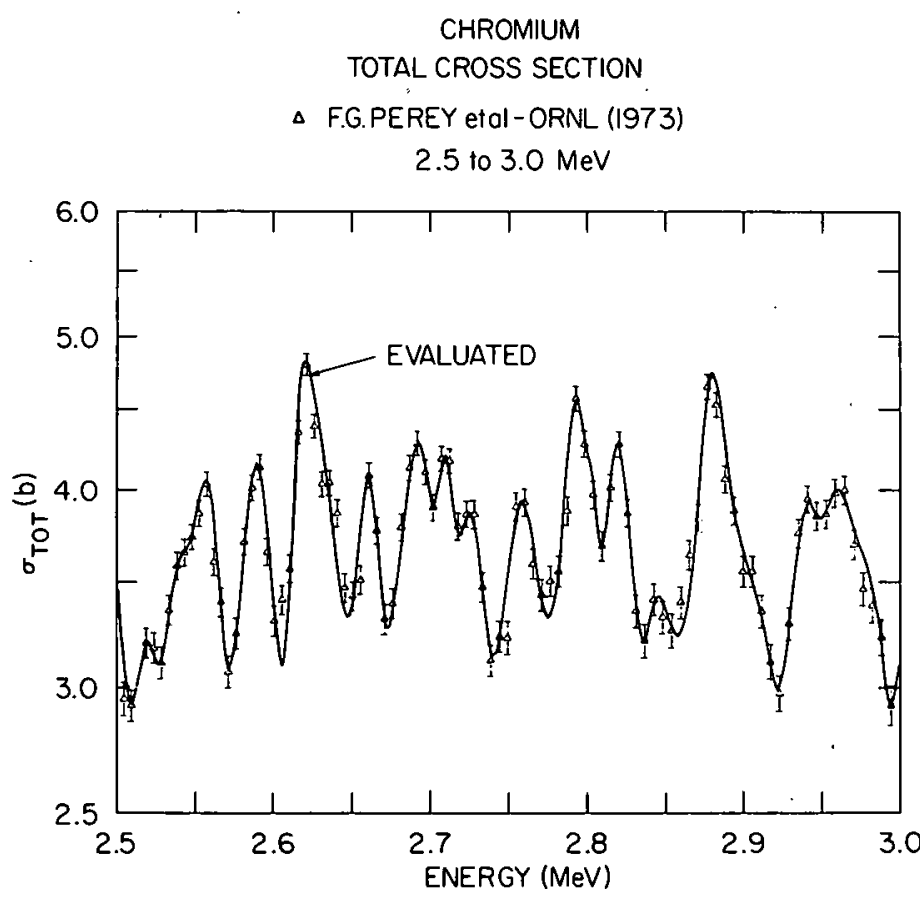

Figure 9.

CHROMIUM

TOTAL CROSS SECTION

$\triangle$ F.G.PEREY etal-ORNL (1973)

3.0 to $5.0 \mathrm{MeV}$

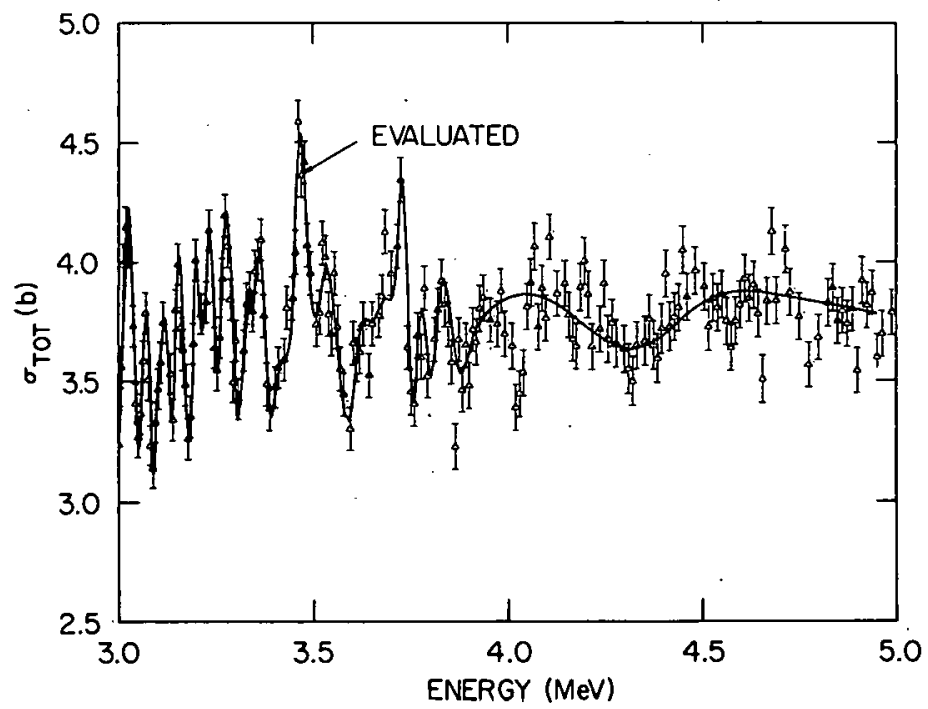

Figure 10. 


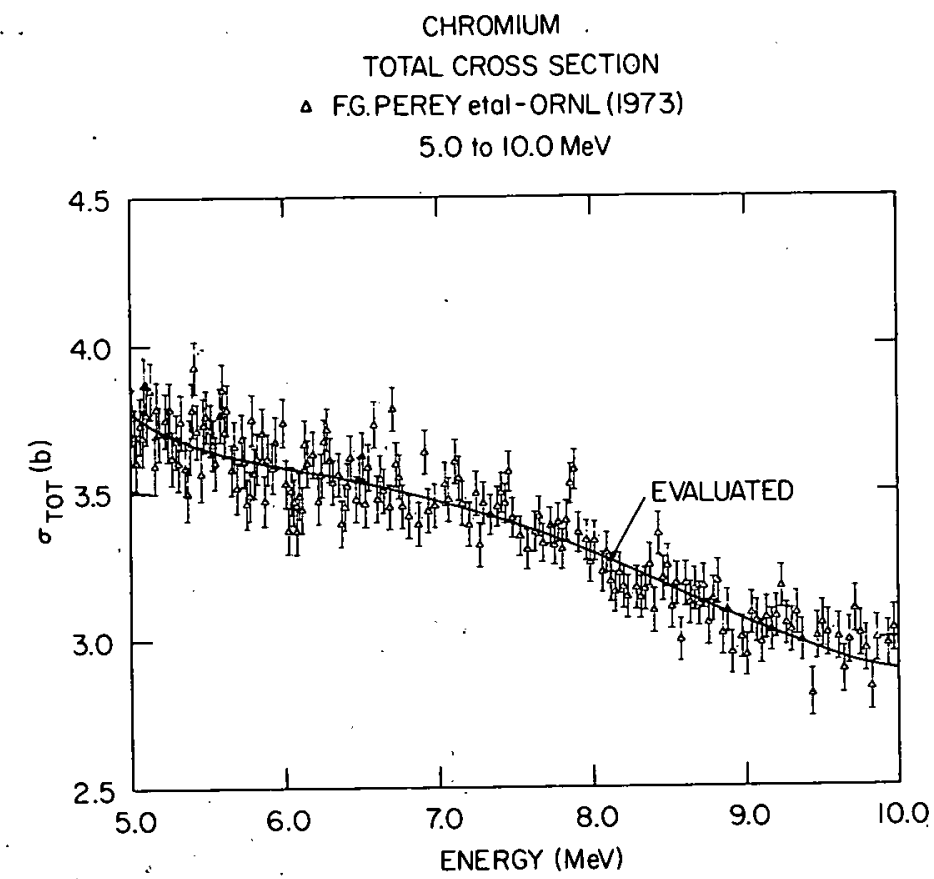

Figure 11.

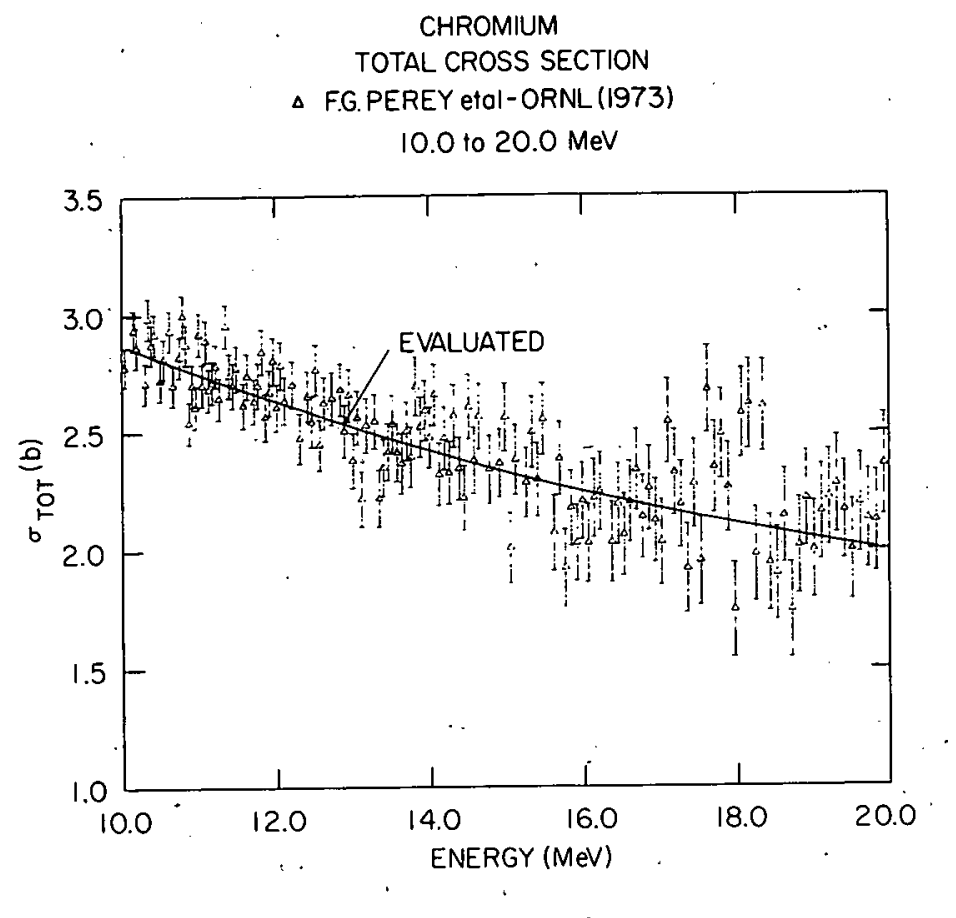

Figure 12. 


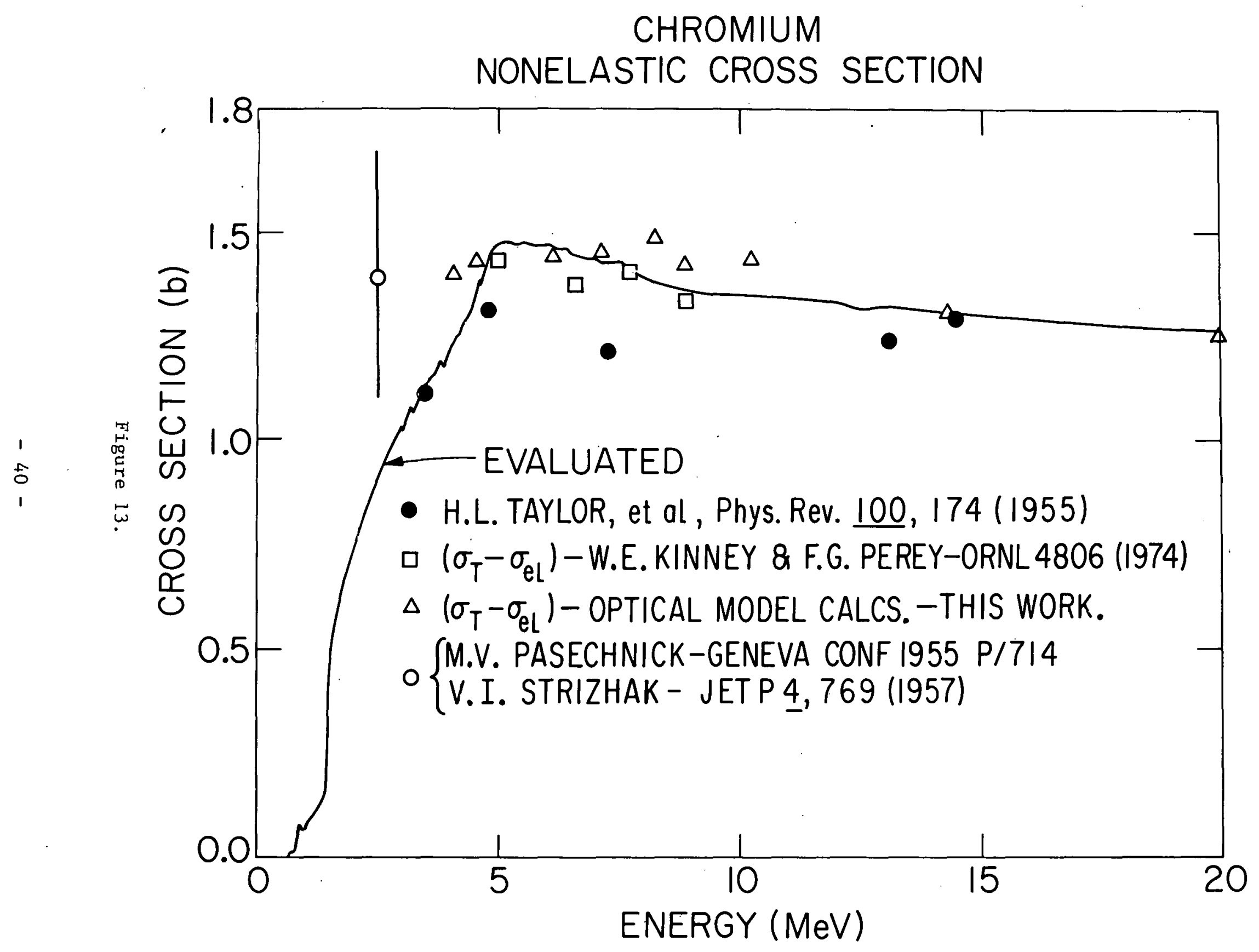




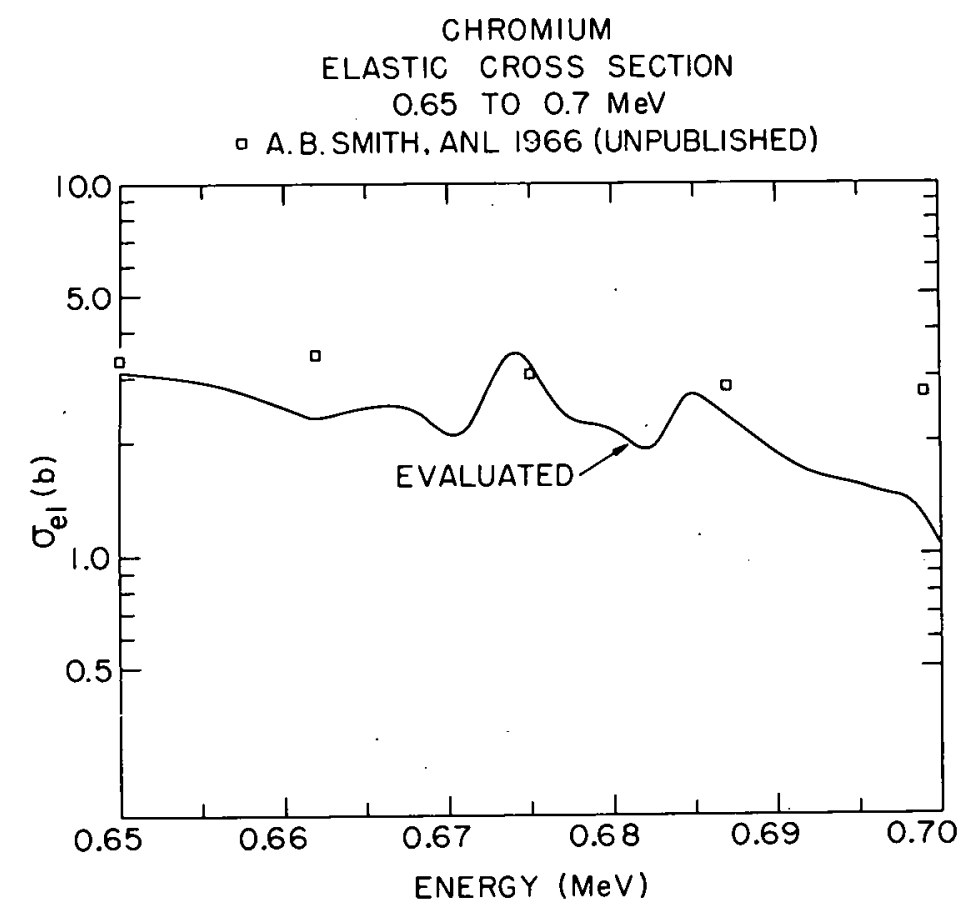

Figure 14.

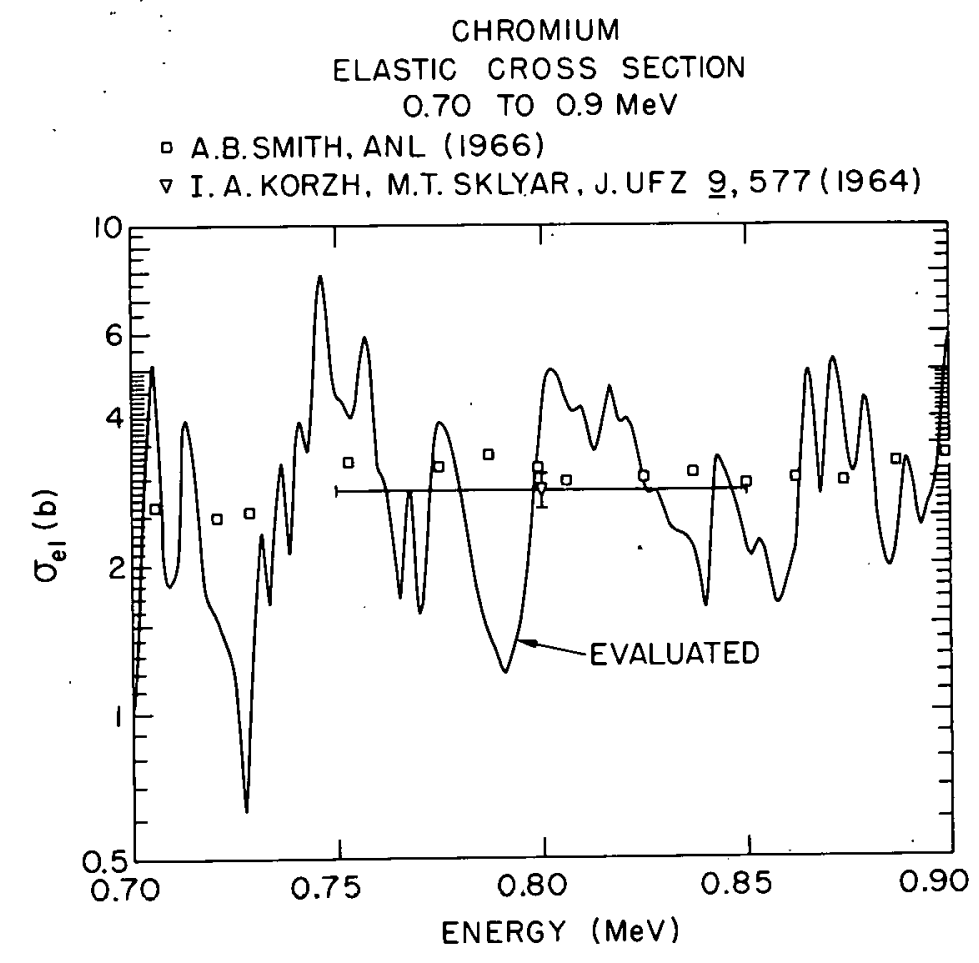

Figure 15. 


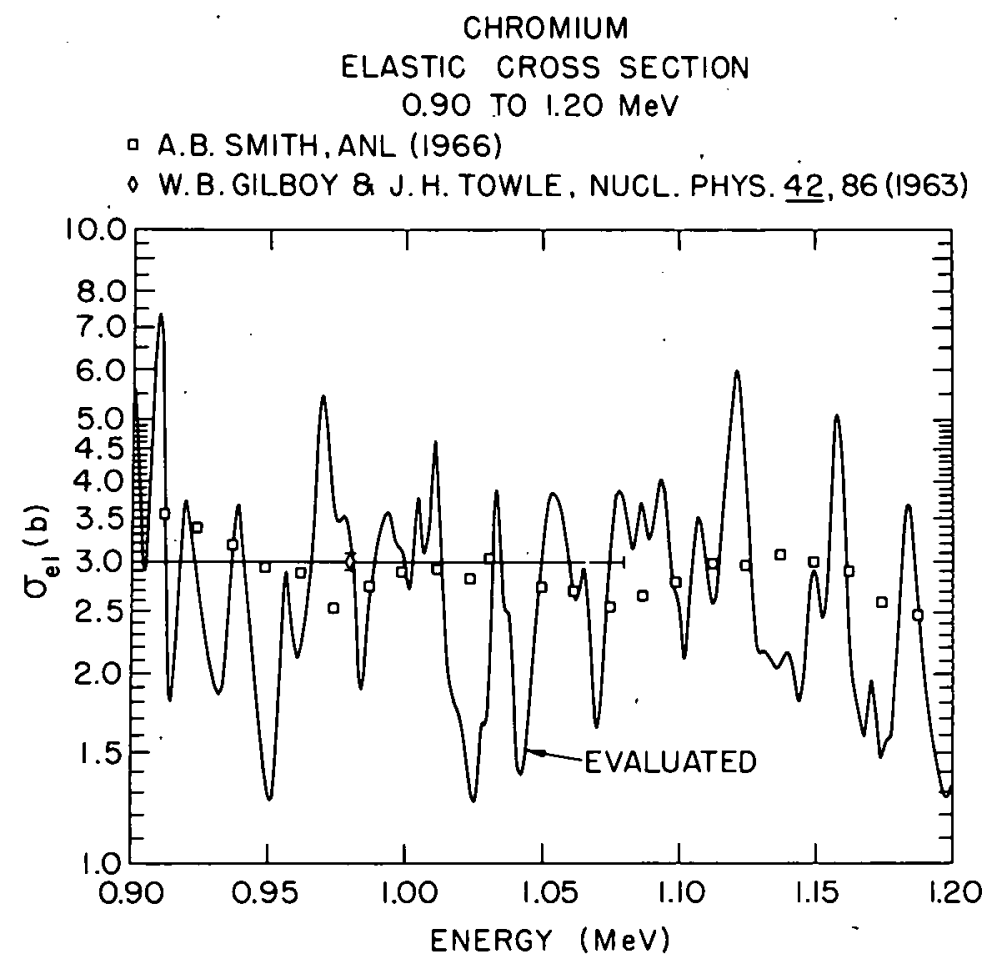

Figure 16.

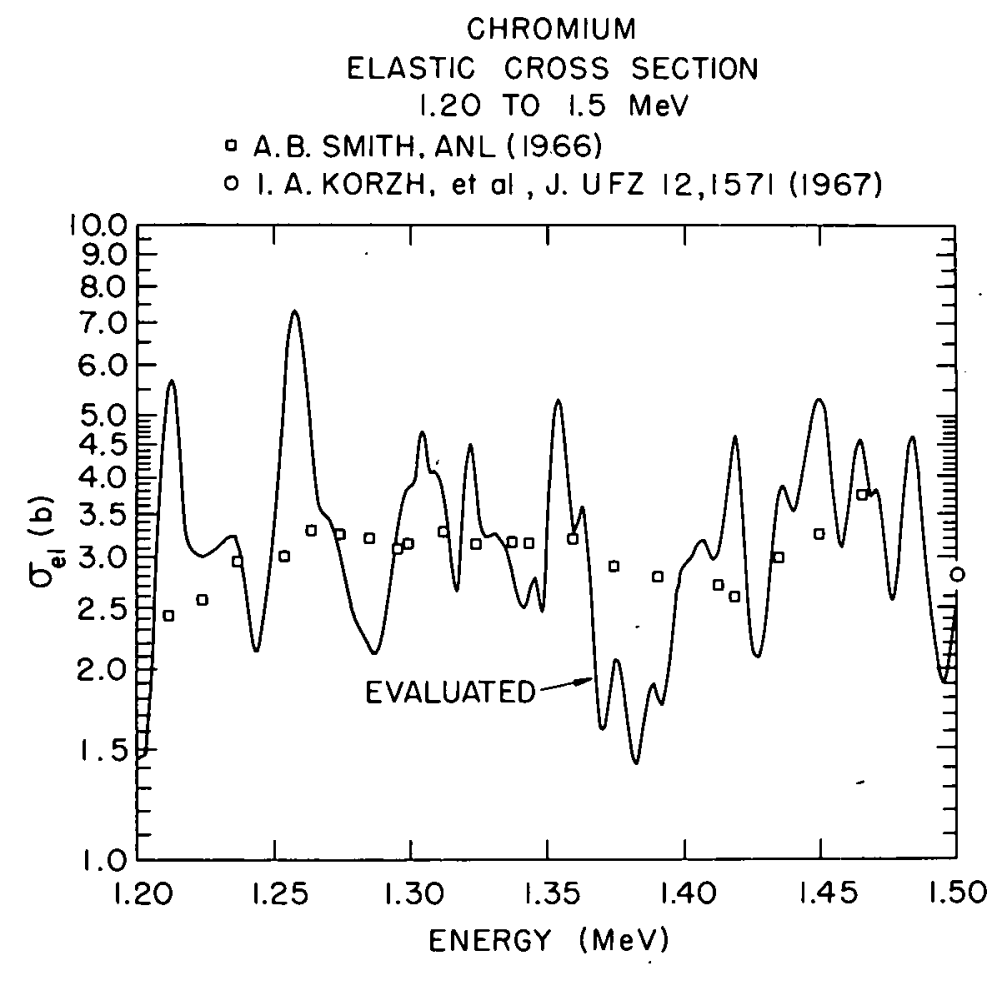

Figure 17. 


\section{CHROMIUM \\ ELASTIC CROSS SECTION}

I.5 TO $2.0 \mathrm{MeV}$

$\triangle$ I. B.HOLMQVIST \& T. WIELDING. AE 385 (1970)

02.1. A. KORZH , J. UFZ 12, 157I(1967)

13. L.YA. KASAKOV. ANTWERP CONF. 576 (1965)

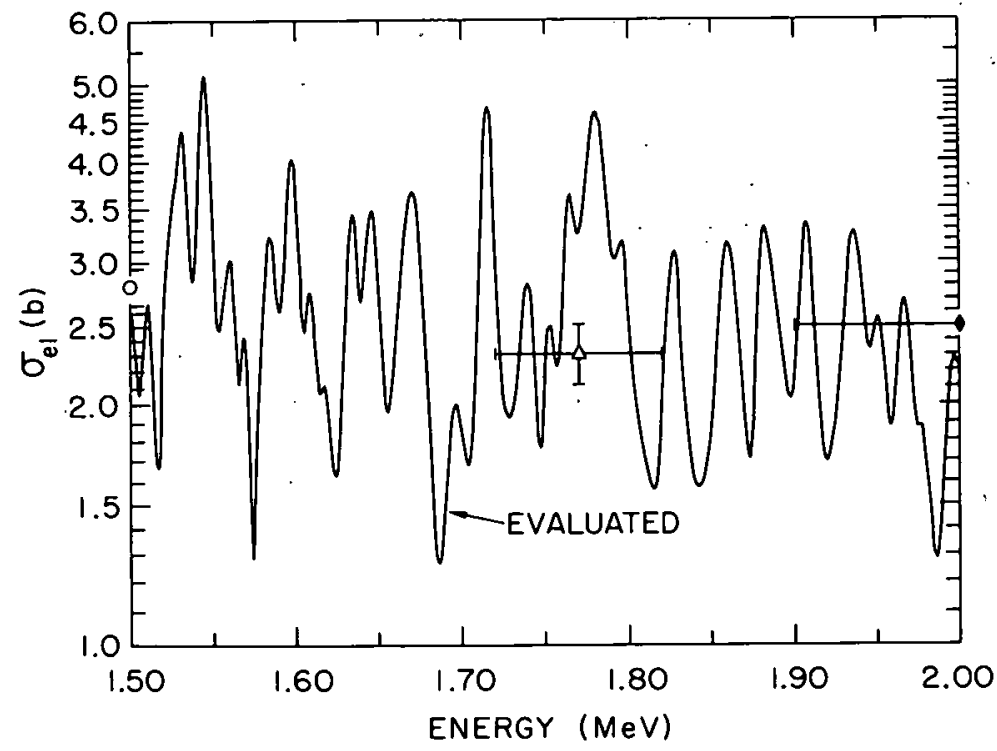

Figure 18.

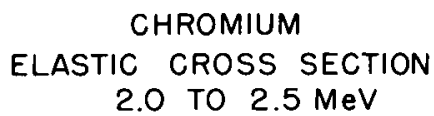

$\times$ I. B. HOLMOVIST \& T.WIEDLING AE 366 (1969)

$\triangle$ 2.B.HOLMOVIST \& T. WIEDLING AE 385 (1970)

- 3. L. YA. KASAKOV. ANTWERP CONF. 576 (1965)

a 4. M.V. PASECHNIK et al, SOV. J.NUCL.PHYS.11 533(1970)

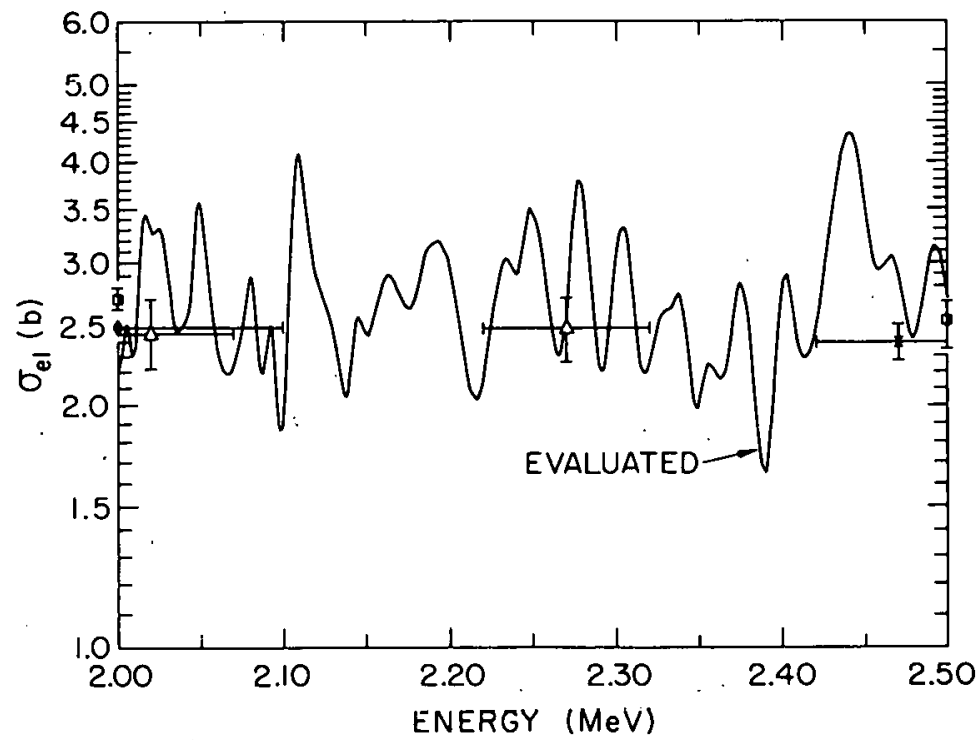

Figure 19. 


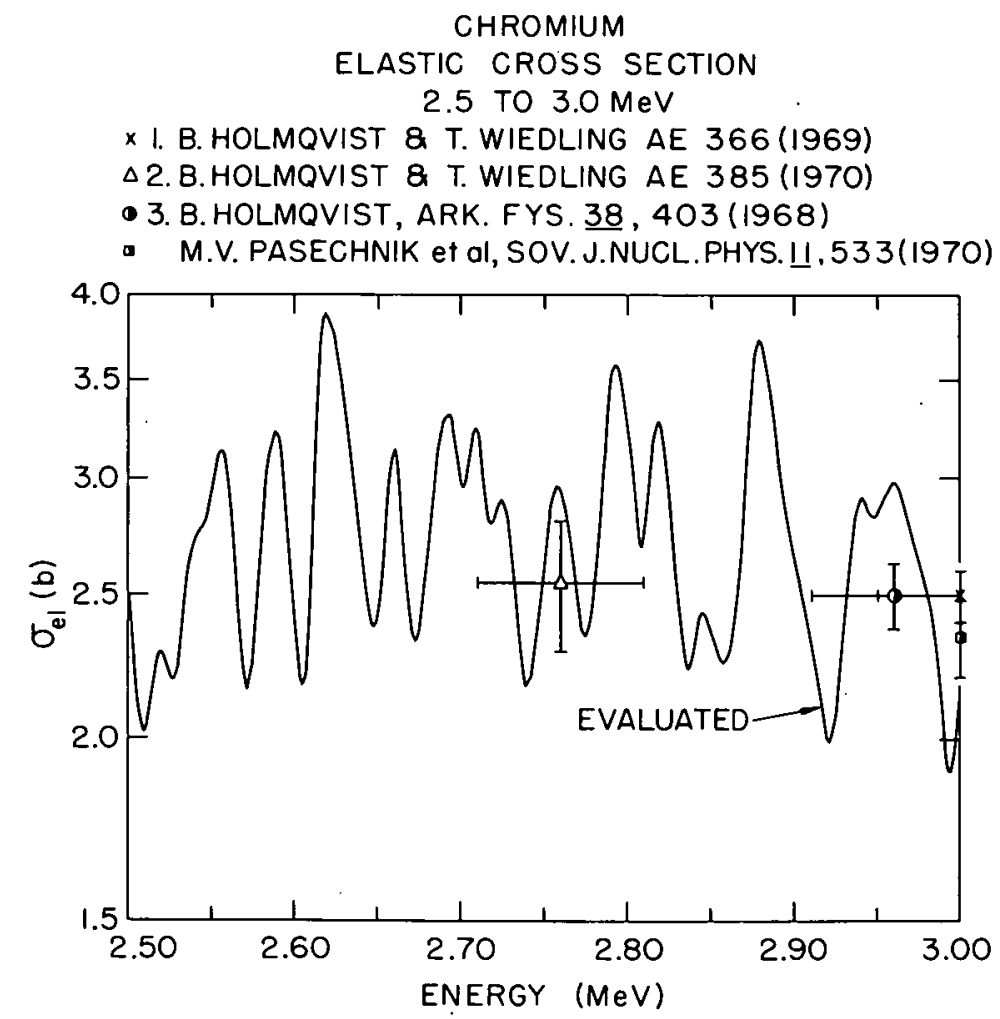

Figure 20.

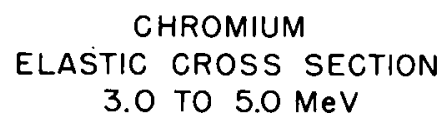

$\times$ I. 8. HOLMQVIST \& T. WIEDLING AE $366(1969)$

2. B. HOLMOVIST. ARK. FYS. 38, 403 (1968)

- W. E. KINNEY \& F. G. PEREY, ORNL 4806(1974)

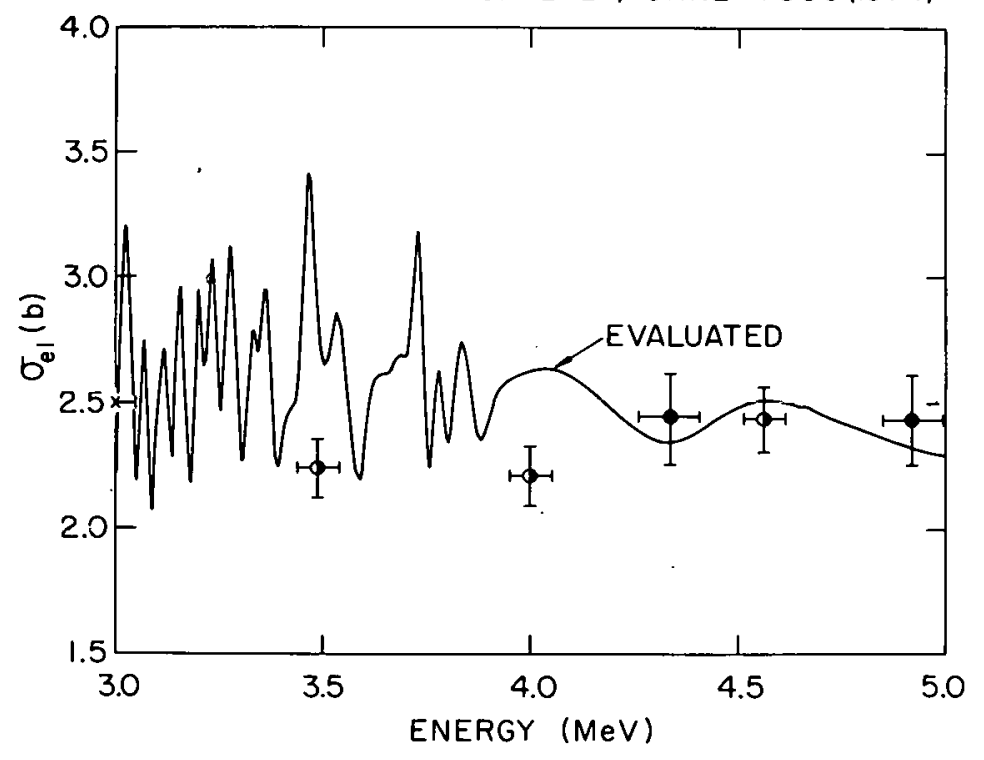

Figure 21 . 
CHROMIUM

ELASTIC CROSS SECTION

5.0 TO $10.0 \mathrm{MeV}$

× I. B. HOLMQVIST \& T. WIEDLING AE 366 (1969)

- 2. B. HOLMQVIST, ARK. FYS. $\underline{38}, 403$ (1968)

- W.E. KINNEY \& F. G. PEREY, ORNL 4806 (1974)

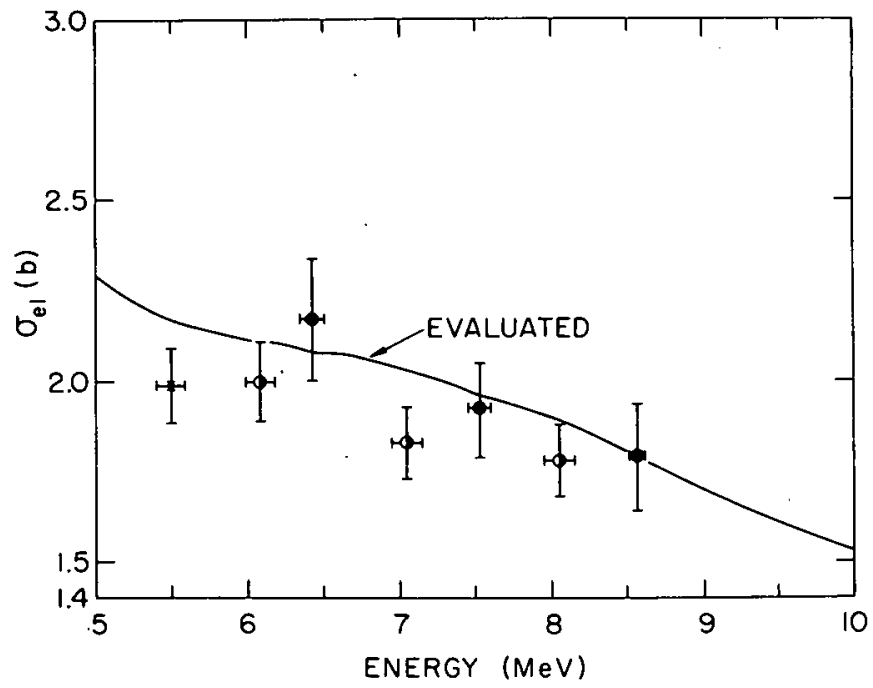

Figure 22.

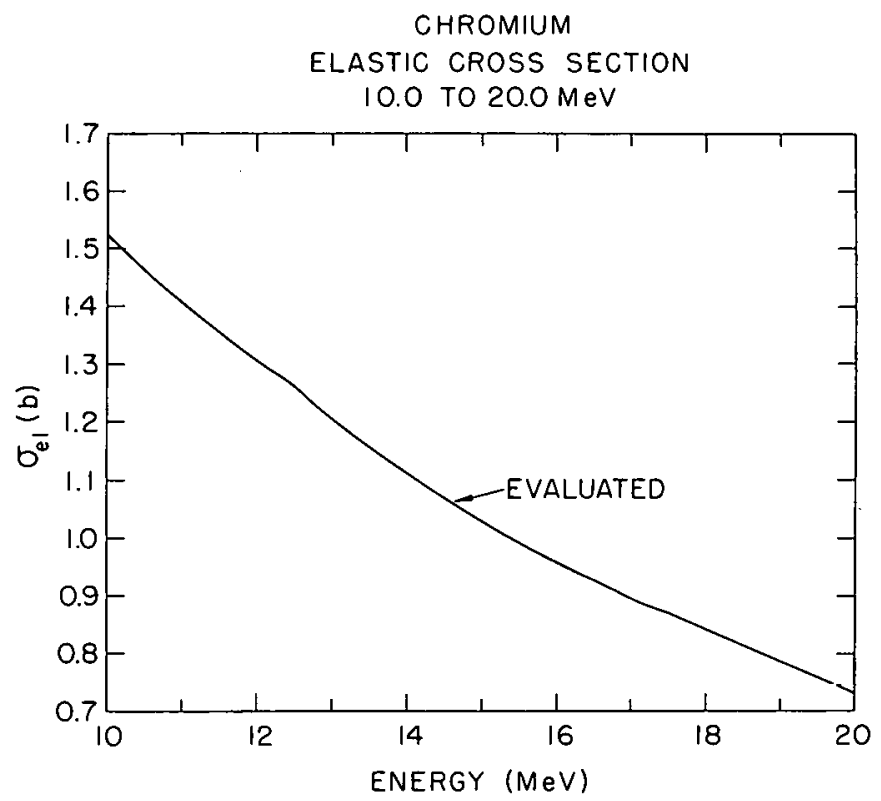

Figure 23. 


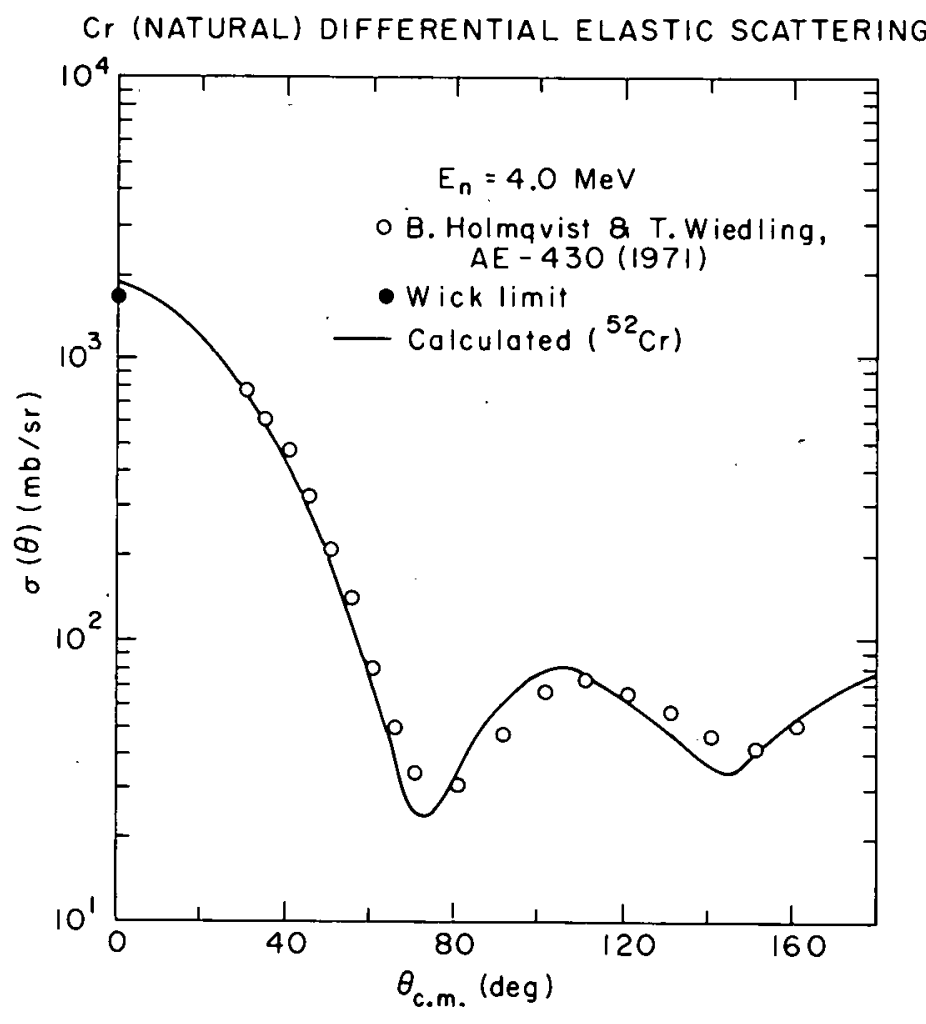

Figure 24.

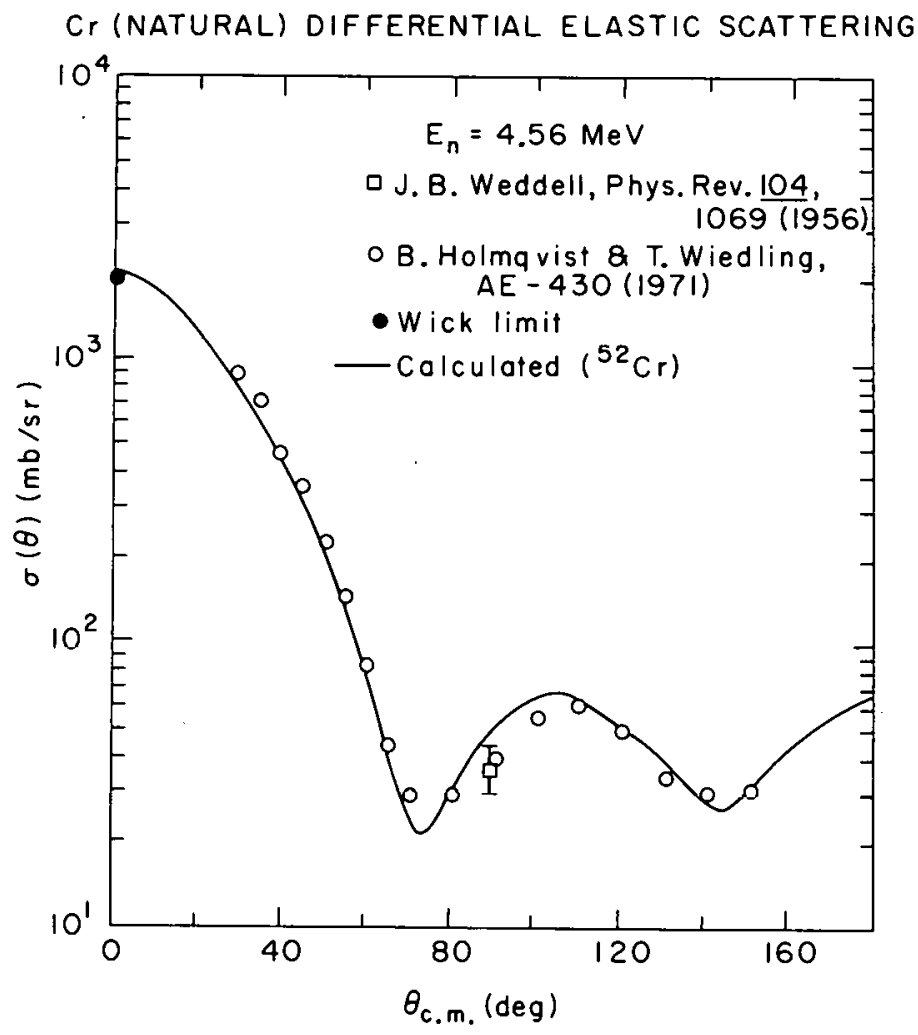

Figure 25. 
Cr (NATURAL) DIFFERENTIAL ELASTIC SCATTERING

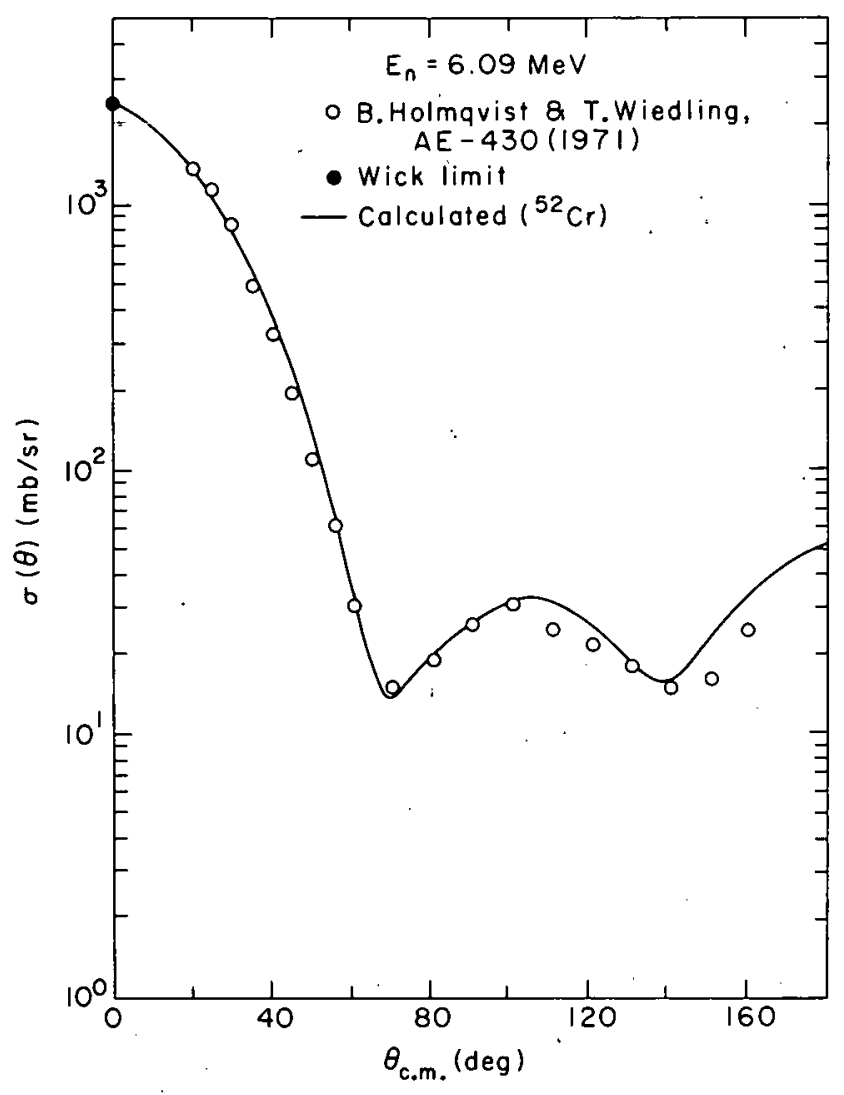

Figure 26.

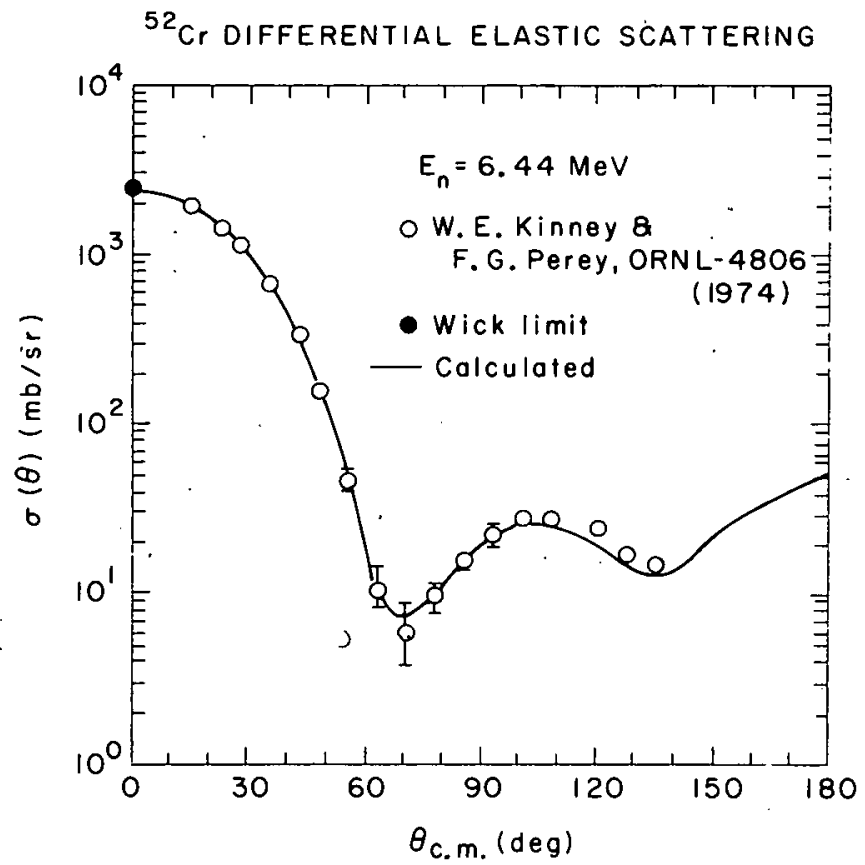

Figure 27. 


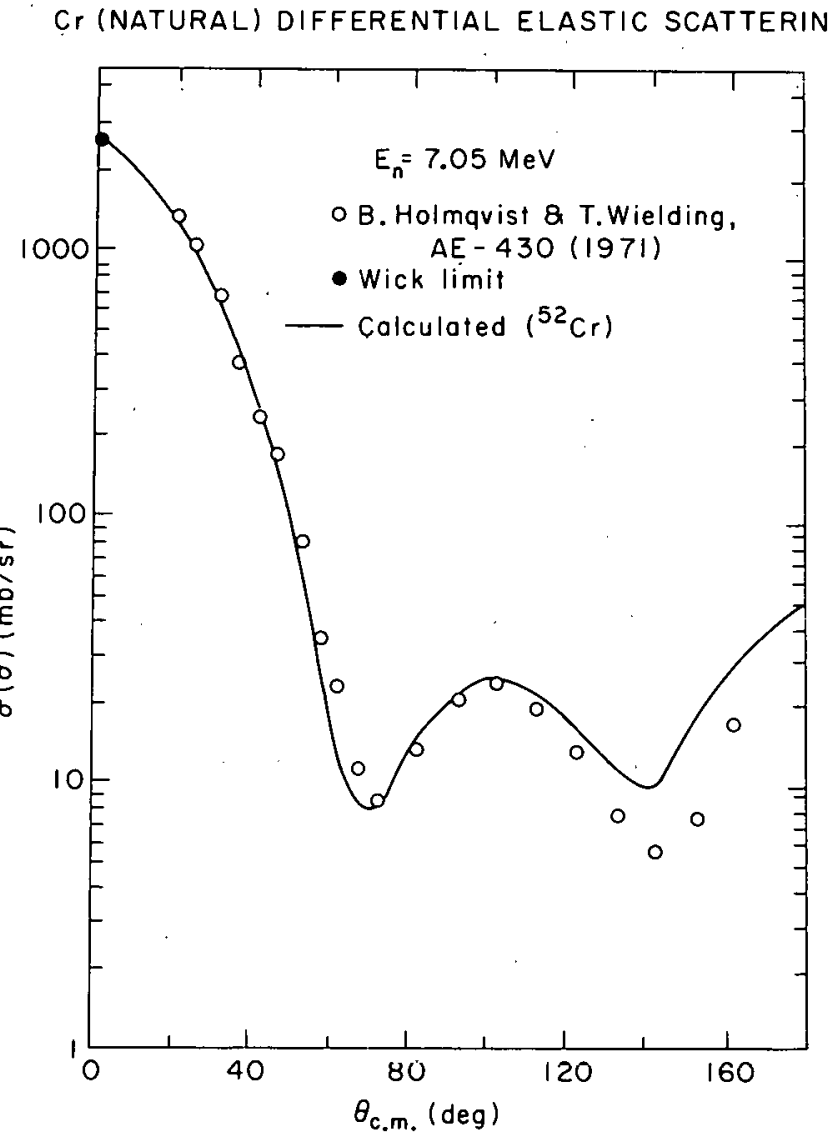

Figure 28.

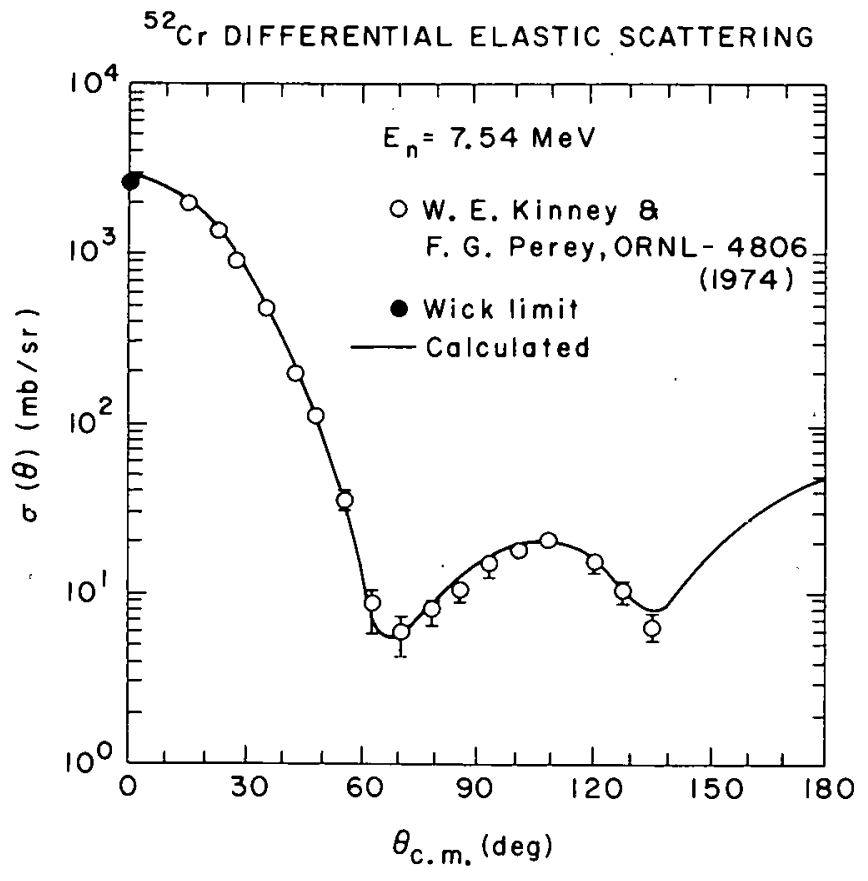

Figure 29. 
Cr (NATURAL) DIFFERENTIAL ELASTIC SCATTERING

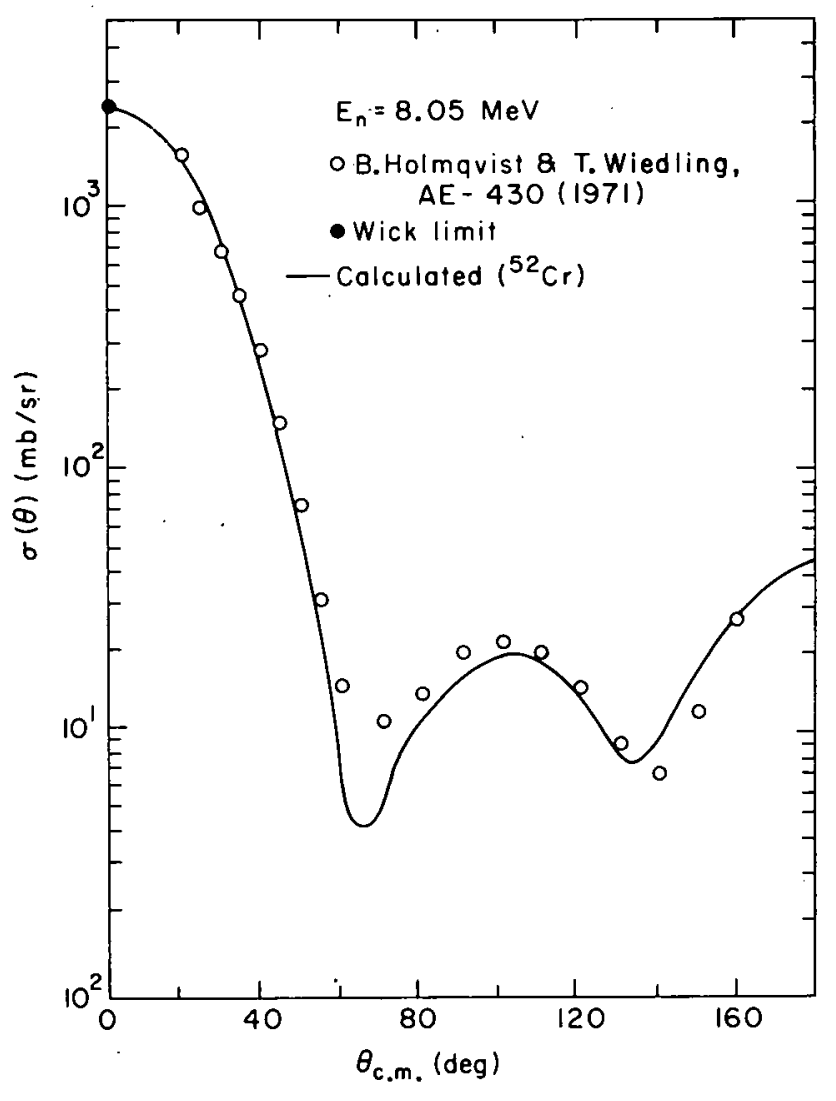

Figure 30.

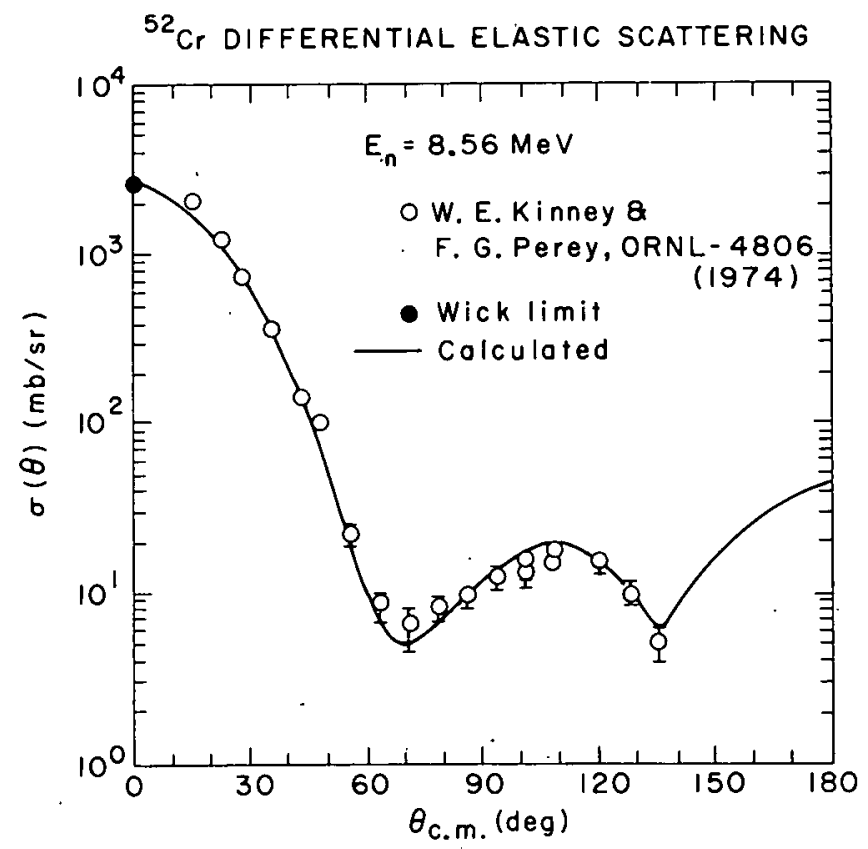

Figure 31. 
Cr (NATURAL) DIFFERENTIAL ELASTIC SCATTERING

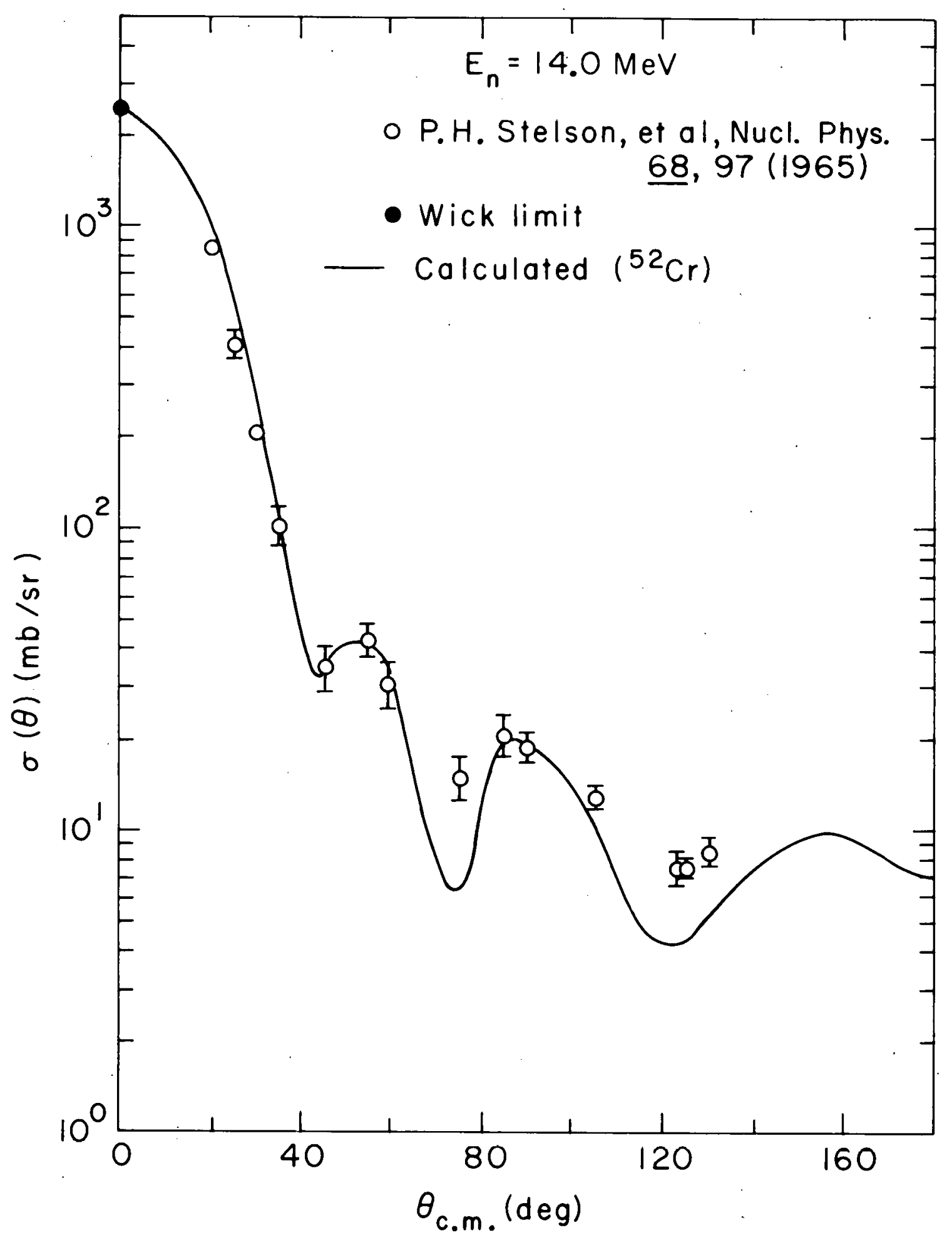

Figure 32 . 


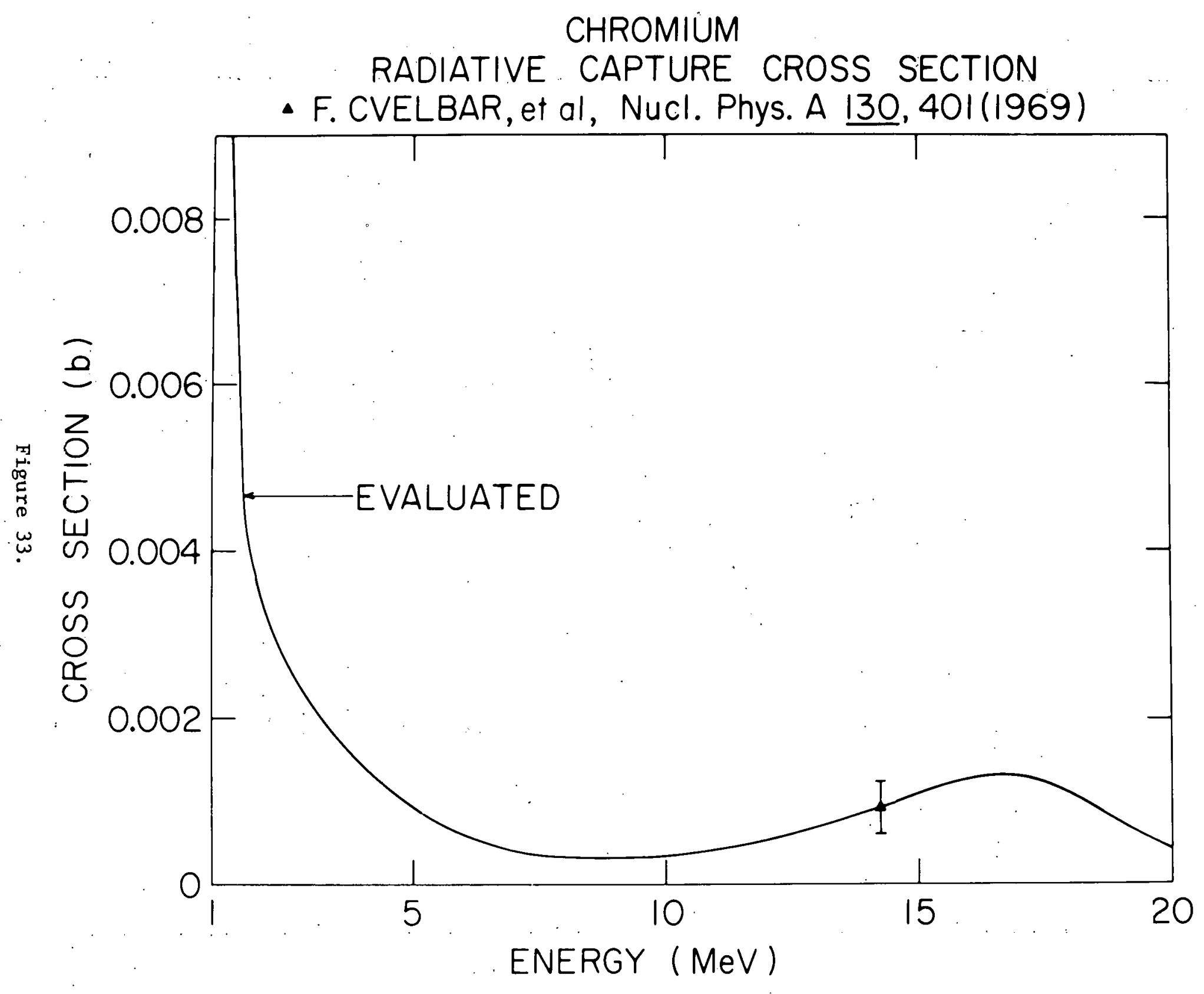




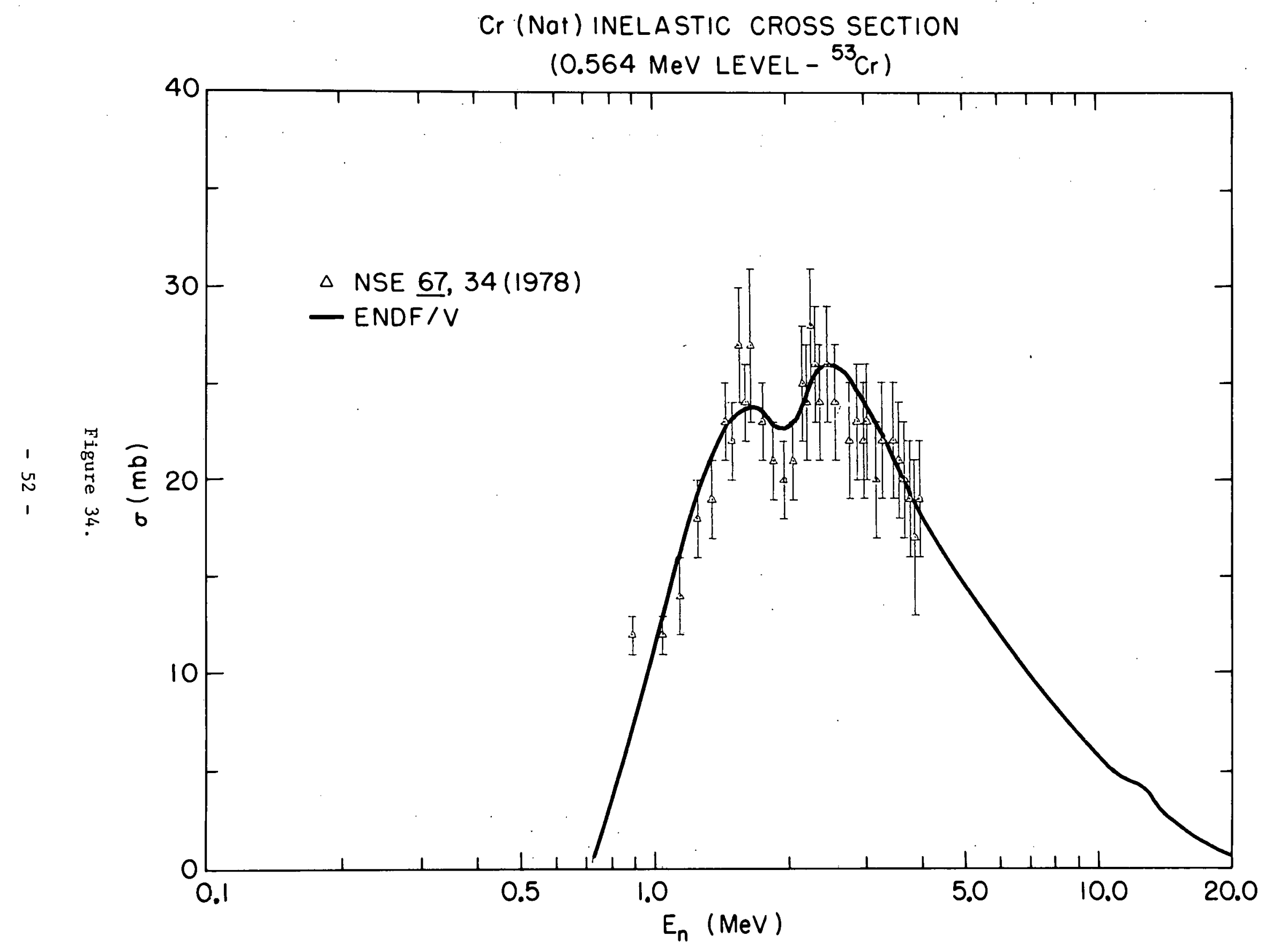




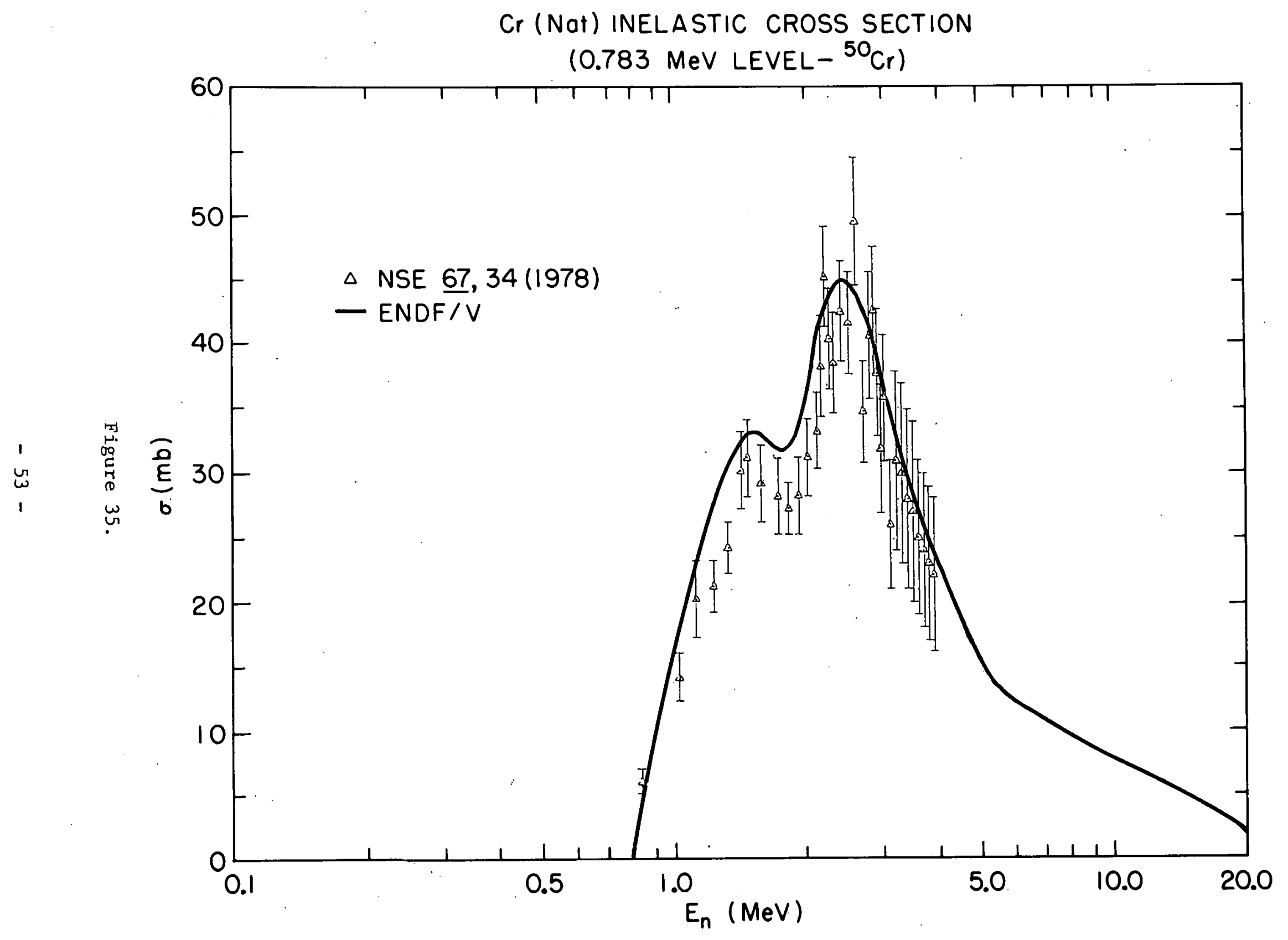


$\mathrm{Cr}$ (Nat) INELASTIC CROSS SECTION ( $0.8348 \mathrm{MeV}$. LEVEL $-{ }^{54} \mathrm{Cr}$ )

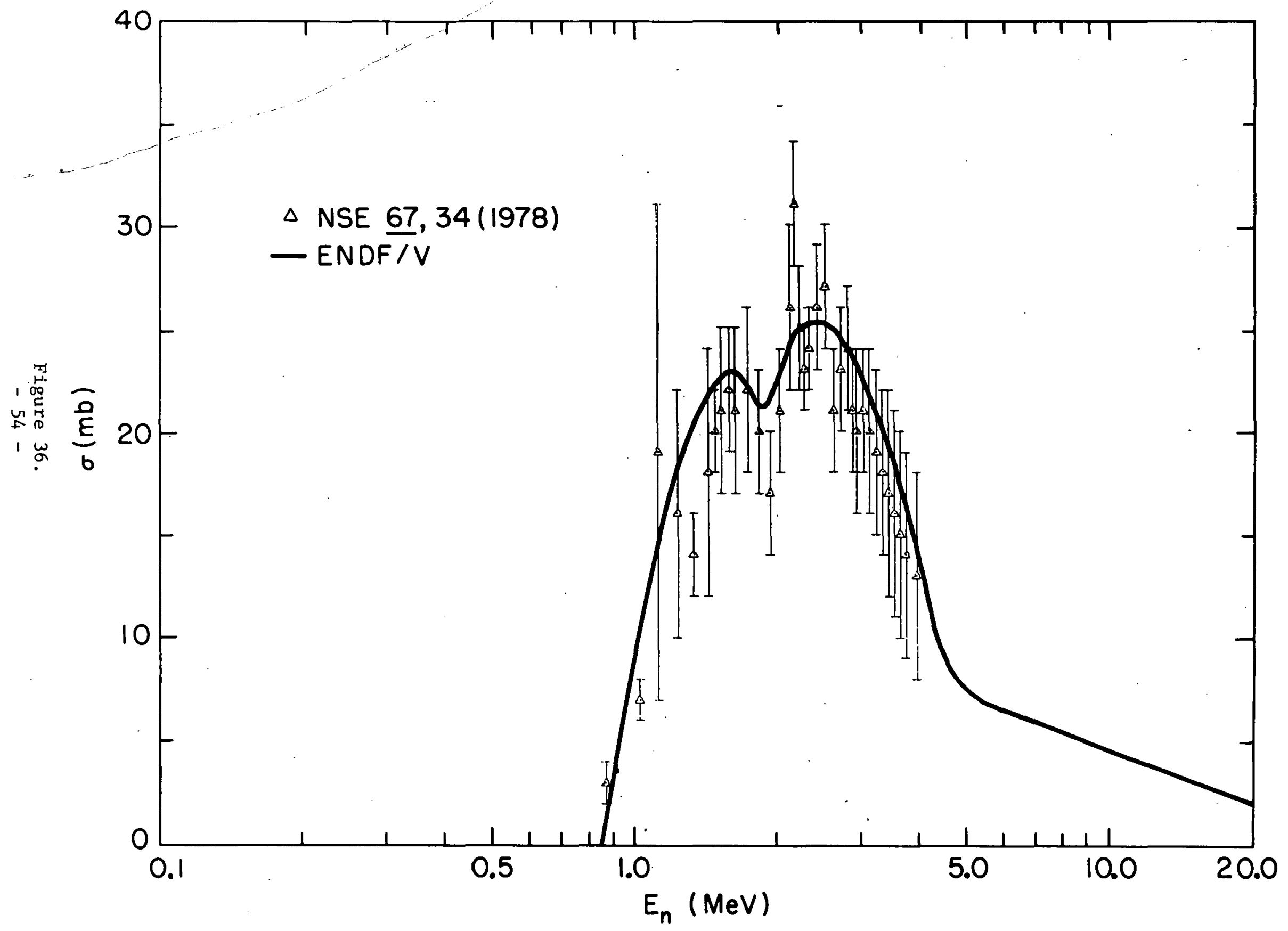




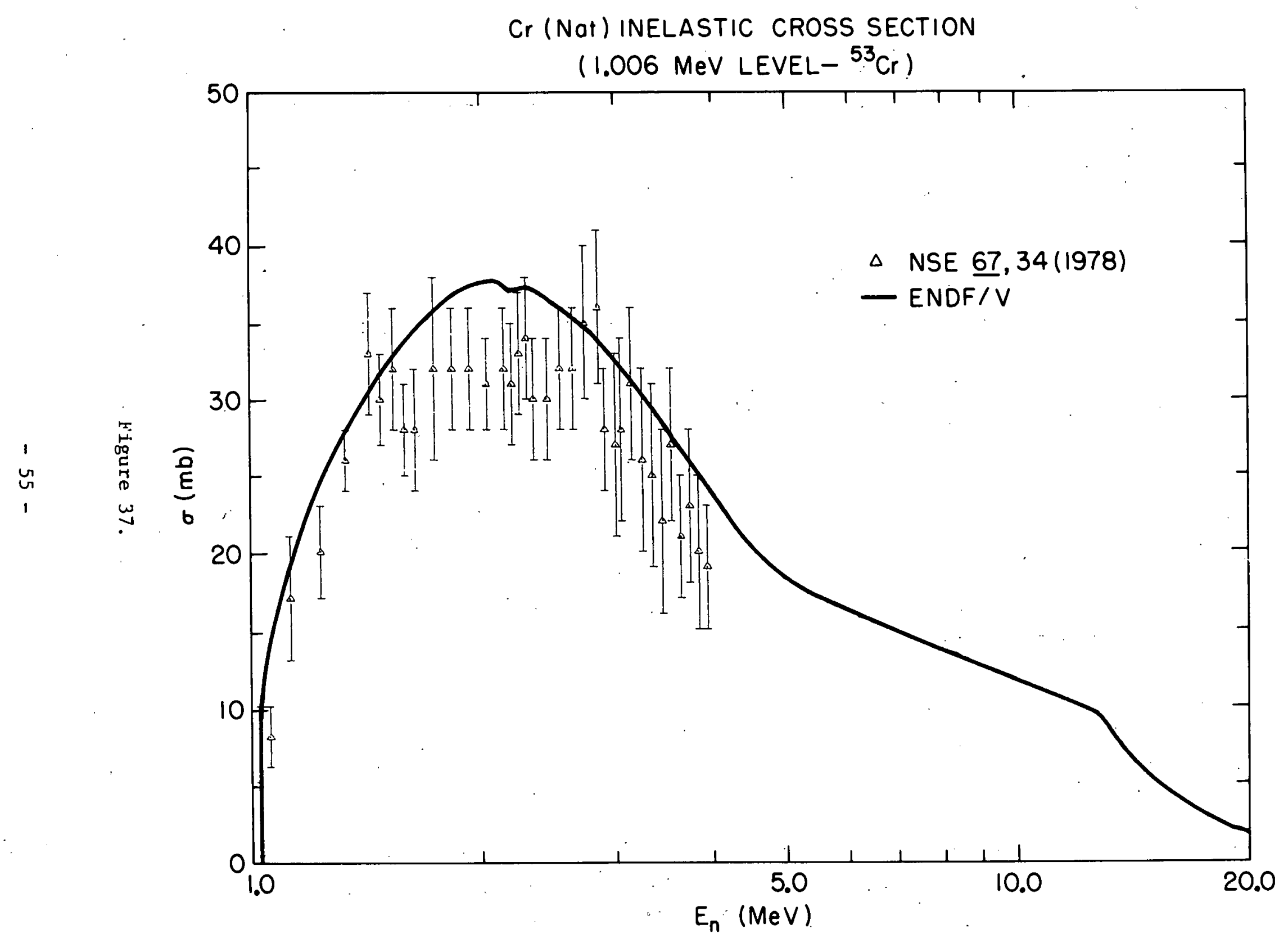




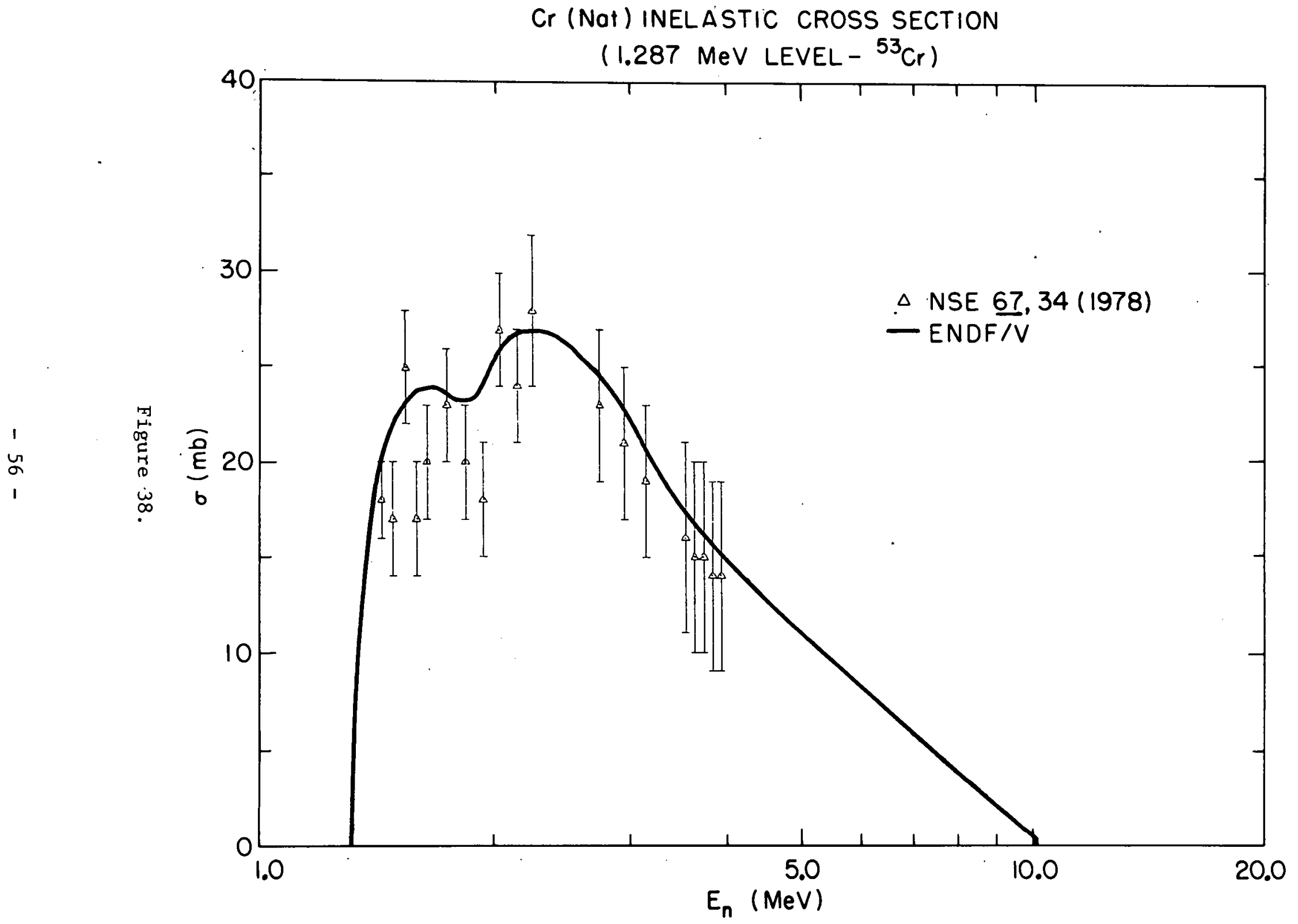




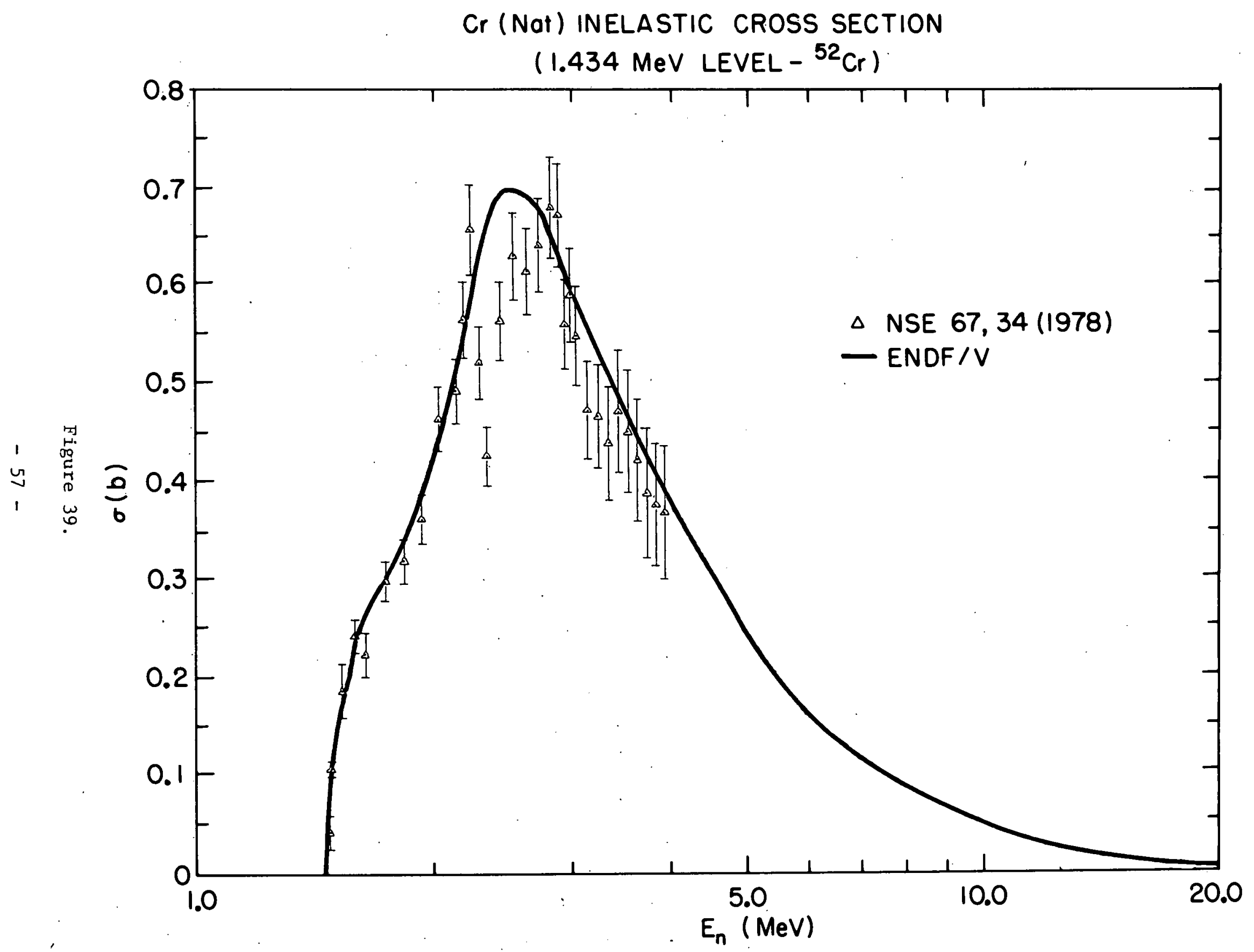




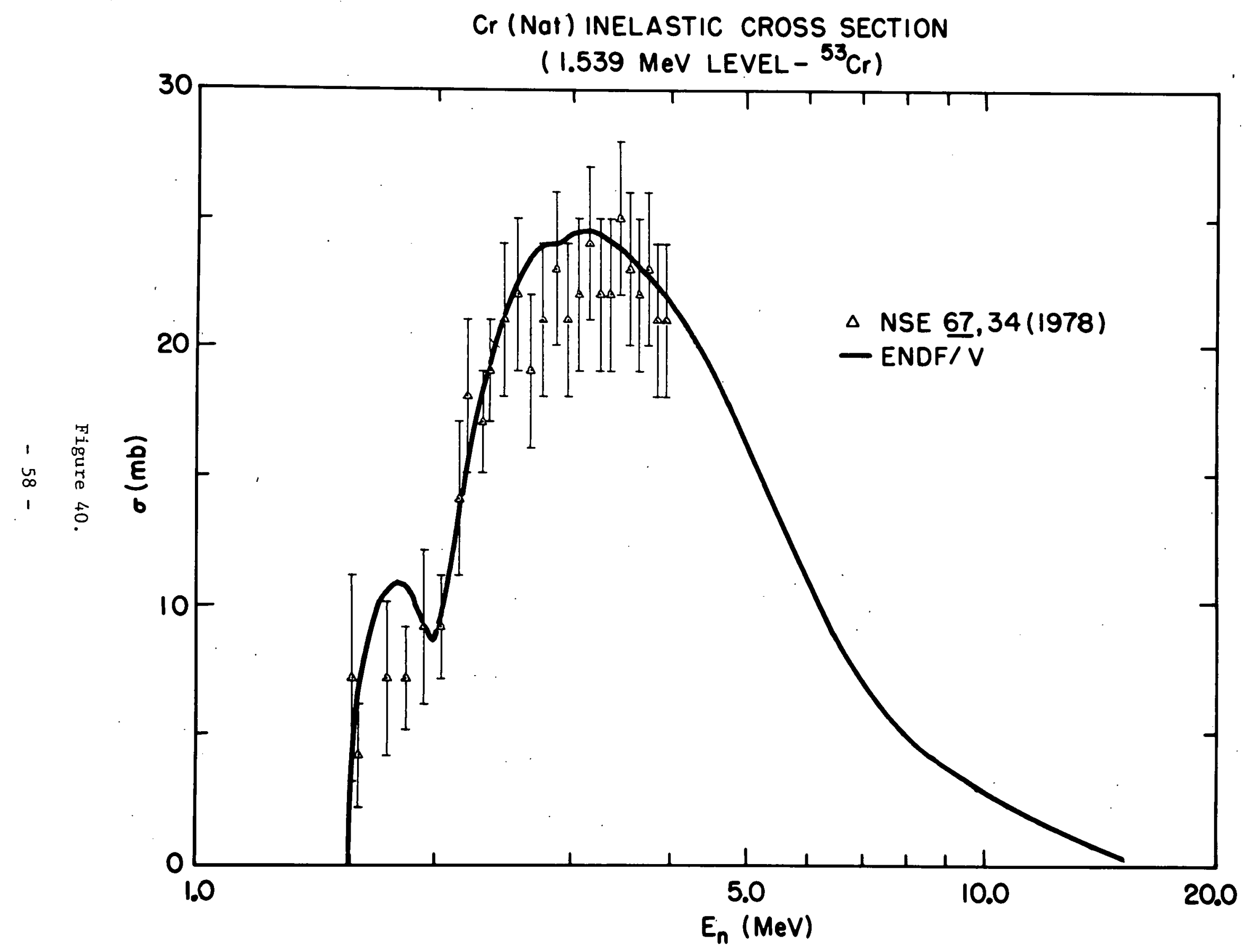




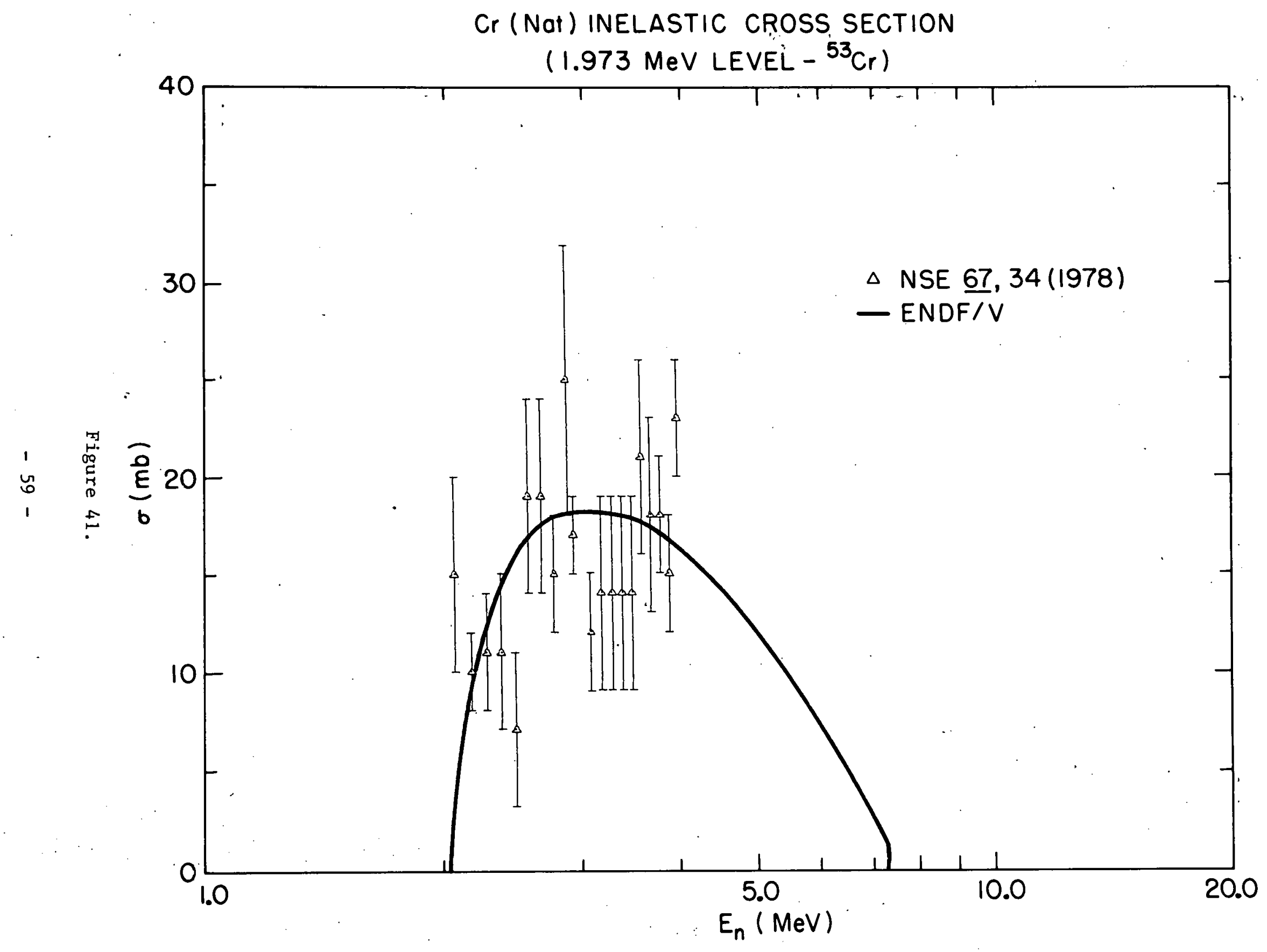




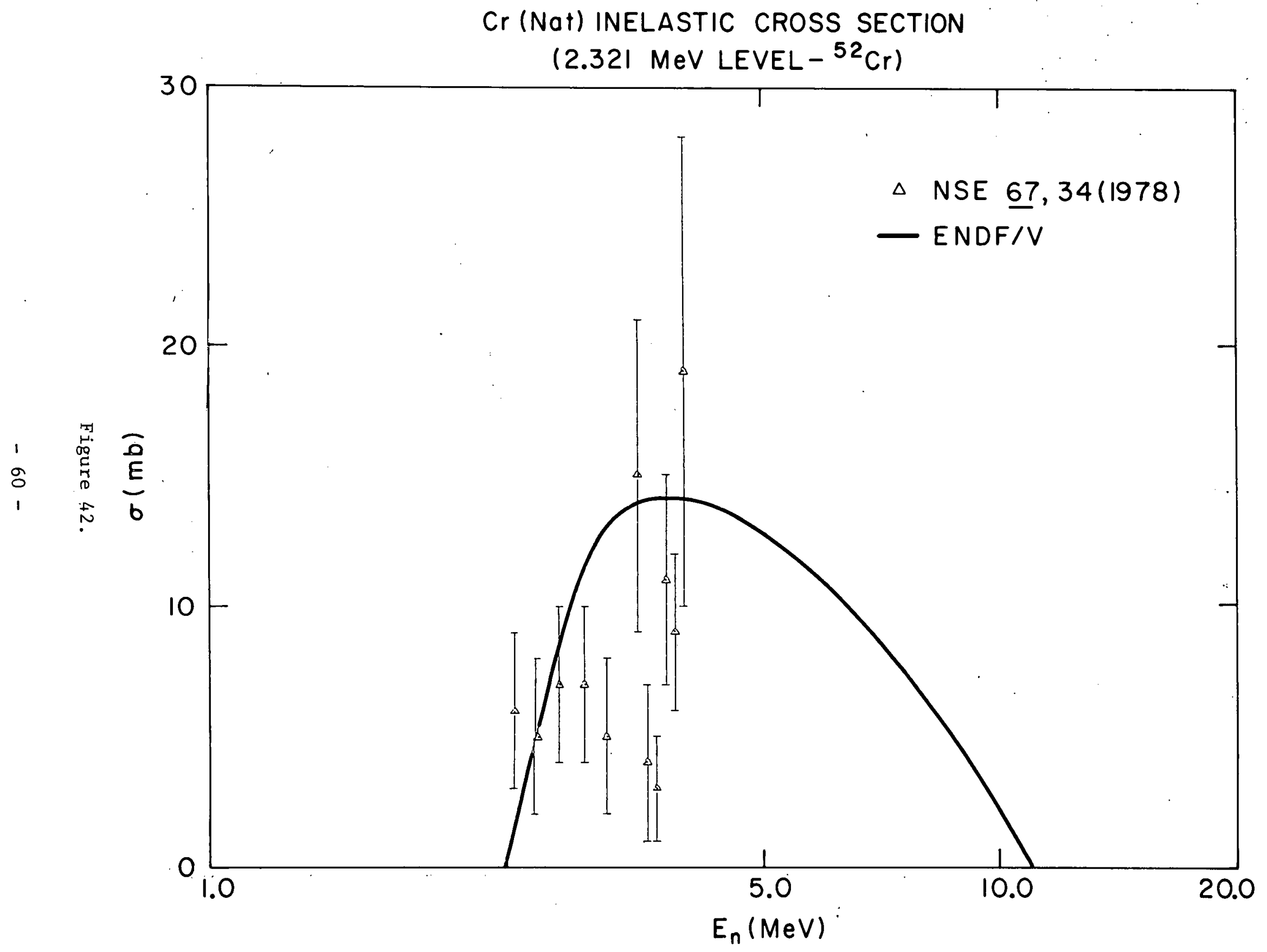




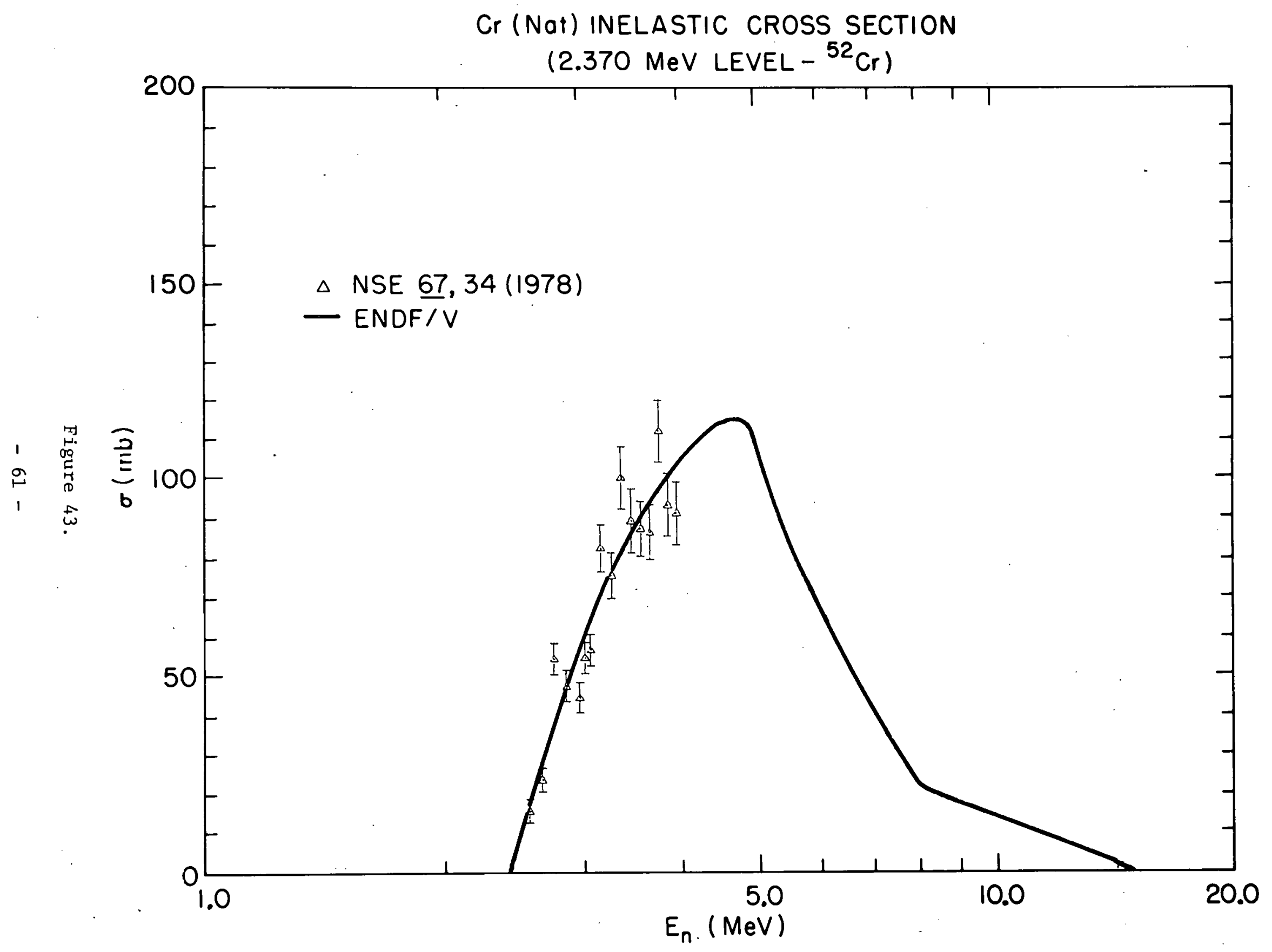




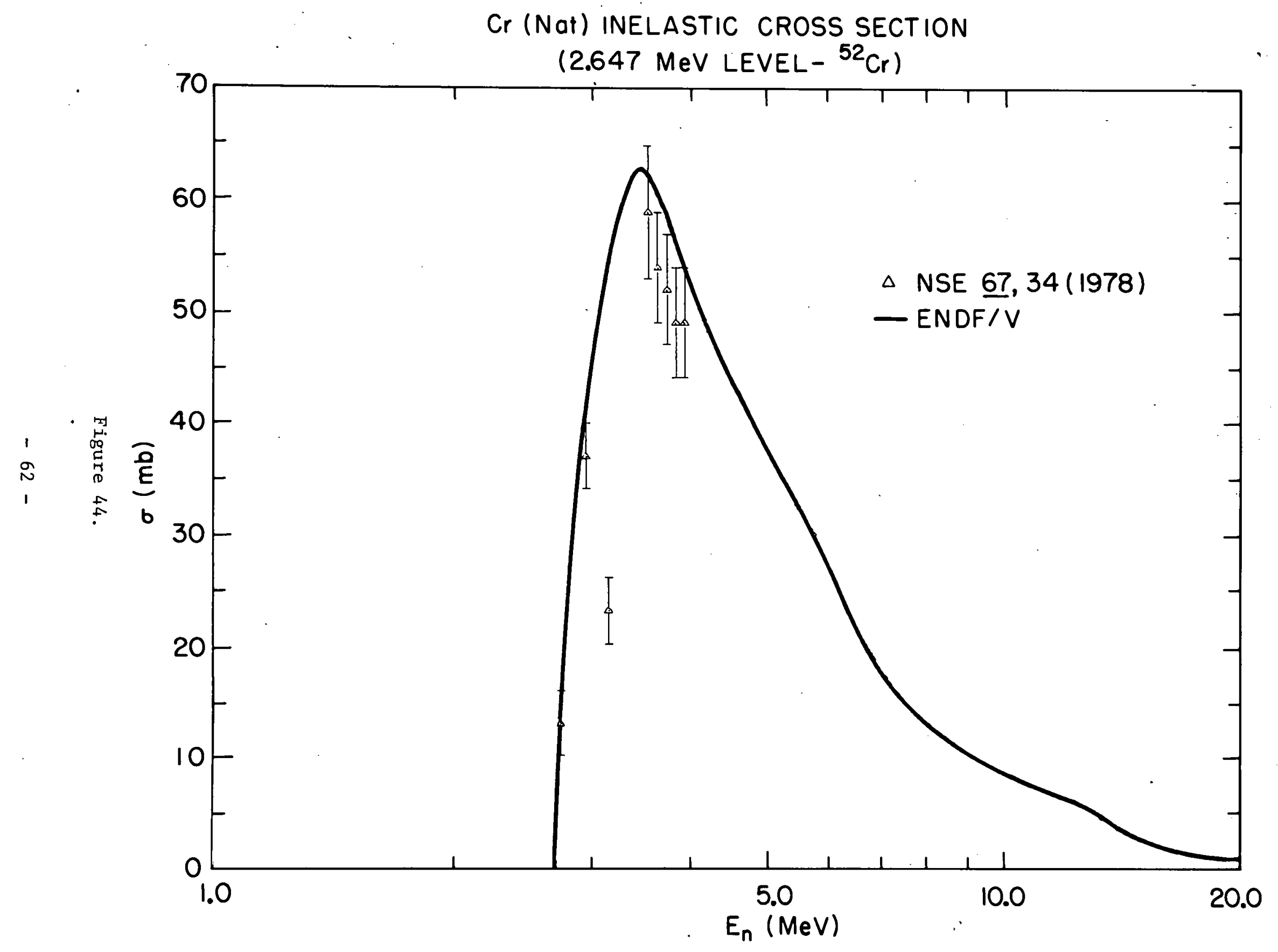




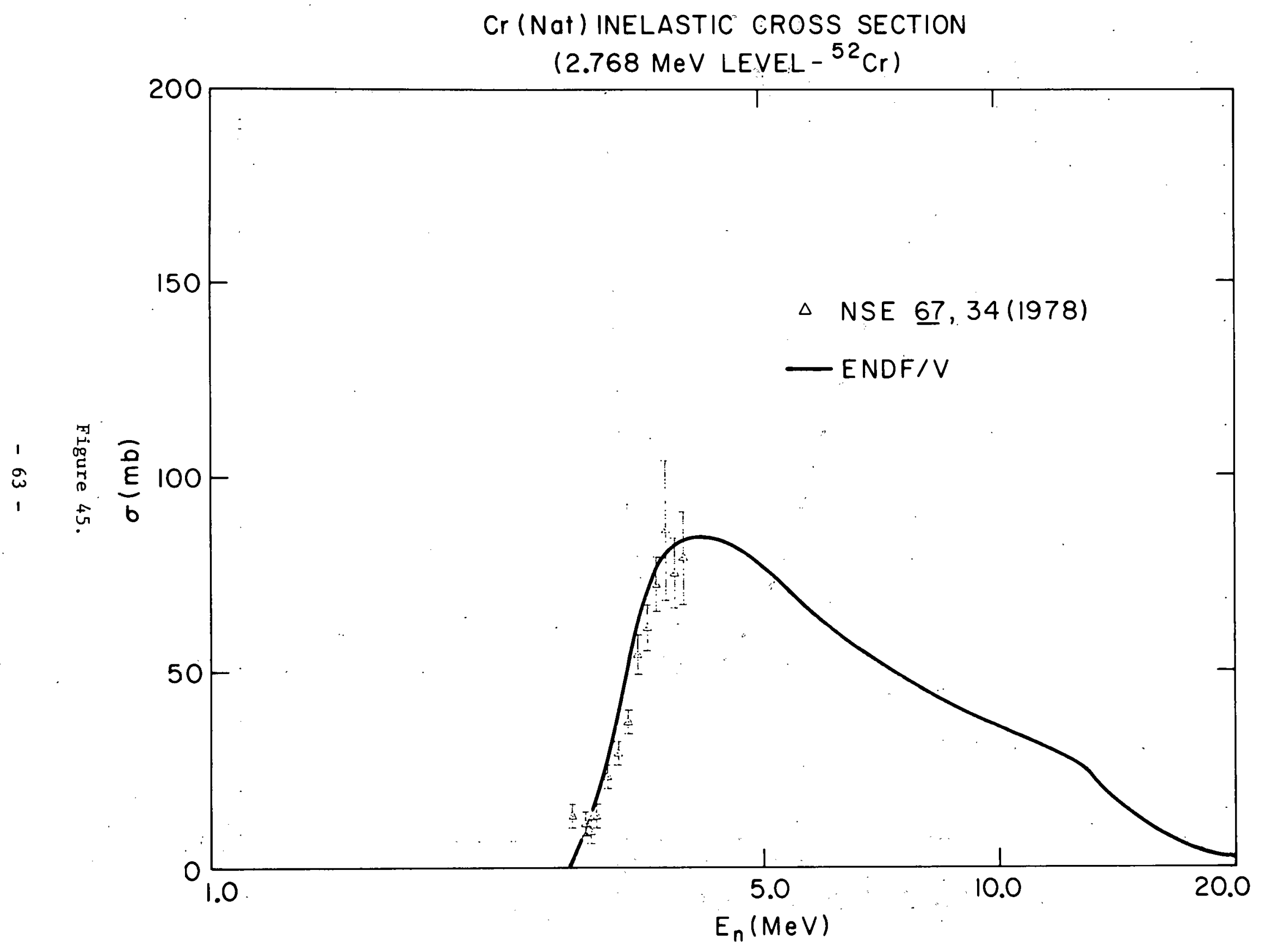




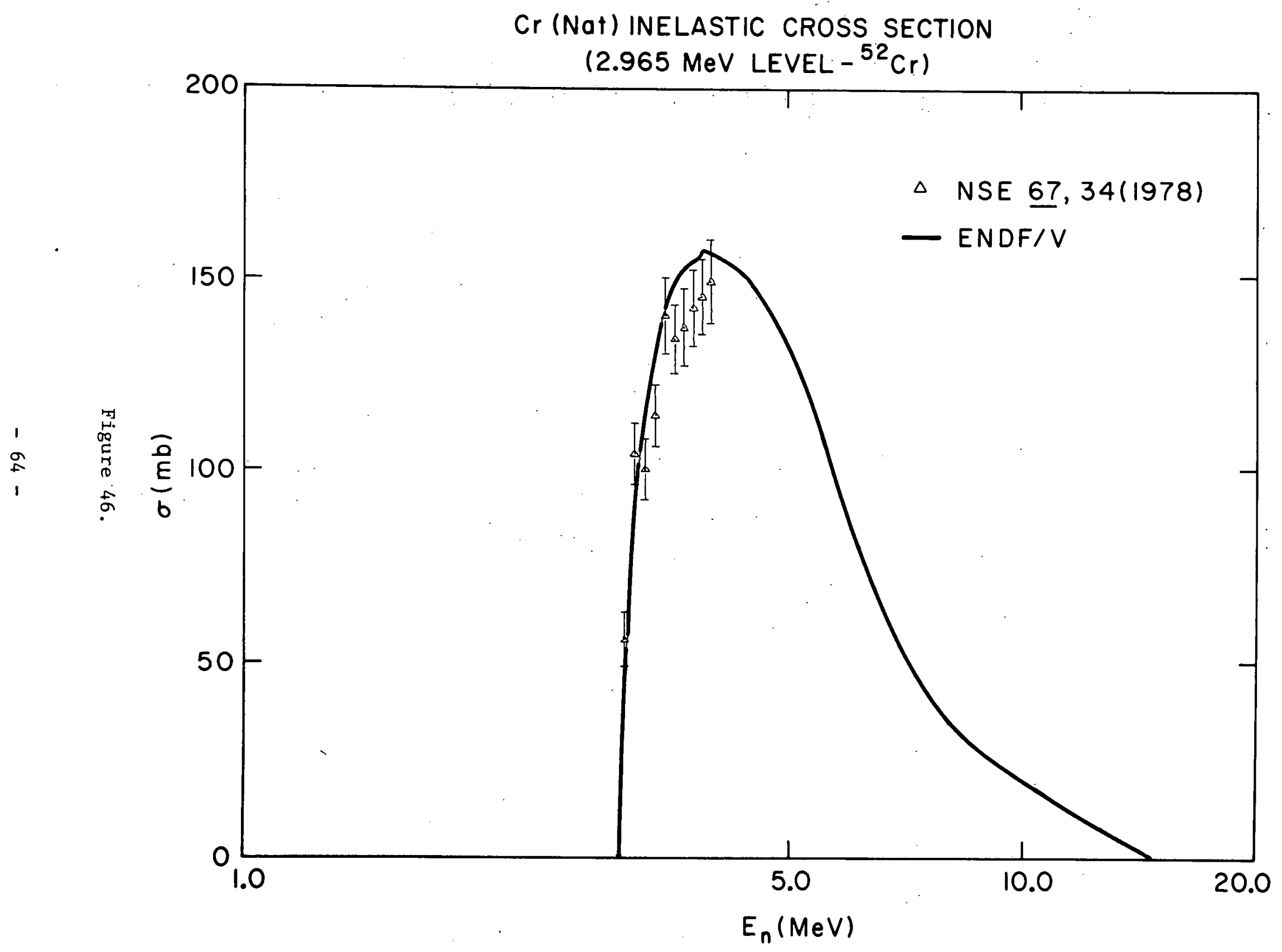


$\mathrm{Cr}$ (Nat) INELASTIC CROSS SECTION

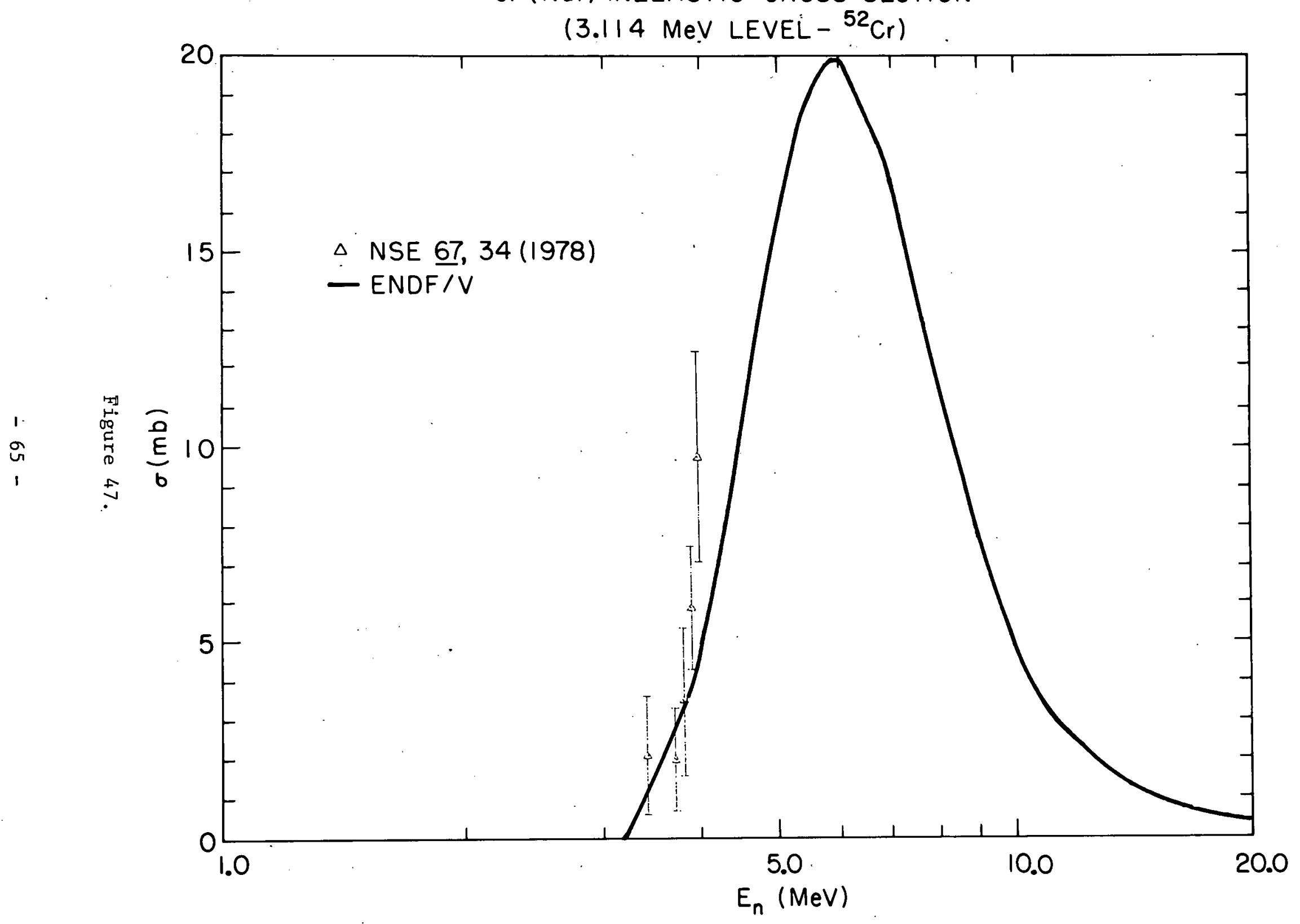




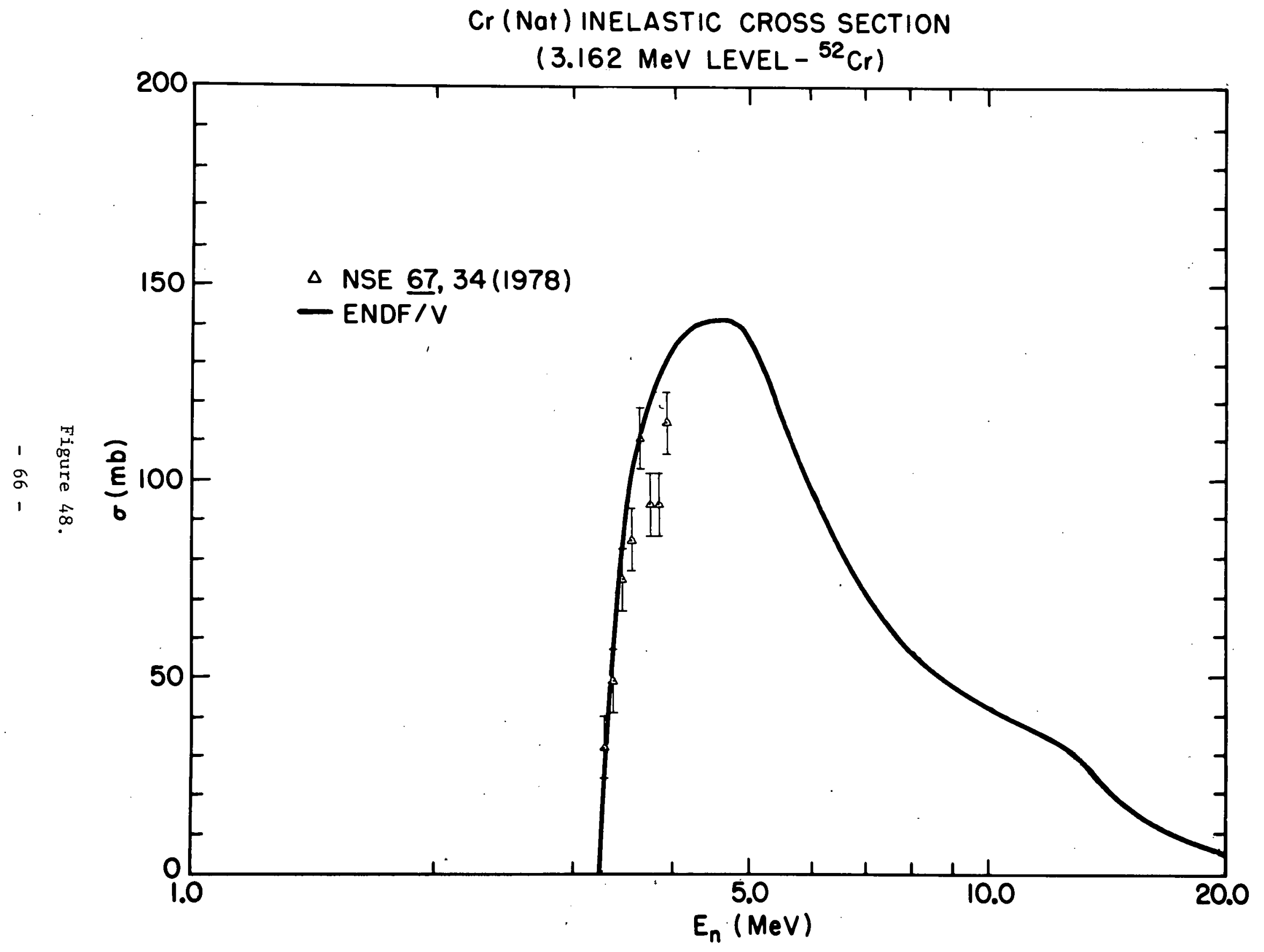




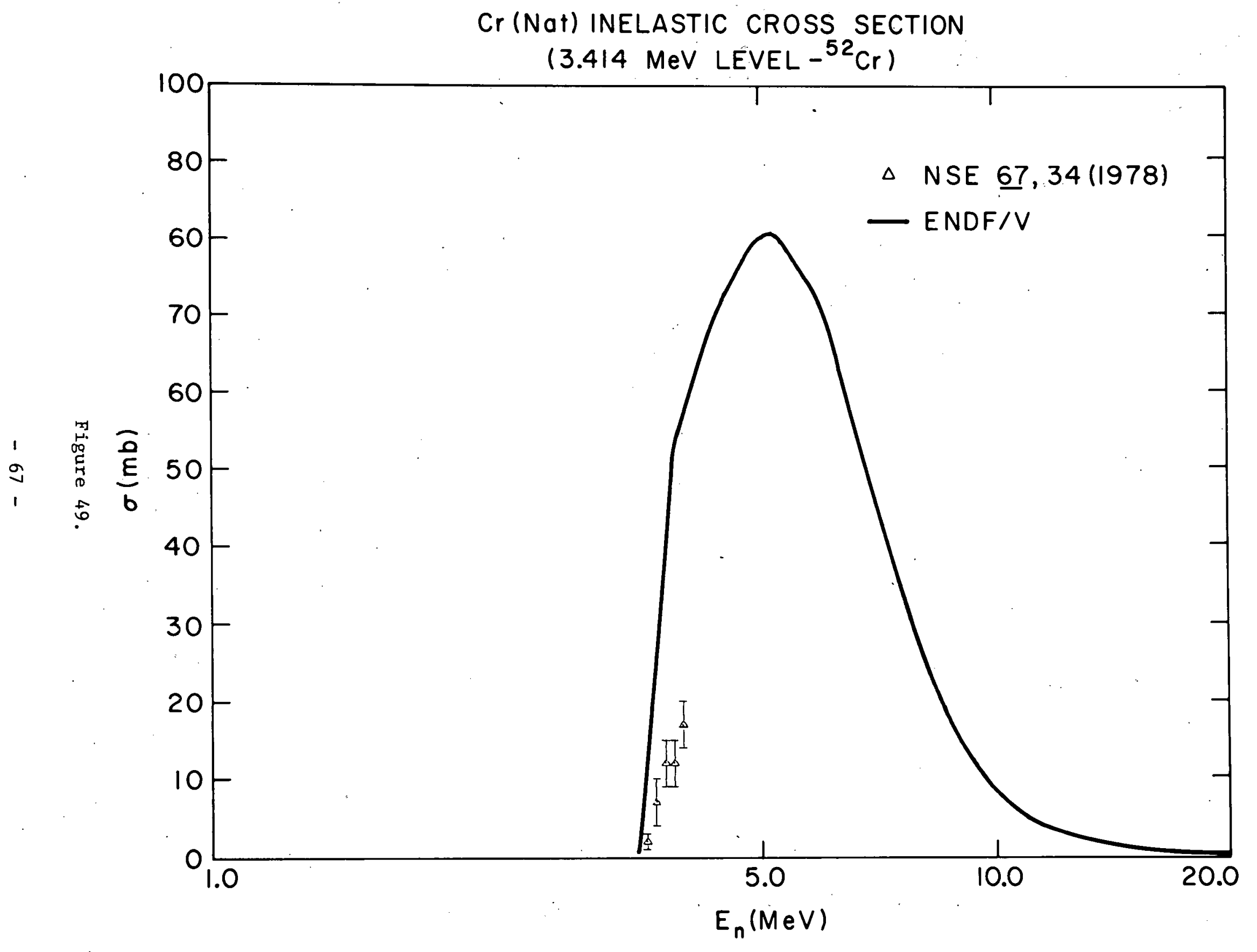




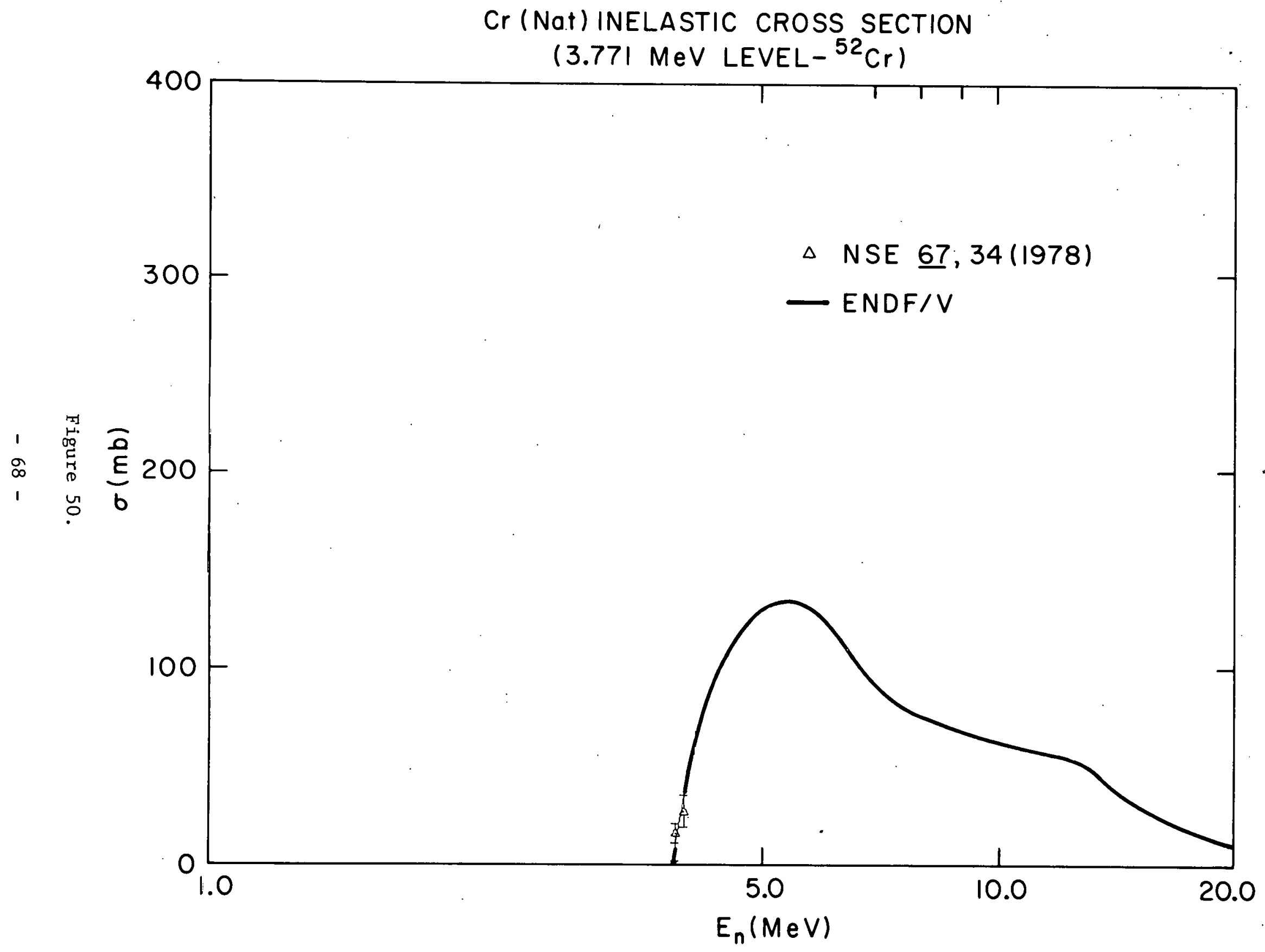


TOTAL NEUTRON INELASTIC CROSS SECTION OF $\mathrm{Cr}$ (Nat)

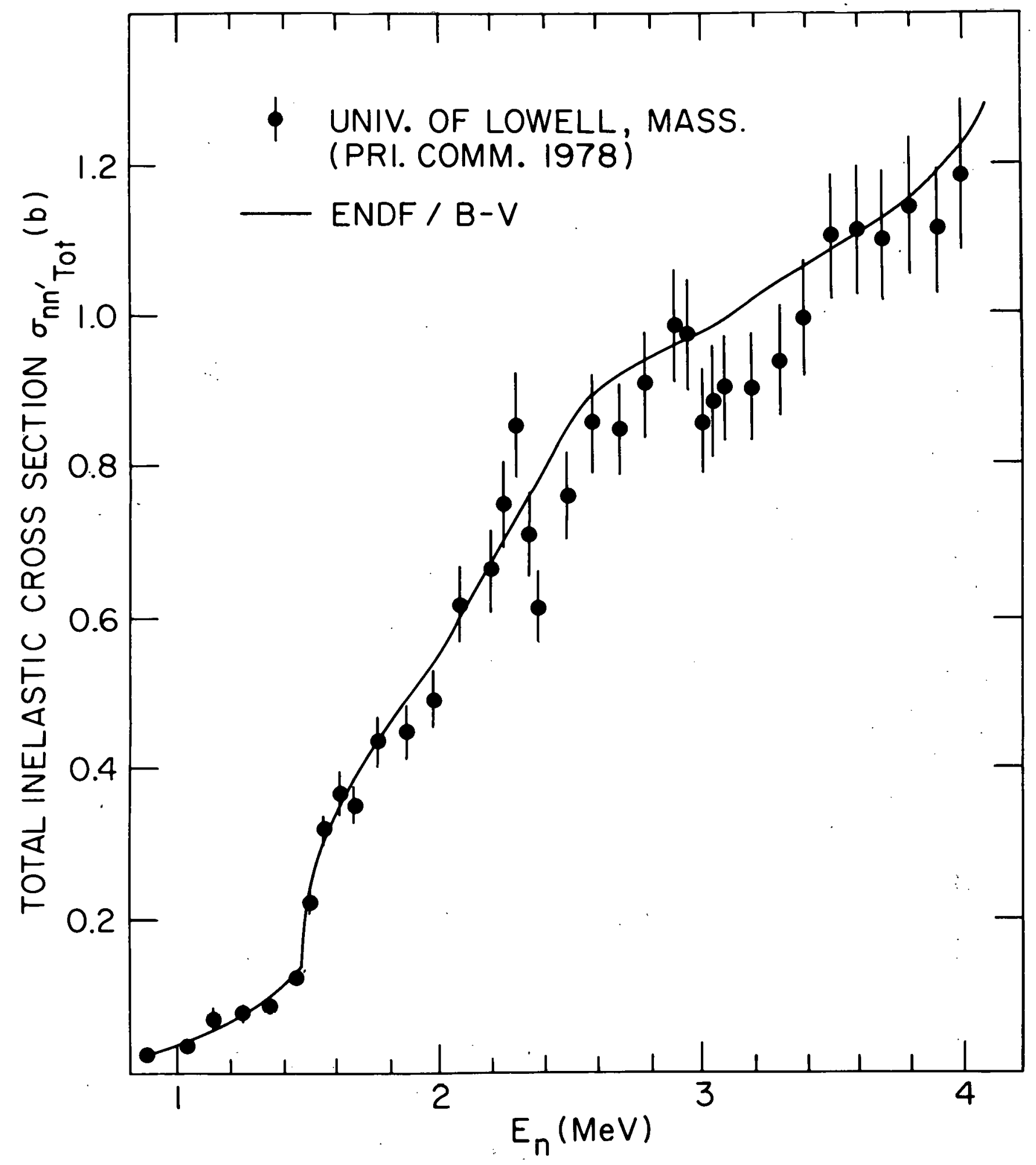

Figure 51. 


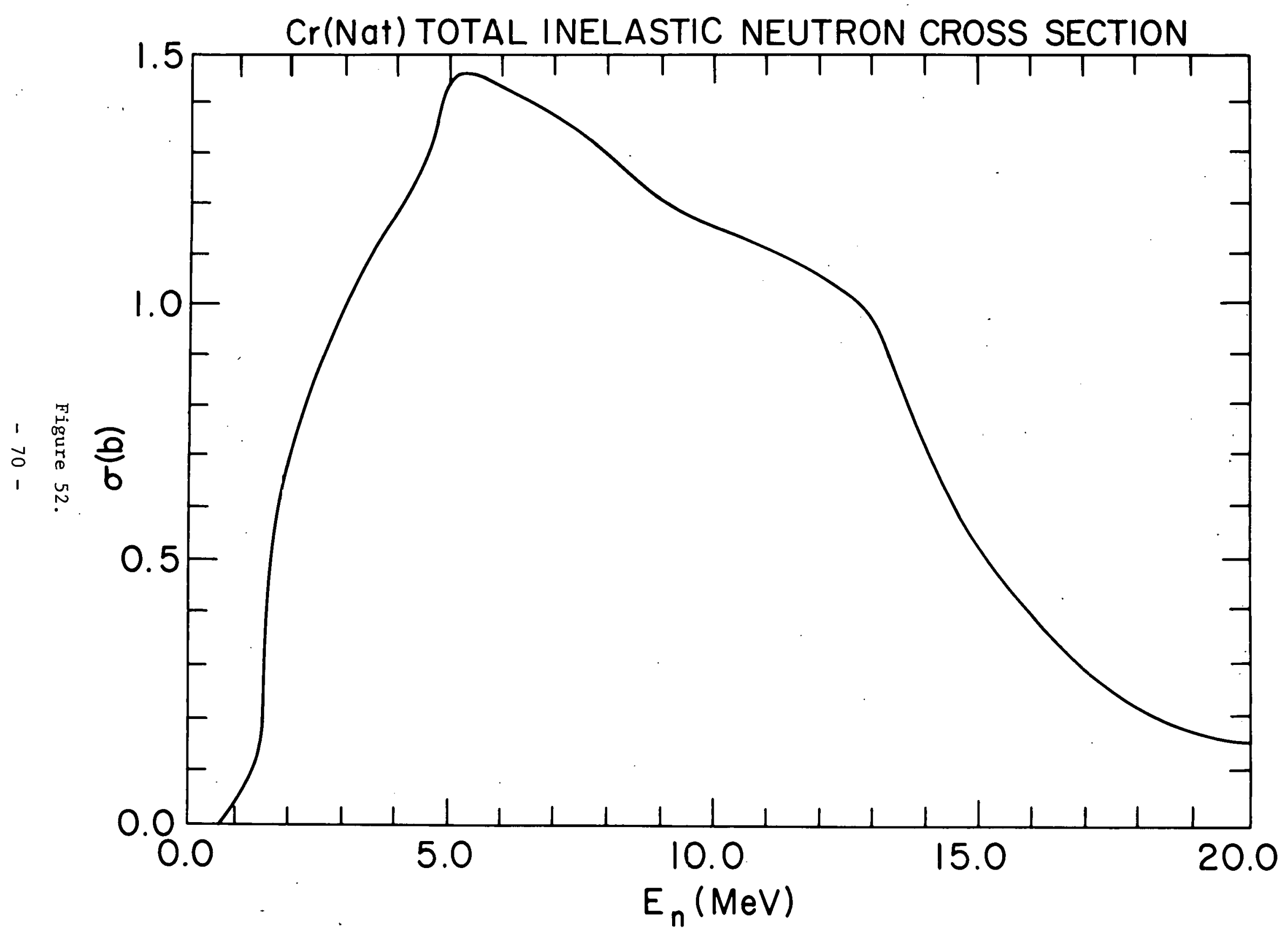




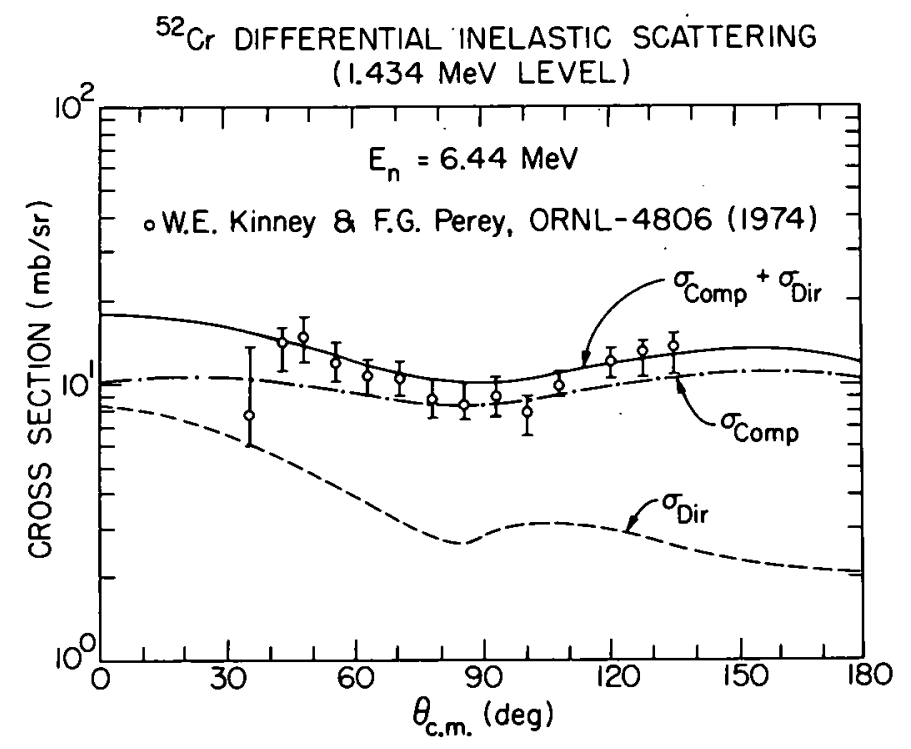

Figure 53.

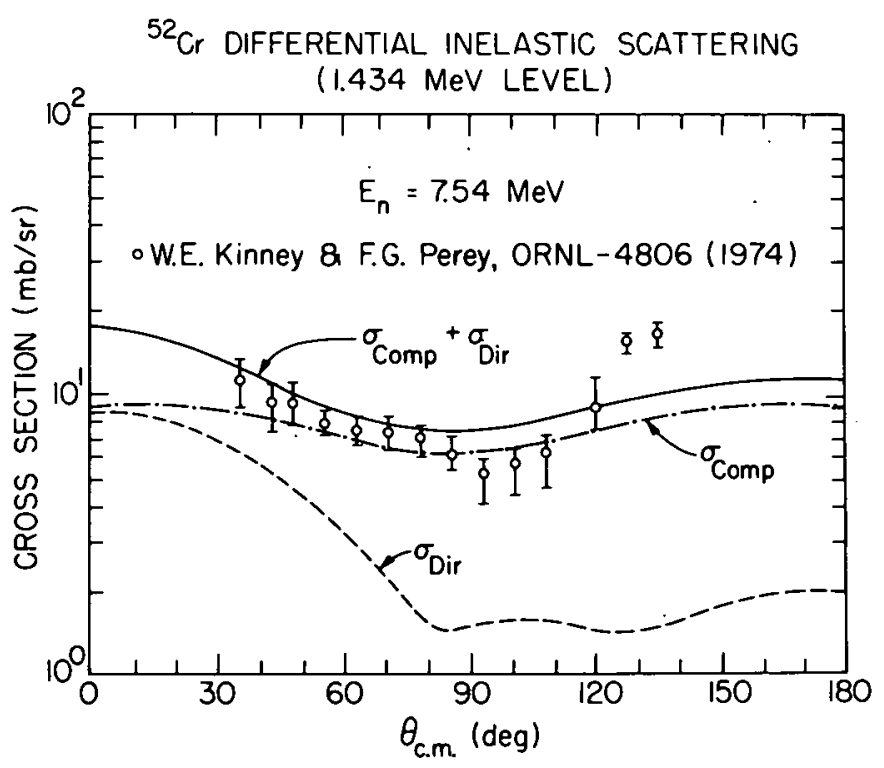

Figure 54. 


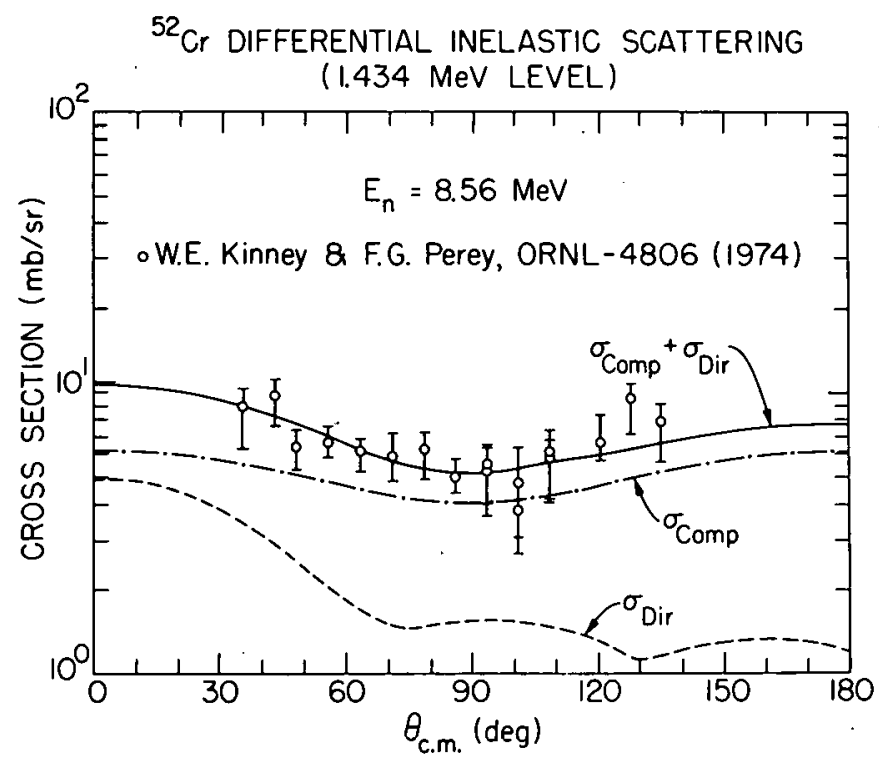

Figure 55.

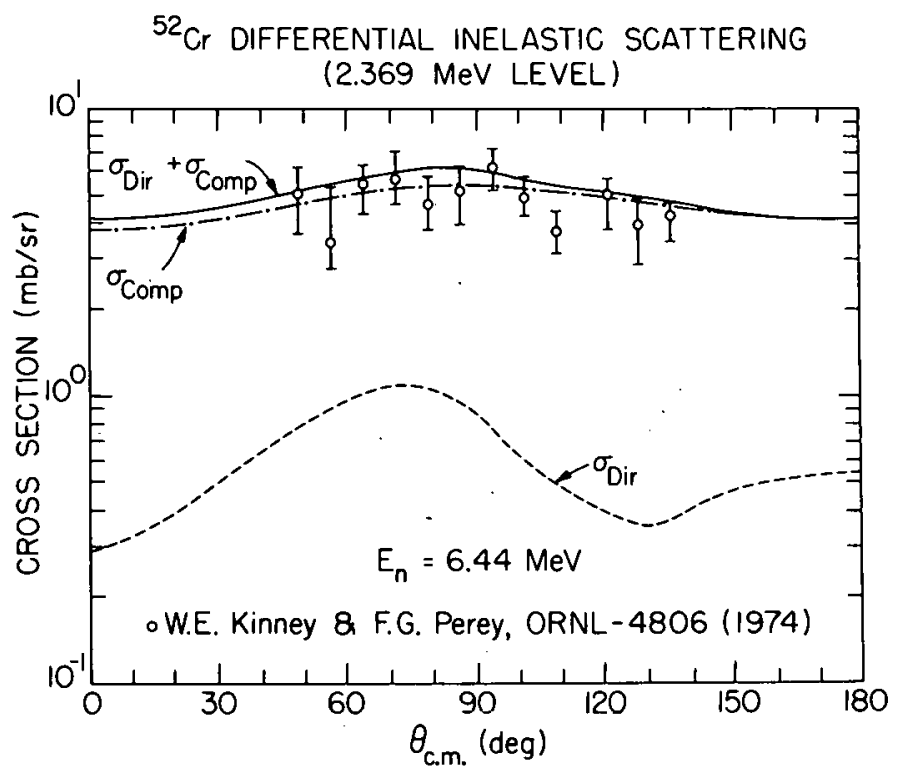

Figure 56. 


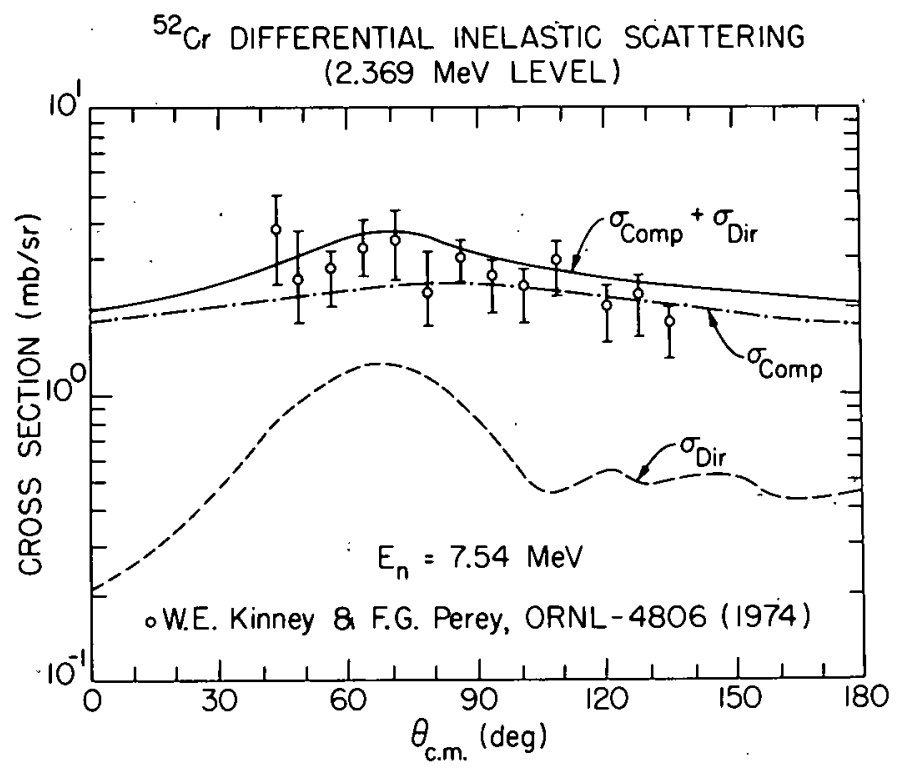

Figure 57.

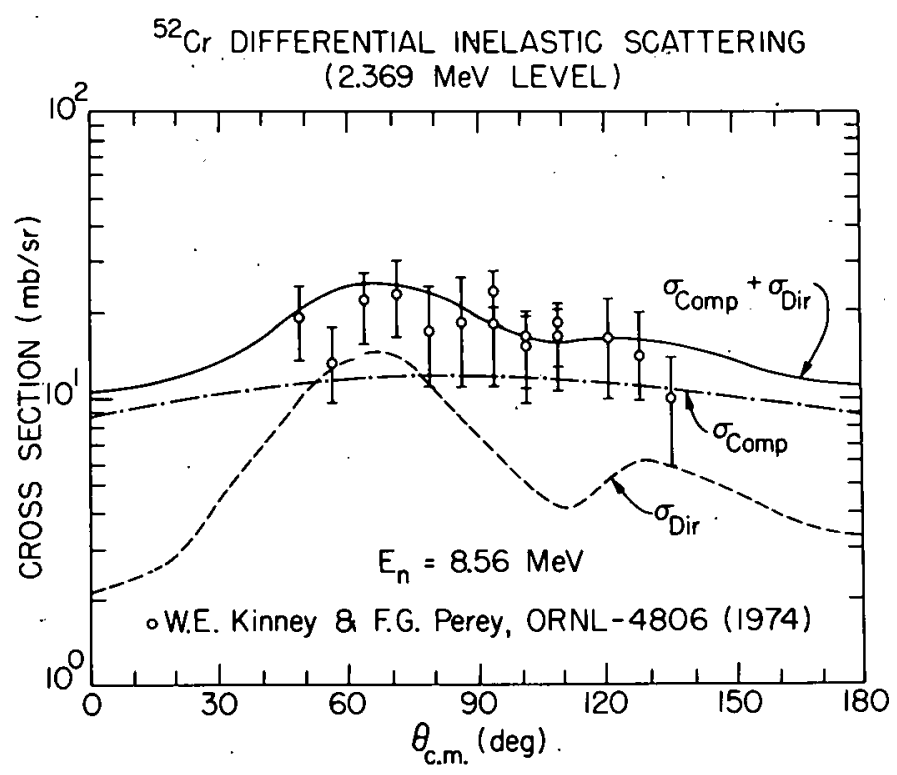

Figure 58. 


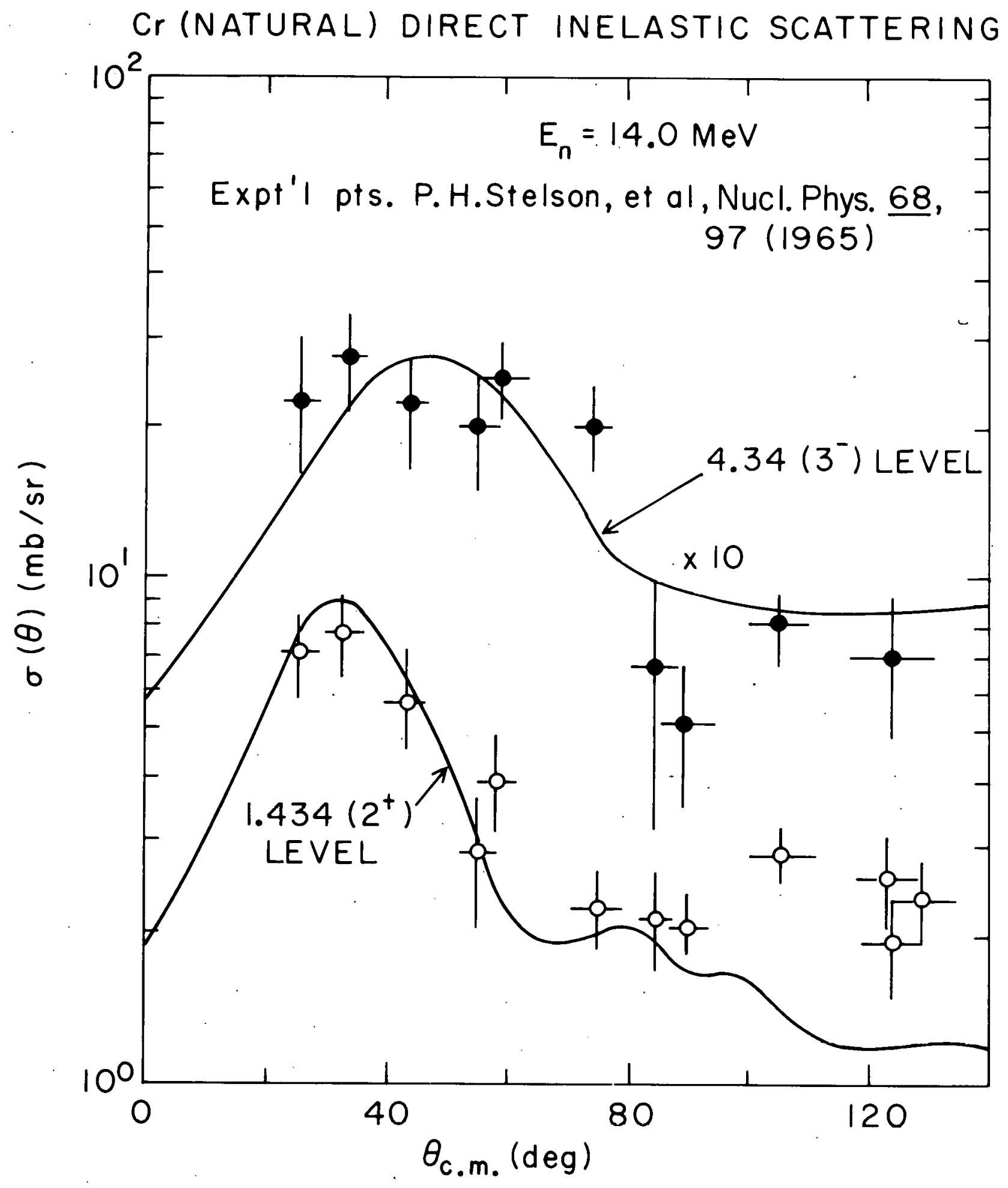

Figure 59. 


\section{REACTION CHAIN FOR ${ }^{54} \mathrm{Cr}(n, 3 n)$}

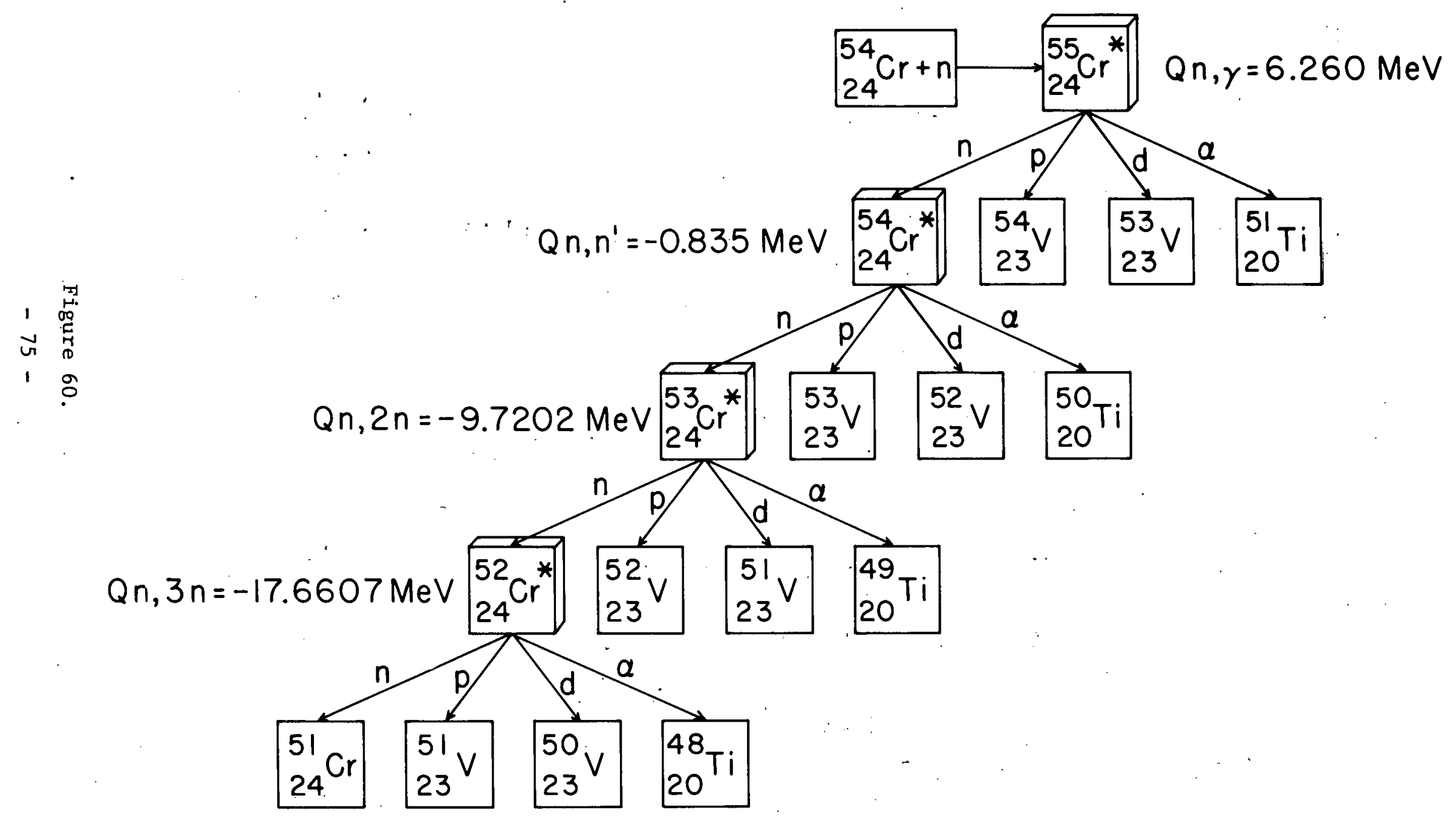




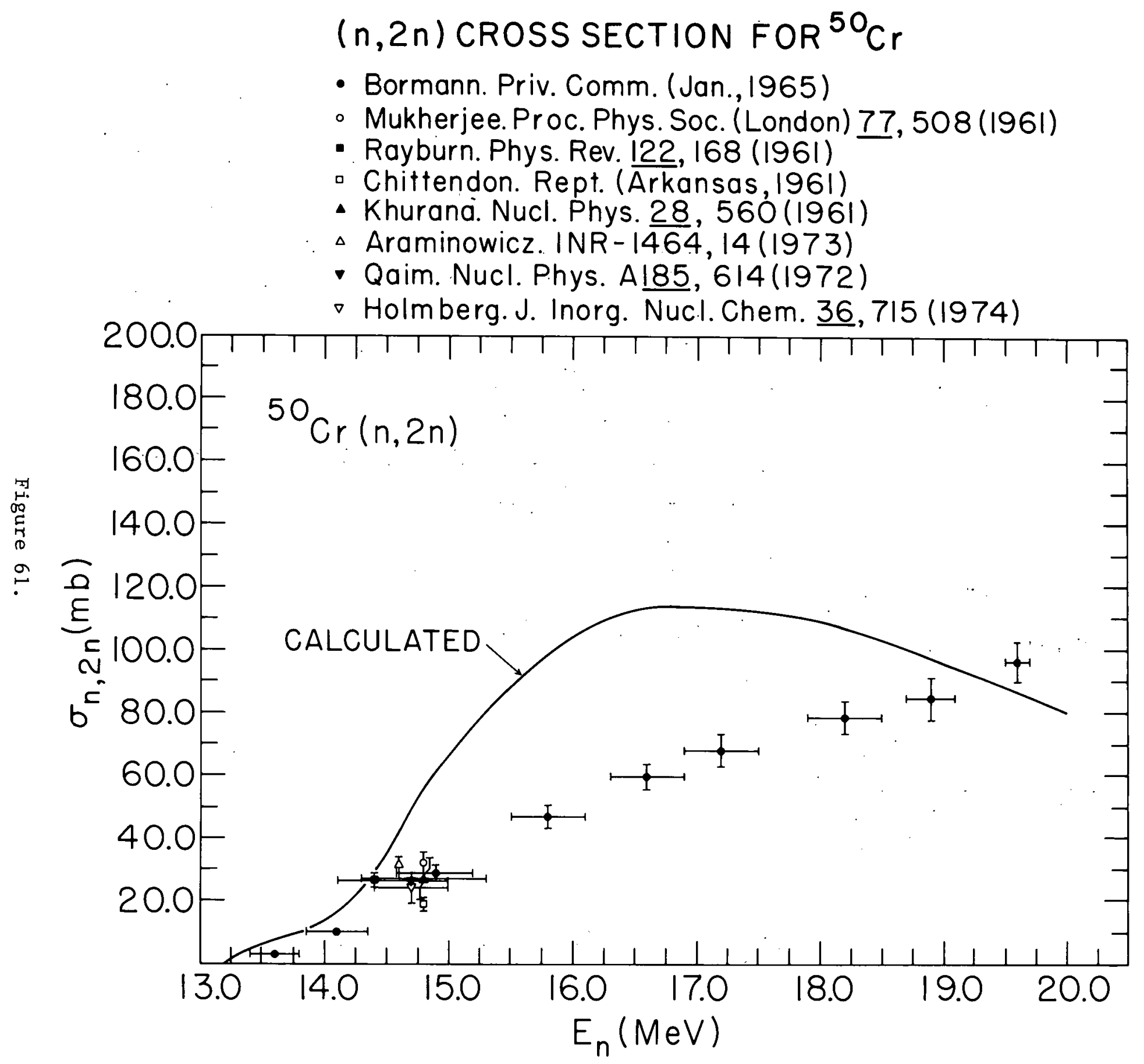


$(n, 2 n)$ CROSS SECTION FOR ${ }^{52} \mathrm{Cr}$

- Bormann. EANDC(E)-76, 5 I (1967). See also Nucl. Phys.

All5, 309 (1968)

- Wenush. Oesterr. Akad. Wiss., Math and Naturw.

Anzeiger 99, I (1962)

- Araminowicz. INR-1464, 14 (1973)

- Maslov. YK-9,50

- Qaim. Nucl. Phys. Al85, 614 (1972)

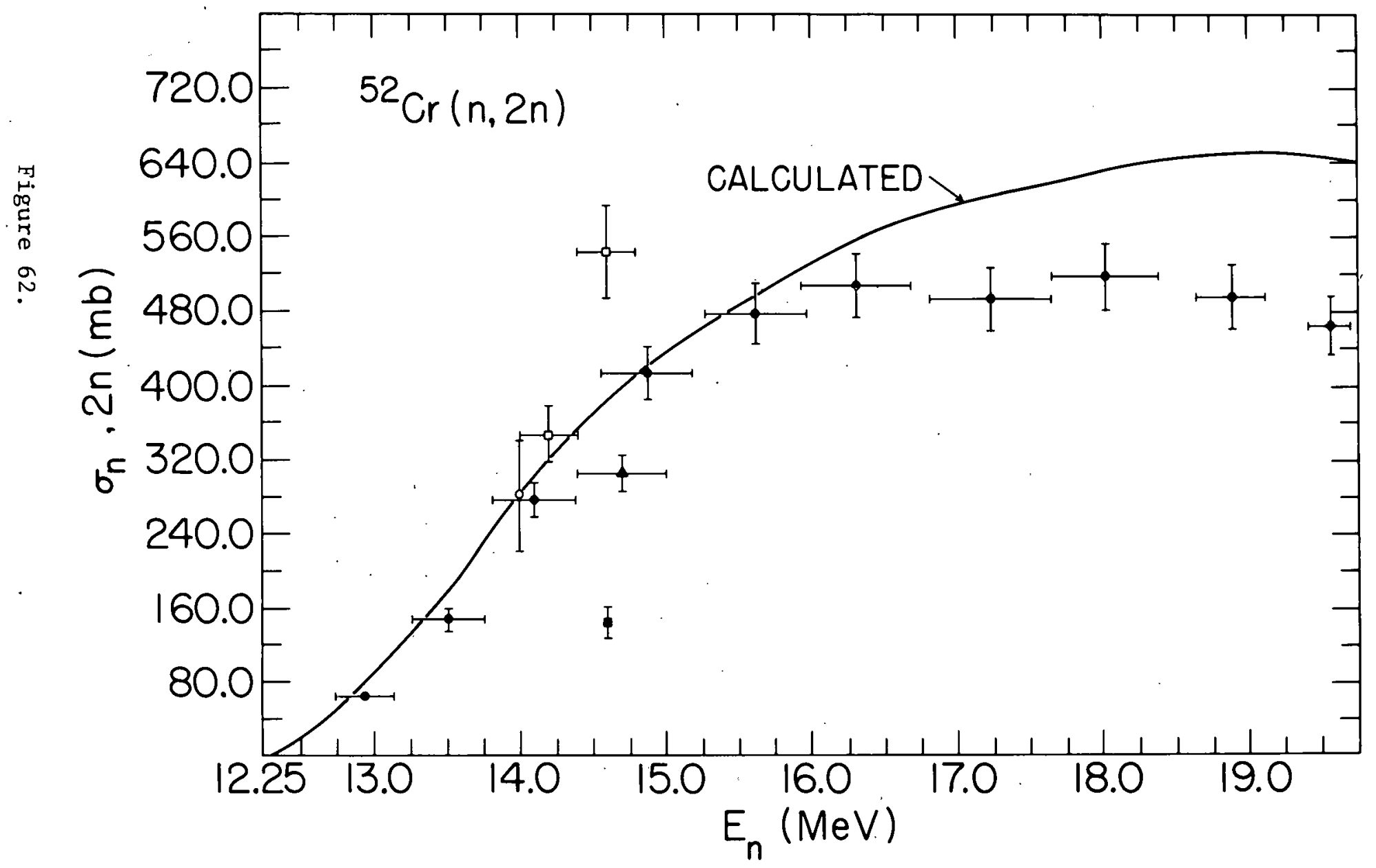


$(n, 2 n)$ CROSS SECTION FOR NATURAL $\mathrm{cr}$.

- Frehaut and Mosinski.

Preprint-Trieste Conf. (Dec., 1975)

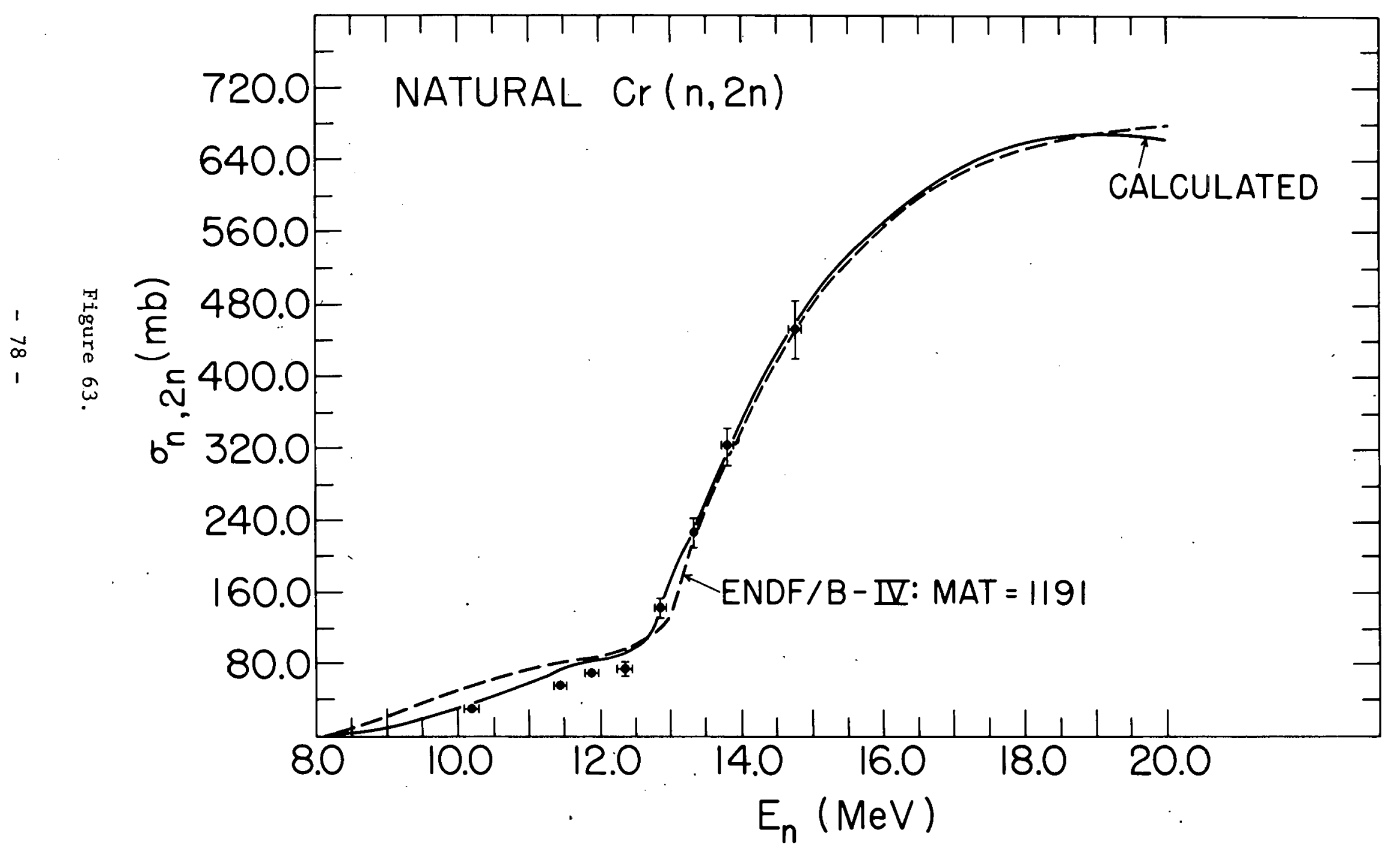




\section{$(n, p)$ CROSS SECTION FOR ${ }^{52} \mathrm{Cr}$}

- Kern. Nucl. Phys. 10, 226 (1959)

- I.G. Clator. Priv. Comm. from T. Clator (1969)

- Paul. Can.J. Phys. 31, 267 (1953)

- Husain. J. Inorg. Nucl. Chem. 29, 2665 (1967)

- Chittenden. Rept. (Arkansas, 1961)

$\triangle$ Allan. Nucl. Phys. 24, 274 (1961)

- Mitra. Nucl. Phys. $\overline{83}, 157$ (1966)

$\checkmark$ Mukherjee. Proc. Phys. Soc. (London) 77, 508 (1961)

$\times$ Dressler. INR-1464, 12 (1973)

- Khuruna. Nucl. Phys 69,153(1965)

- Holmberg. J. Inorg. Nucl. Chem. 36, 715 (1974)

- Aleksandrov. Sov. Atomic Energy 39,736(1976)

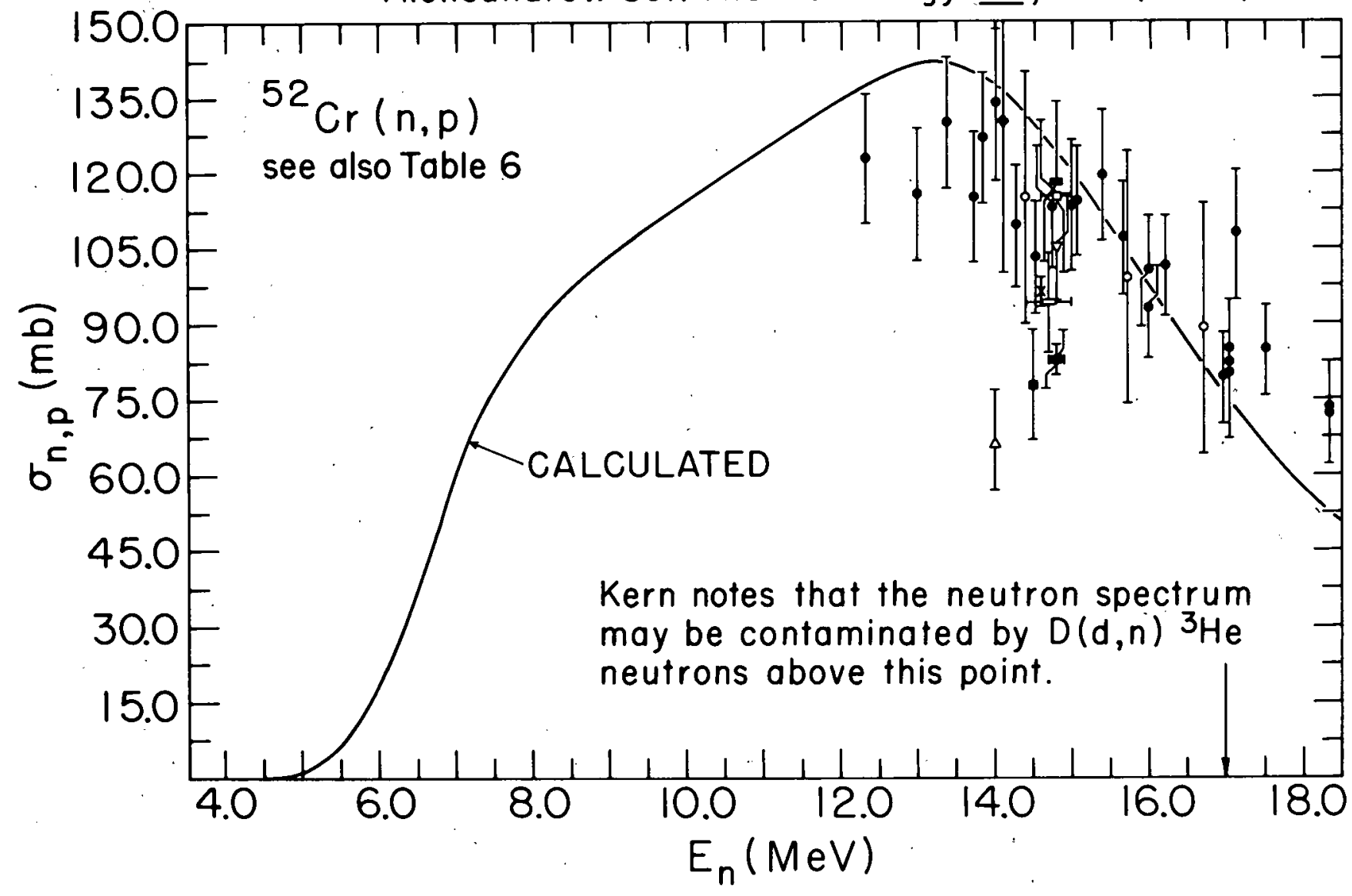

Figure 64 . 
$(n, p)$ CROSS SECTION FOR NATURAL $c r$.

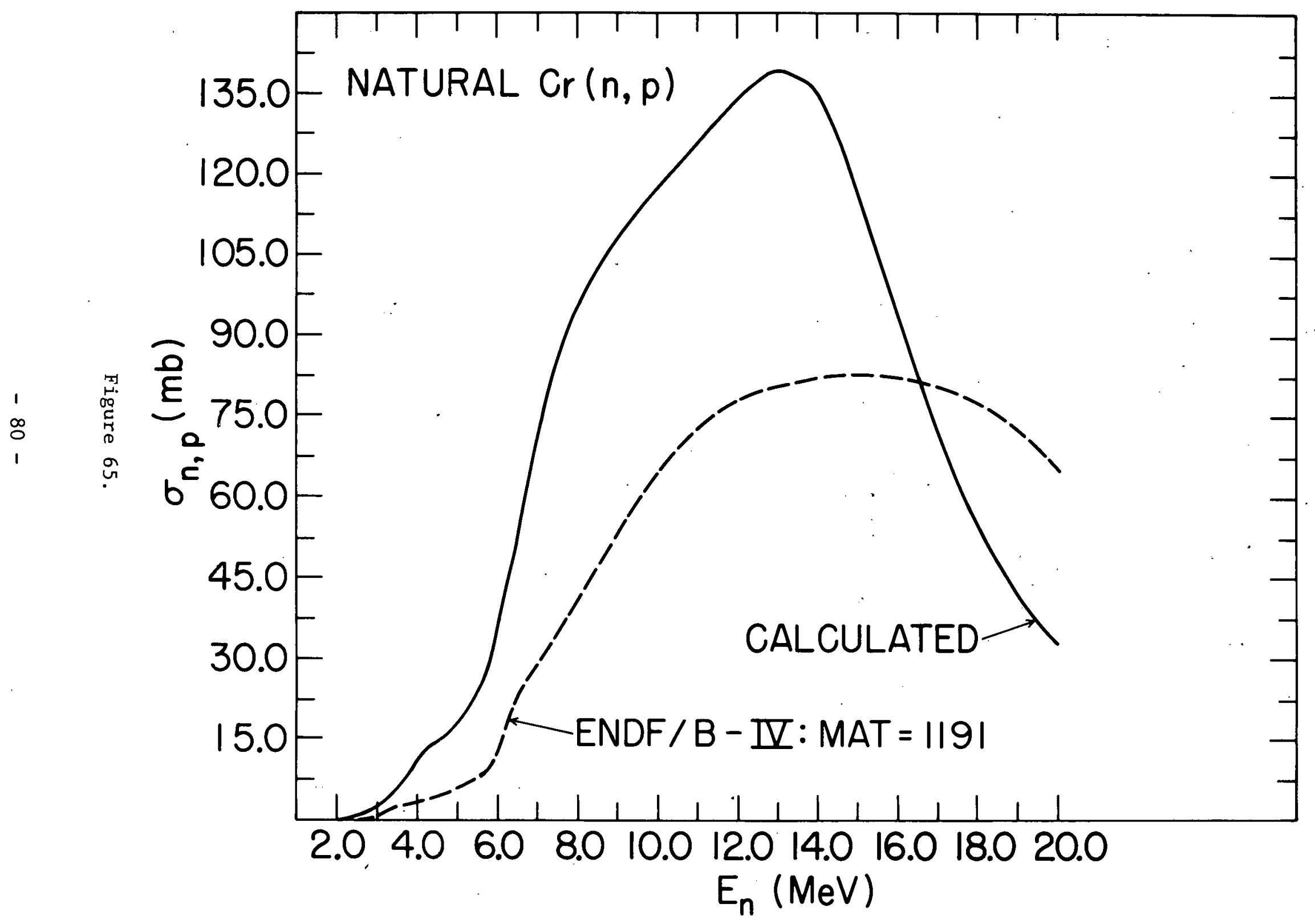




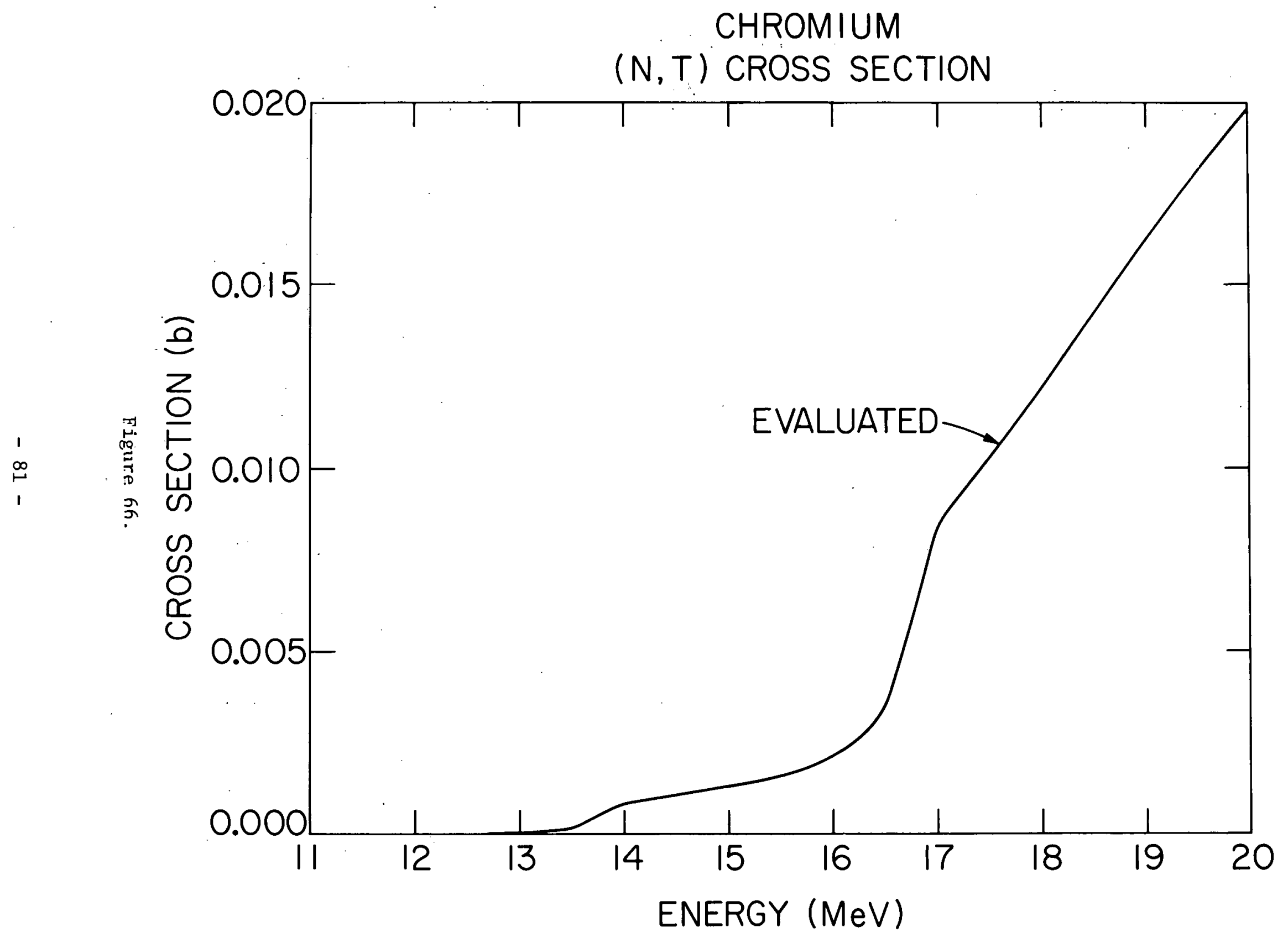




\section{CHROMIUM}

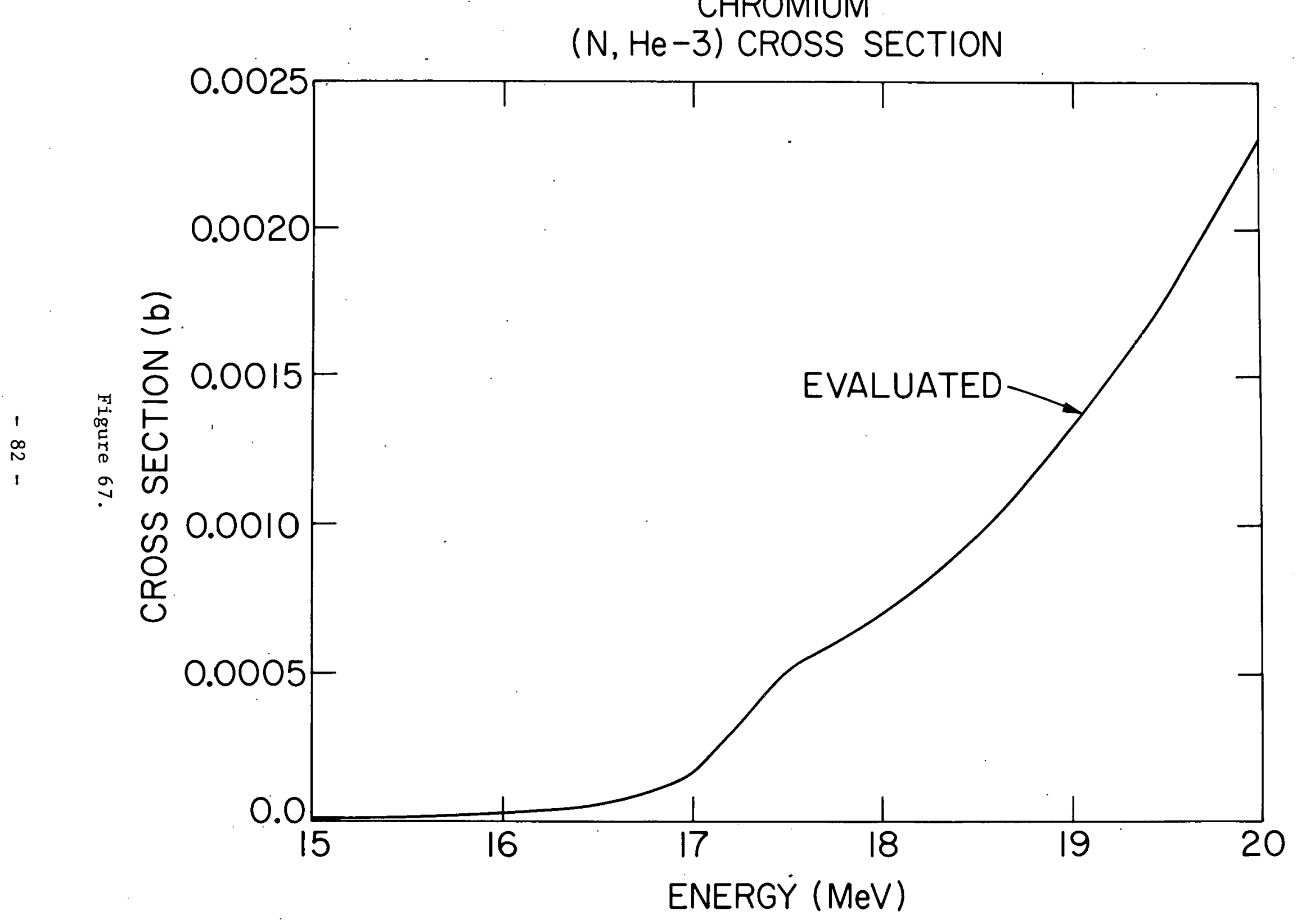


${ }^{50} \mathrm{Cr}$ GAS PRODUCTION CROSS SECTIONS CALCULATED USING UHL'S CODE (BNL VERSION)

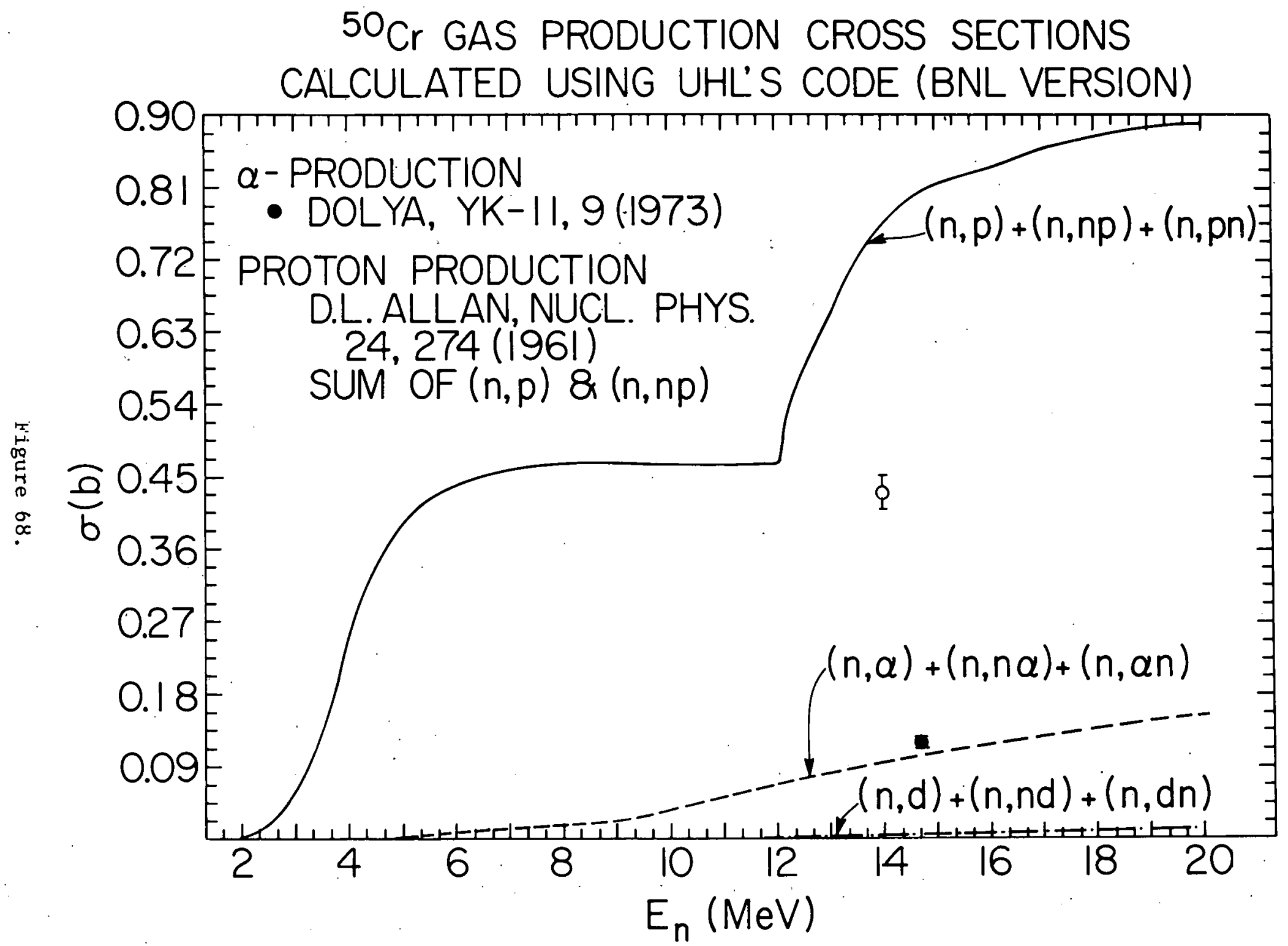




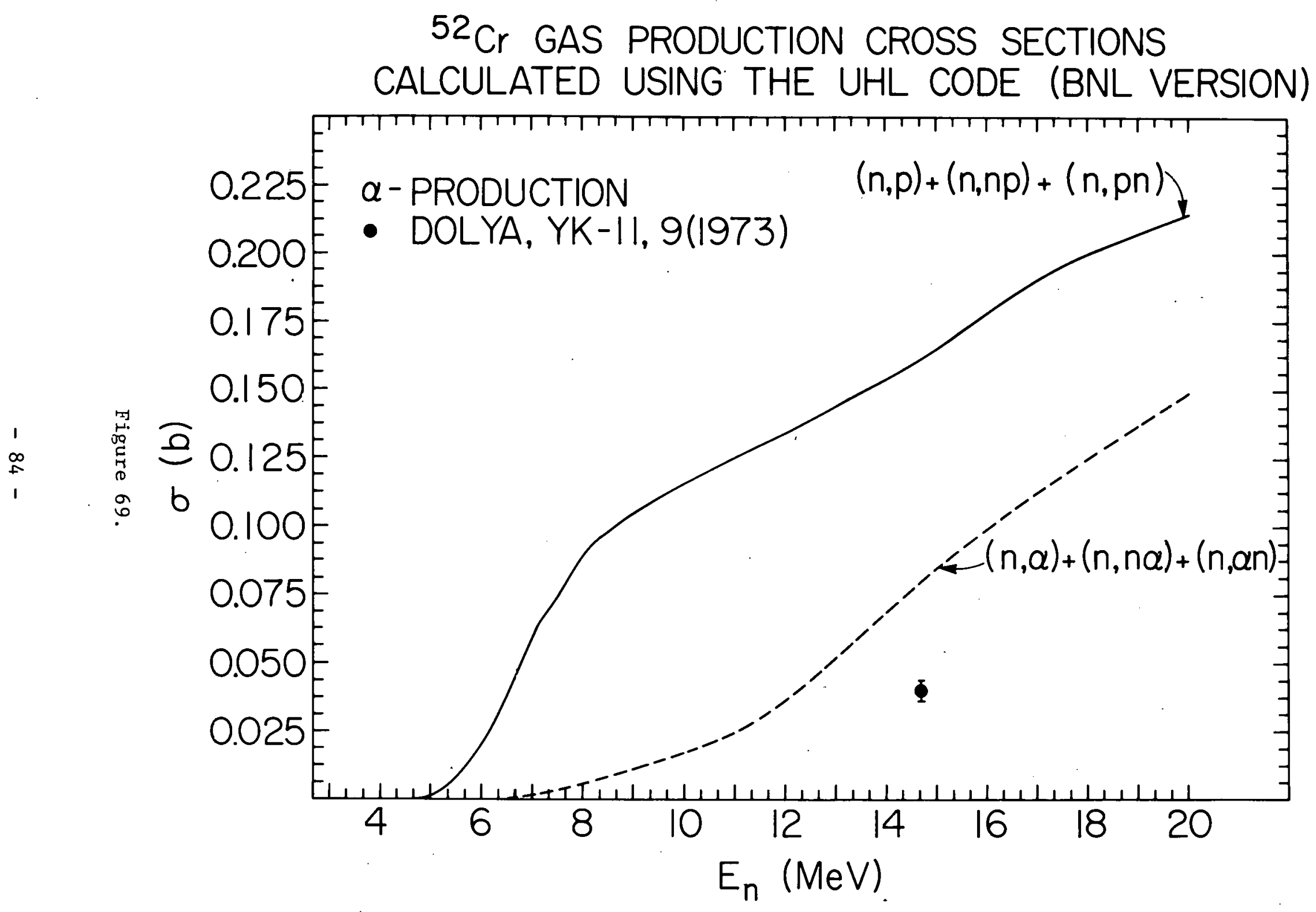




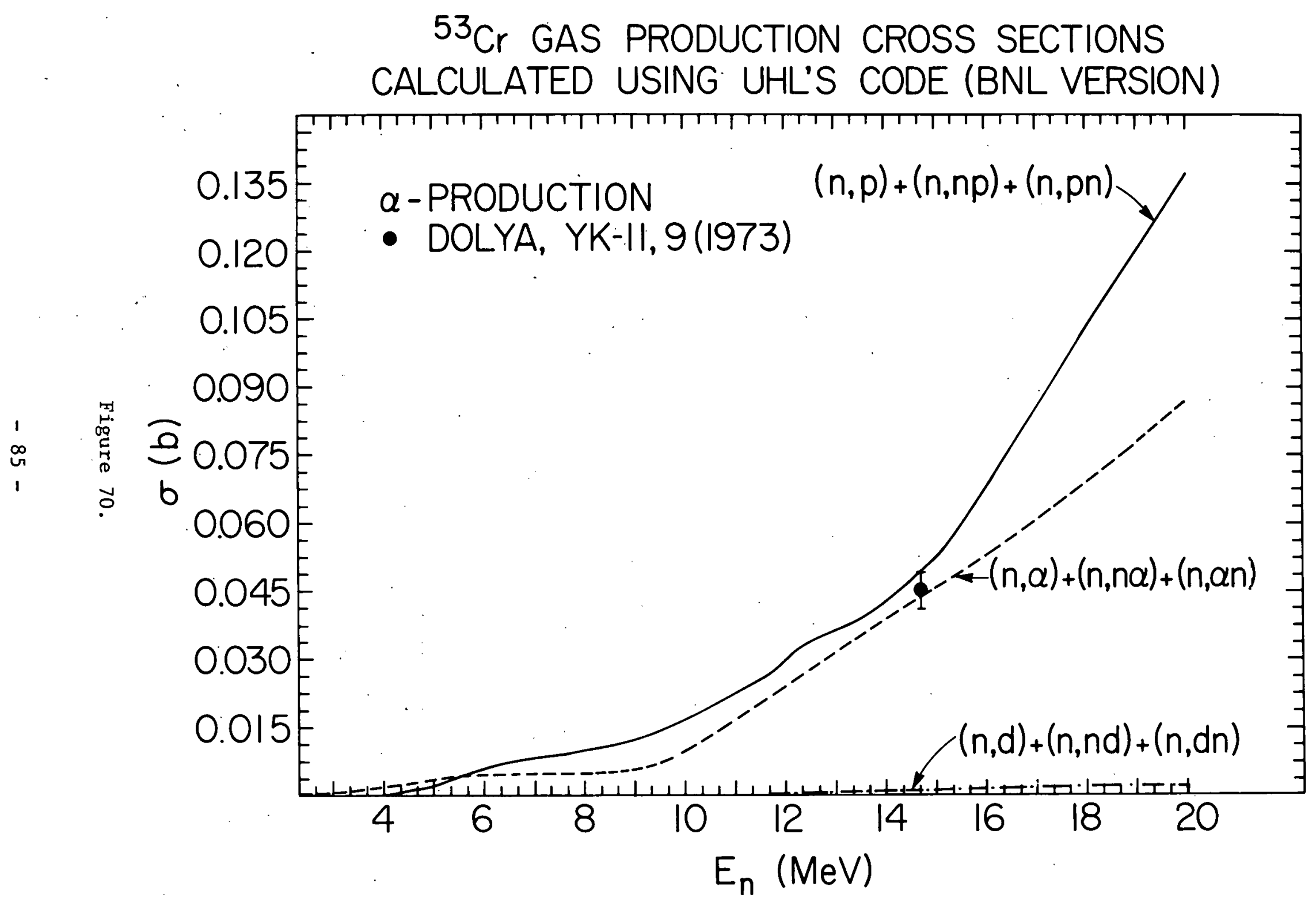


${ }^{54}$ GAS PRODUCTION CROSS SECTIONS CALCULATED USING UHL'S CODE (BNL VERSION)

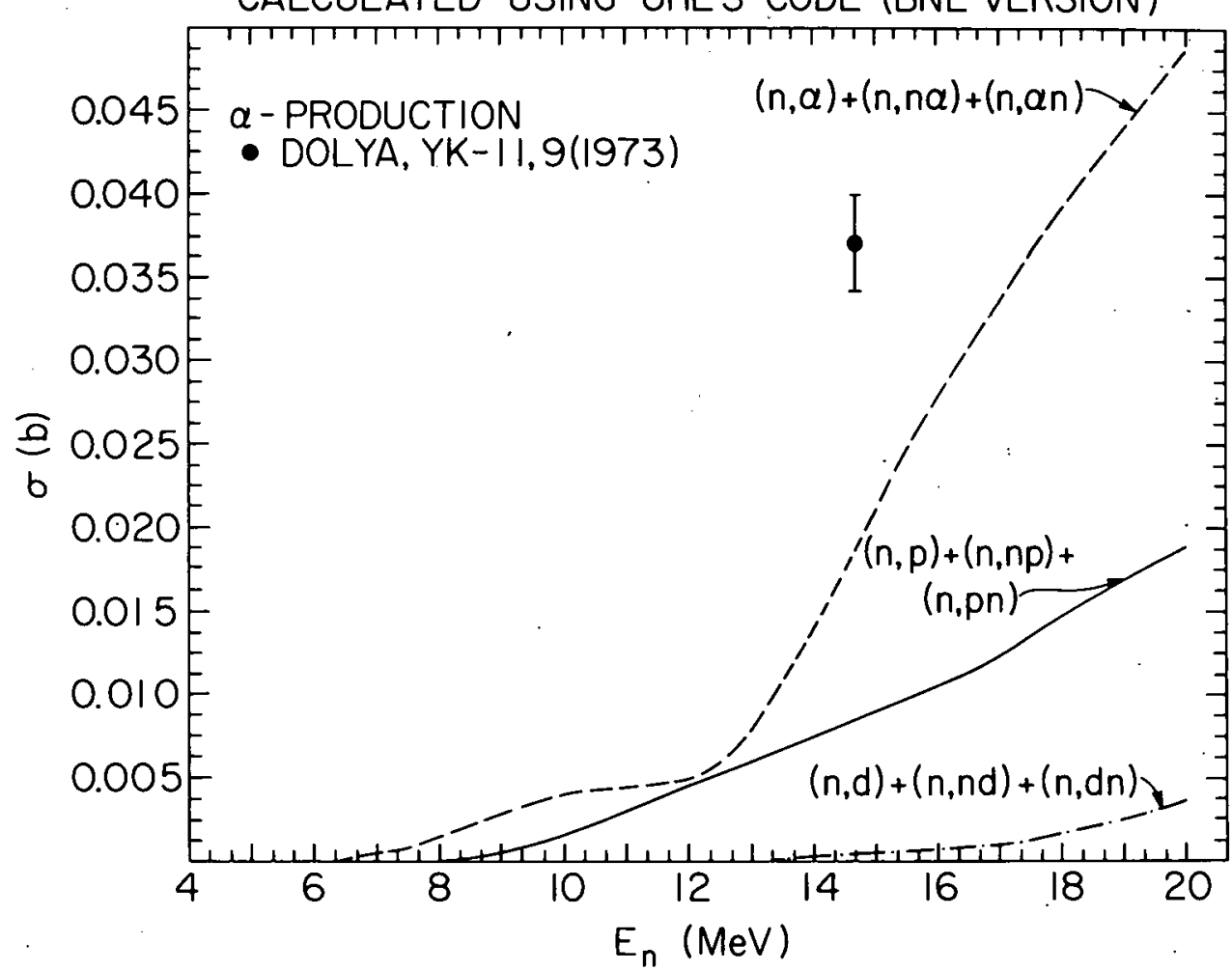

Figure 71.

NATURAL CHROMIUM GAS PRODUCTION CROSS SECTIONS (BNL VERSION)

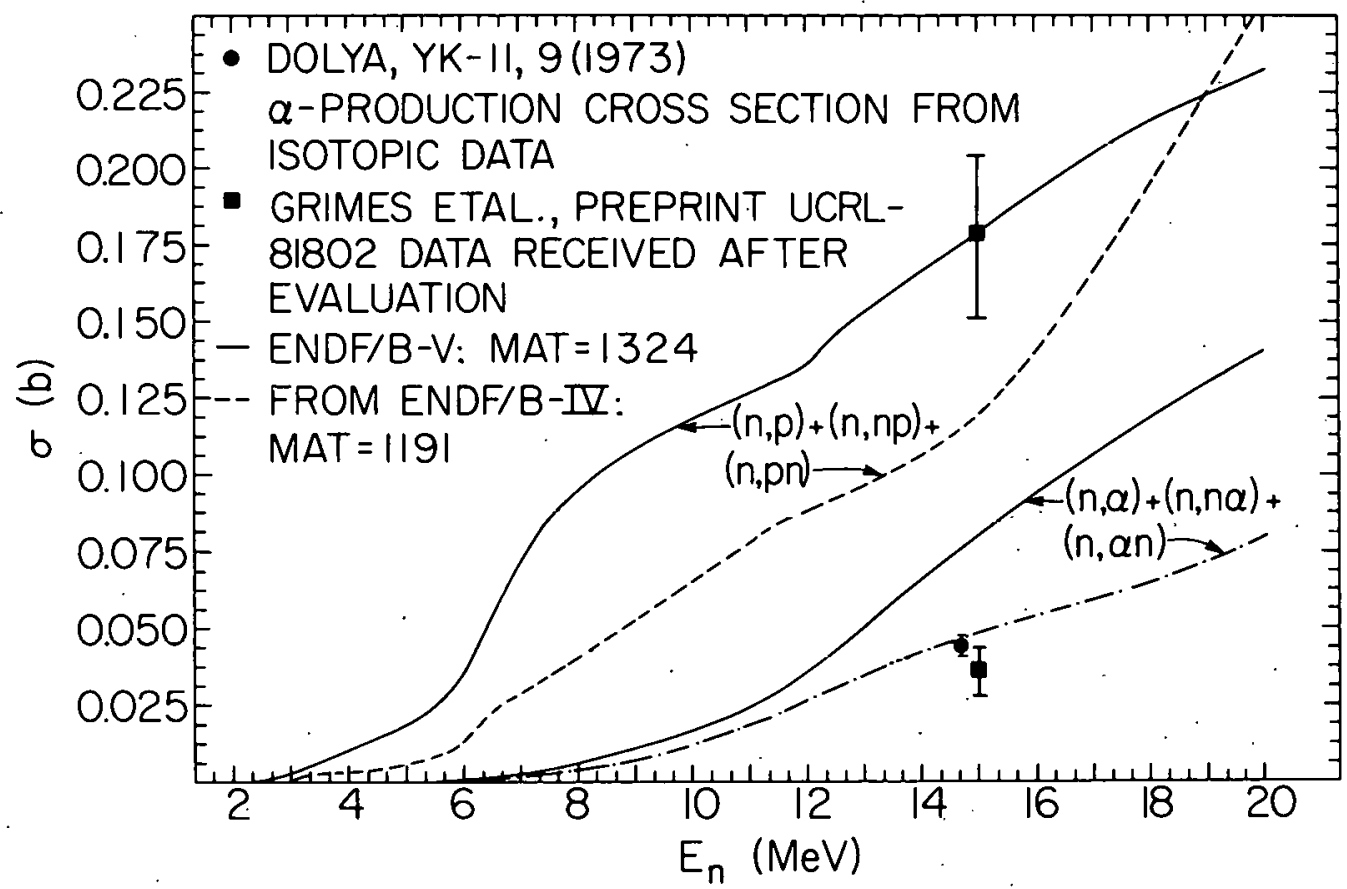

Figure 72 . 